\title{
Information Markets, Administrative Decisionmaking, and Predictive Cost-Benefit Analysis
}

\author{
Michael Abramowicz†
}

FutureMAP, a project of the Defense Advanced Research Projects Agency (DARPA), was an experiment to determine whether information markets could improve Defense Department decisionmaking. Information markets generate predictions from the prices of securities created for that purpose rather than primarily for investment. In this Article, Professor Abramowicz concludes that information markets could discipline administrative agency predictions, but only if technical hurdles such as the danger of manipulation can be overcome. The objective predictions of wellfunctioning information markets exhibit many of the same virtues as cost-benefit analysis. Both approaches can help to overcome cognitive errors and thwart interest group manipulation. The two forms of analysis might be combined to produce a "predictive cost-benefit analysis." In such an analysis, an information market would predict the outcome of a retrospective cost-benefit analysis, to be conducted some years after the decision whether to enact a particular policy. Because the prediction does not depend on the identity of current agency officials, they cannot shade the numbers to justify policies that they prefer.

\section{INTRODUCTION}

At the end of July 2003, one news story about American intelligence efforts briefly captured headlines, while attention continued to focus on another. The short-lived story concerned a Defense Department program called FutureMAP, announced and immediately cancelled, which was to use a market mechanism to predict future terrorist attacks.' The ongoing story was about the failure to find weapons of mass destruction in Iraq, despite confident pre-war pronouncements that such weapons existed. Though the link between these stories was not discussed in the media at the time, ${ }^{3}$ FutureMAP was a governmen-

$\dagger$ Associate Professor, George Washington University Law School. The author thanks the George Mason University School of Law, and in particular the Critical Infrastructure Project and the Law and Economics Center at George Mason, which helped support the author's research when he was an associate professor of law there. For comments and suggestions, the author thanks Terrence Chorvat, Emily Frye, Robin Hanson, Shi-Ling Hsu, Stephen Parr, Dan Polsby, and Steven Schooner, as well as participants at a University of Chicago Law and Economics Workshop. Anthony Ellis provided outstanding research assistance.

1 See Carl Hulse, Pentagon Prepares a Futures Market on Terror Attacks, NY Times A1 (July 29, 2003); Carl Hulse, Swiftly, Plan for Terrorism Futures Market Slips into Dustbin of Ideas without a Future, NY Times A1 (A10 in later editions) (July 30, 2003).

2 See, for example, Walter Pincus and Kevin Sullivan, Scientists Still Deny Iraqi Arms Programs: U.S. Interrogations Net No Evidence, Wash Post A1 (July 31, 2003).

3 Noam Scheiber did eventually note the connection: "[T] he principle behind PAM [Policy Analysis Market] is the very same principle behind the Democrats' criticism of the war in Iraq: 
tal program to make predictions, while the weapons-of-massdestruction controversy was about a prediction. The technology underlying FutureMAP could have been used before the war to aggregate intelligence agents' predictions about whether weapons of mass destruction would be found. One argument for such a market might have been that it would be better at aggregating information than government officials, but the stronger argument is that it would have provided the public an objective indication of what governmental officials really believed, without release of the underlying intelligence information.

This Article explains how information markets could help provide objective assessments of governmental decisions. Policymaking by governmental agencies often depends, either implicitly or explicitly, on predictions about the future: Economic policy depends on anticipation of economic conditions; decisions whether to build prisons depend on projections of the number of prisoners. Nonetheless, there is no provision in the Administrative Procedure Act specifying how agencies should make predictions, and so predictions, in effect, are treated like any other agency findings. ${ }^{6}$ If FutureMAP had any promise, it was not so much as an antiterrorism tool, but as a method for systematizing administrative agency predictions, a method that might be useful in other regulatory areas even if not for terrorism.

The phrase "information market" evokes the mechanics of the approach and highlights the intuition underlying it. An information market, as traditionally constructed, is a stock market created for the purpose of extrapolating information from share prices. The securities in such a market do not serve as claims to corporate ownership, but rather offer payoffs contingent on the occurrence of some future event specified by the market's sponsor. A security in an antiterrorism program, for example, might be issued with the proviso that its face

the importance of basing national security decisions on expert opinion (especially when that opinion is at odds with the opinions of administration high-ups)." Noam Scheiber, Futures Markets in Everything, NY Times Mag 68 (Dec 14, 2003).

4 An information market to predict whether such weapons would be found emerged after the war, though trading was not restricted to government officials. See http://web.archive.org/ web/20030522045107/http://www.tradesports.com (visited Apr 22, 2004).

55 USC $\$ 551$ et seq (2000).

6 There is some uncertainty in the case law about whether predictions should be treated as fact findings, and thus subject to the substantial evidence test, or as policy decisions, and thus subject to hard look review. Compare American Textile Manufacturers Institute, Inc v Donovan, 452 US 490, 543 (1981) (Stewart dissenting) ("OSHA's prediction of the cost of the Cotton Dust Standard lacks a basis in substantial evidence."), with Marsh v Oregon Natural Resources Council, 490 US 360,373-74 (1989) (noting that the agency is required to take a "hard look" at the potential environmental effects of its action). 
value will be paid if and only if a cyberterrorism attack succeeds in shutting down the New York Stock Exchange in the next year. By examining the price at which the security is traded, the Defense Department would be able to obtain an estimate of this risk.' Although some firms might use such a market as a means of hedging risk, ${ }^{8}$ its primary purpose is to harness the power of securities markets to aggregate information. An information market is potentially useful whenever an agency decision depends in part on information about the future and a security can be constructed whose price would provide a relevant prediction.

The word "market," however, can be misleading. Information markets need not depend on either trading or the issuance of securities at all, and indeed this Article will endorse an approach that does not rely on buying or selling. Broadly conceived, an information market is any device that gives third parties financial incentives to make predictions or to improve upon others' predictions and that combines the predictions into a single consensus value. The literature suggesting that conventional stock markets exhibit at least a weak form of market efficiency ${ }^{10}$ does not itself guarantee comparable performance levels in all information markets. Similarly, the behavioral finance literature identifying irrationalities in aggregate stock market investment is of little applicability, at least to the information market form endorsed

7 Presumably, such information would permit the Department of Defense to take action to prevent an attack. The example, however, immediately presents an obvious problem with this particular implementation of information markets: A trader with information about a cyberterrorism attack would likely have no incentive to trade on the information if such trading would succeed in thwarting the attack. See Part II.B.1.

8 The securities traded in information markets are derivatives, but because securities will exist only for a small subset of all risks, the introduction of these derivatives may not necessarily enhance welfare, apart from the use of these securities for informational purposes. See Peter $\mathrm{H}$. Huang, Securities Price Risks and Financial Derivative Markets, 21 Nw J Intl L \& Bus 589 (2001) (explaining that the introduction of a new derivative market has indeterminate consequences for consumer and investor welfare).

9 See Part I.C.2 (discussing the "market scoring rule").

10 For a discussion of the three possible levels of market efficiency, see Eugene F. Fama, $E f$ ficient Capital Markets: A Review of Theory and Empirical Work, $25 \mathrm{~J}$ Fin 383, 383 (1970). Some finance scholars have found deviations from semi-strong form efficiency. See Ronald J. Gilson and Reinier H. Kraakman, The Mechanisms of Market Efficiency, 70 Va L Rev 549, 626 n 205 (1984) (collecting studies). There has long been a consensus, however, that markets exhibit at least weak-form efficiency, meaning that future price movements cannot be predicted solely on the basis of past prices. See Jonathan R. Macey and Geoffrey P. Miller, Good Finance, Bad Economics: An Analysis of the Fraud-on-the-Market Theory, 42 Stan L Rev 1059, 1081 (1990) (noting "overwhelming empirical support for weak-form efficiency"). See generally Michael L. Wachter, Takeover Defense When Financial Markets Are (Only) Relatively Efficient, $151 \mathrm{U}$ Pa L Rev 787, 801-04 (2003) (providing a recent review of the market efficiency literature). 
here." A small economics literature on information markets, however, has offered preliminary assessments of the accuracy of these markets ${ }^{12}$ based on examinations of existing information markets, such as the Iowa Electronic Markets, ${ }^{13}$ which primarily allow for trading on election outcomes. These studies indicate that information markets are generally superior to other forecasting tools, such as polls, because information markets aggregate various types of information and a range of individuals' predictions.

There has been no legal scholarship on information markets' potential uses to aggregate information for administrative decisionmaking. ${ }^{15}$ This aggregation function alone could make information markets a modestly useful tool in administrative decisionmaking, perhaps providing a small advantage over relying on a single expert to combine various information sources. There is, however, an additional attribute

11 For a review of the literature, see Andrei Shleifer, Inefficient Markets: An Introduction to Behavioral Finance (Oxford 2000). Behavioral finance scholars worry less about the relative valuations of securities than about aggregate investment. See, for example, Jeeman Jung and Robert J. Shiller, One Simple Test of Samuelson's Dictum for the Stock Market, (NBER Working Paper No 9348, 2002), online at http://papers.nber.org/papers/w9348.pdf (visited Apr 22, 2004) (providing a test confirming the prediction that capital markets are more efficient for individual stocks than for the aggregate stock market). Paul Samuelson made this point as follows:

Modern markets show considerable micro efficiency (for the reason that the minority who spot aberrations from micro efficiency can make money from those occurrences and, in doing so, they tend to wipe out any persistent inefficiencies). In no contradiction to the previous sentence, I had hypothesized considerable macro inefficiency, in the sense of long waves in the time series of aggregate indexes of security prices below and above various definitions of fundamental values.

Letter from Paul Samuelson to John Campbell and Robert Shiller, quoted in Robert J. Shiller, Irrational Exuberance 243 (Broadway Books 2001). Aggregate investment is not a concern with information markets constructed in the manner that this Article recommends. Participants' sole incentive with this approach is to offer the best predictions possible, so while increased participation in a market should enhance accuracy, unike conventional markets, there are no securities whose prices will be bid up as a result of increased investment.

12 See Part I.B. The literature is small, but the Defense Department's program has triggered some interest among economists, many of whom gave presentations at a DARPAsponsored June 2002 workshop on information markets. See http://marteksys.com/martek/ DARPAConference.html (visited Apr 22, 2004) (conference announcement).

13 See http://www.biz.uiowa.edu/iem (visited Apr 22, 2004).

14 For an article describing how information markets aggregate information, see David M. Pennock and Michael P. Wellman, A Market Framework for Pooling Opinions (unpublished manuscript 2001), online at http://dpennock.com/publications.html (visited Apr 22, 2004).

15 Before the controversy erupted, FutureMAP received far less media attention than the Information Awareness Office's data mining program. Early media references to FutureMAP include DARPA Continues Efforts to Develop Future-Forecasting Markets, Inside Air Force (Jan 6, 2003) (available on Westlaw at 2003 WL 7601951); Shane Kite, Project Seeks Terror Clues in Marts, Securities Industry News (Mar 17, 2003) (available on Westlaw at 2003 WL 7547217); and James Surowiecki, Decisions, Decisions, New Yorker 33 (Mar 24, 2003) (mentioning FutureMAP in a brief article on information markets). 
of information markets that has received little attention in the economics literature despite its far greater significance for governmental decisionmaking: Information markets provide objective predictions, ${ }^{16}$ though only if concerns such as the possibility of market manipulation can be overcome. Even if information markets offered little in the way of improved accuracy relative to a single, well-motivated decisionmaker's prediction, the objectivity of well-functioning information markets makes them a promising potential administrative decisionmaking tool. Agencies that regularly utilize information markets might limit the influences of interest group pressure, availability cascades," and related pathologies of bureaucratic life. Information markets thus help discipline agency predictions in much the same way that cost-benefit analysis disciplines normative agency decisionmaking. The results of information markets could be useful, though not dispositive, in judicial review of agency action, either in an agency's defense of a challenged decision or in a plaintiff's challenge to the action.

The objectivity of information markets, assuming that they could be made to function as proposed, might appear to be both their greatest limitation and their greatest virtue in governmental decisionmaking. The most difficult challenge for administrative agencies, after all, is generally not the prediction of the future, but the evaluation of what should be done given such predictions. As described in the existing literature, information markets serve to provide data inputs into policy analysis, not to resolve a normative inquiry that may depend on a number of variables. Information markets emerge in the literature as predictive tools for analyzing objectively verifiable facts about the world. ${ }^{19}$ The identity of the decisionmaker who announces the final

16 By "objective," I mean simply that information markets report what participants really believe, rather than what they want others to believe. See Part II.A.2 (considering whether information markets are objective in this sense). At least one commentator has mentioned the potential usefulness of such markets in controlling bias. See George R. Neumann, Using Markets to Make Decisions slide 2 (unpublished presentation 2002), online at http://hanson.gmu.edu/ PAM/Conf-6-11-02/Presentations_files/Neumann.pdf (visited Apr 22, 2004) (noting the possibility of a "yes'-man effect in organizations" or "institutional biases"). These concerns also underlie one of the first papers to consider information markets, which discussed the markets' possible use as an alternative to peer review in science. See Robin D. Hanson, Could Gambling Save Science? Encouraging an Honest Consensus, 9 Soc Epistemology 3 (1995). No commentator to my knowledge, however, has considered the potential for information markets to overcome the problems frequently identified with governmental decisionmaking.

17 See Timur Kuran and Cass R. Sunstein, Availability Cascades and Risk Regulation, 51 Stan L Rev 683, 683 (1999) (defining an "availability cascade" as "a self-reinforcing process of collective belief formation by which an expressed perception triggers a chain reaction that gives the perception increasing plausibility through its rising availability in public discourse").

18 See Part II.A.1.

19 Actual markets recognize that objective facts can have a normative component. That is, 
value from which traders' profits are calculated thus has little or no relevance. An information market, however, could easily be used to make predictions about future normative assessments of legal policy, even if these normative assessments are wholly subjective. There must be some procedure for determining who will make the future subjective assessment, so in a sense any normative assessment that resolves an information market is in itself an objectively verifiable fact. Such a market, however, would predict what someone will say about the relevant issue rather than directly predicting some number on which all decisionmakers should be expected, more or less, to agree.

This Article's principal contribution is to defend the proposition that markets of this type, which I will call normative information markets, may be particularly useful, and indeed that they have significant advantages in legal decisionmaking over information market types that the literature previously envisioned, which I will label positive information markets. The literature's failure to discuss normative information markets is understandable. Opinions, after all, are inherently subjective, and it might appear that there is no point in making objective predictions of subjective assessments. This response, however, ignores that whether policies are ultimately enacted depends on subjective assessments of whether those policies are desirable, and normative information markets can reveal how decisionmakers on average, rather than just particular agency bureaucrats, would assess policies. While positive information markets can provide data that may serve as useful inputs into a policy decision, a normative information market can provide a bottom-line assessment of the policy itself. Normative information markets are thus easier to interpret and avoid some of the technical problems that may beset positive information markets. ${ }^{20}$

For an example of how a prediction of a subjective assessment could be useful, imagine a very primitive normative information market used to predict whether ten years from now an agency official will conclude that a set of safety regulations being considered today is

people may debate whether a "fact" exists. See, for example, Claim Clone-Human Clone before 2005, online at http://www.ideosphere.com/fx-bin/Claim?claim=Clone (visited Apr 22, 2004) (recognizing the possibility of ambiguity as to whether a given entity constitutes a human clone). I have found no existing information market that attempts to predict a largely subjective decision. Nor have $I$ found any articles suggesting that information markets be used in this way. To the contrary, the literature on information markets seems to emphasize that the variable being predicted should be capable of objective measurement. Robin Hanson, for example, discusses an information market assessing a criminal justice policy: "[Y]ou must state your claim clearly. . . You might decide to focus on your state's murder rate, using some standard govemment statistic M as your official measure of it." Robin D. Hanson, Decision Markets, 14 IEEE Intelligent Sys 16, 17 (May/June 1999).

20 See Part III.B.1. 
"good" or "bad." If each market security would pay $\$ 1$ if the final evaluation is that the regulations are judged as good, then a trading price of thirty cents would reflect an objective market prediction that there is a 30 percent chance that the eventual decisionmaker will also conclude that the decision was good. Such a prediction, if made before the decision, ${ }^{21}$ would serve as a reality check that might help avoid decisions that seem superficially attractive but that on closer analysis seem likely to prove misguided over time. At the same time, this information market type might assist in exposing an agency, or agency decisionmaker, acting on impermissible or socially inefficient motivations, ${ }^{2}$ in a way that a market reporting only one input into an agency decision cannot, given the agency's ability in many cases to justify decisions on the basis of other, not easily measured factors. Of equal significance, a market prediction indicating that there is a 70 percent possibility of a "good" assessment might help an agency to defend farsighted actions against superficial attacks.

The prediction of a normative information market, however, may not be all that meaningful if the decisionmaker who will perform the eventual policy assessment is known in advance. The market would be considerably more useful if the eventual decisionmaker were unknown, because the market prediction would then reflect an expectation of what an average decisionmaker would decide. An information market that predicts a future retrospective evaluation of a decision allows for a normative policy analysis that is not influenced by the party affiliation or ideology of current agency decisionmakers. Thus, even if the eventual evaluation is partly or completely subjective, an information market can furnish a relatively objective datum on how the average person would be expected to make that subjective, retrospective assessment. Although a hypothetical average decisionmaker is not identical to the heuristic median voter commonly identified in political science literature, ${ }^{23}$ the concepts are similar. An agency's an-

21 A complication here is how to liquidate the market if the agency in fact decides not to make the decision. There are at least two possibilities: First, the rules might provide that all investments will be refunded at cost if the decision is not made. However, this approach leads to a potential selection bias problem. See notes 76-77 and accompanying text. Second, the rules might provide for a retrospective assessment regardless of whether the safety regulations are in fact enacted. See Part III.A (describing a similar approach).

22 For example, an agency might be motivated by a desire to help a particular wellconnected group or corporation but might deny such a motivation. If traders assume that the future decisionmaker's allegiance is unknown, then they may predict a negative evaluation if the factors that the agency uses to justify its policy decision do not themselves seem persuasive.

23 Whether a political system should aspire to enshrine the preferences of the median voter is more complicated. As Robert Cooter notes, there may be a tradeoff between institutions that produce policies appealing to the median voter and those that allow bargaining to reflect in- 
nounced intent to enact regulations does not, by itself, indicate whether policymakers would generally share the agency's assessment of the issue or whether the agency is driven by idiosyncratic factors. A normative information market can provide an objective assessment of whether policymakers in general would reach the same conclusion as the agency.

The primitive normative market described so far, while producing useful data, is flawed because it does not take into account predictions about either how good or bad a decision is likely to be. If, for example, there were a 40 percent chance that a decision would have disastrous consequences and a 60 percent chance that a decision would have modest benefits, the information market described so far would produce an incomplete and misleading assessment. One way to take into account the magnitude of effects, as well as the intensity of preferences, would be to combine an information market with the tool that agencies often use to perform normative policy evaluations: costbenefit analysis. This Article thus imagines predictive cost-benefit analysis, an information market used to predict a cost-benefit analysis that would be performed some time after a decision whether to enact a policy. Such a market would produce an objective prediction of an eventual subjective evaluation. The purpose of the eventual costbenefit analysis that the information market predicts would not be to make a decision, but rather solely to discipline the cost-benefit analysis produced by the information market.

As long as the actual cost-benefit analysis is performed at a date sufficiently distant to guarantee that traders would be unable to predict the political parties and ideologies of those who will conduct it, predictive cost-benefit analysis is not vulnerable to the principal critiques made of the more familiar form of cost-benefit analysis.

First, because information markets are objective, an agency cannot manipulate predictive cost-benefit analysis to produce an ad hoc rationale for decisions that the administrative agency would have made anyway. ${ }^{24}$ Second, the methodologies used in cost-benefit analy-

tensity of preferences. See Robert Cooter, Constitutional Consequentialism: Bargain Democracy versus Median Democracy, 3 Theor Inq in L 1, 10-11 (2002). Because the primitive information market described here assesses whether a majority of decisionmakers would approve of regulations, it will tend to produce policies of which the median voter would approve, assuming that the decisionmakers are representative. Predictive cost-benefit analysis, described below, does not allow for explicit bargaining, but it does register the intensity of preferences.

24 See, for example, Cost-Benefit Analysis: Wonder Tool or Mirage?, Report of Subcommittee on Oversight and Investigations, House Committee on Interstate and Foreign Commerce, 96th Cong, 2d Sess 5 (1980) (arguing that agency officials manipulate cost-benefit analyses to suit their policy preferences); Thomas O. McGarity, Professor Sunstein's Fuzzy Math, 90 Georgetown 
ses whose results are predicted by the information market could be relatively flexible. Some proponents of cost-benefit analysis have argued that such analysis must proceed according to relatively clear rules to prevent manipulation. ${ }^{25}$ The problem with rigid cost-benefit analysis is that it necessarily makes value choices, whether by setting particular values for variables or by declaring certain types of noneconomic considerations irrelevant. ${ }^{26}$ The result is that such costbenefit analysis can be justified only to those who agree with the rules governing it. If agencies can no longer use cost-benefit analysis to rationalize decisions, then manipulation is no longer a danger, and rigid rules are no longer necessary. Predictive cost-benefit analysis would reflect the values that average decisionmakers would set for variables about which there is substantial controversy, including discount rates, ${ }^{27}$ the value of a statistical life, ${ }^{28}$ and the benefit that citizens receive from the existence of species, clean air, and the like. ${ }^{29}$ Similarly, it would allow incorporation of effects, such as distributive consequences, that

L J 2341, 2366 (2002) (arguing that cost-benefit analysis entails "frequently preposterous and always manipulable number spinning"); Christopher H. Schroeder, In the Regulation of Manmade Carcinogens, If Feasibility Analysis Is the Answer, What Is the Question?, 88 Mich L Rev 1483, 1494 (1990) ("Cost-benefit analysis has been frequently faulted for requiring data that is, practically speaking, often unavailable and that, when available at all, is subject to manipulation by industry interests."); Steve Bennett, Note, Cost-Benefit Analysis and the Feasibility Requirement of the Occupational Noise Regulation, 55 Geo Wash L Rev 123, 146 (1986) (rejecting the applicability of cost-benefit analysis to a particular regulation because of its susceptibility to manipulation).

25 See, for example, Steve P. Calandrillo, Responsible Regulation: A Sensible Cost-Benefit, Risk versus Risk Approach to Federal Health and Safety Regulation, 81 BU L Rev 957, 998-1000 (2001) (urging the use of objective data and providing an anecdotal example of how subjectivity may adversely affect risk calculations). See also notes 286-94 and accompanying text.

26 Frank Ackerman and Lisa Heinzerling, Pricing the Priceless: Cost-Benefit Analysis of Environmental Protection, 150 U Pa L Rev 1553, 1576 (2002) ("Because value-laden premises permeate cost-benefit analysis, the claim that cost-benefit analysis offers an 'objective' way to make government decisions is simply bogus.").

27 See, for example, John J. Donohue III, Why We Should Discount the Views of Those Who Discount Discounting, 108 Yale L J 1901 (1999) (defending the use of discount rates in costbenefit analysis); Daniel A. Farber and Paul A. Hemmersbaugh, The Shadow of the Future: Discount Rates, Later Generations, and the Environment, 46 Vand L Rev 267 (1993) (discussing the accuracy of discount rates currently used by government agencies); Lisa Heinzerling, Discounting Our Future, 34 Land \& Water L Rev 39 (1999) (arguing against the use of discounting in the context of environmental regulation); Richard L. Revesz, Environmental Regulation, CostBenefit Analysis, and the Discounting of Human Lives, 99 Colum L Rev 941 (1999) (suggesting limits and improvements on discounting techniques used by the government).

28 For a recent work on improving valuations of statistical lives by the most influential commentator in this area, see W. Kip Viscusi, The Value of Life: Estimates with Risks by Occupation and Industry, Discussion Paper No 422 (Harvard Olin Center for Law, Economics, and Business 2003), online at http://www.law.harvard.edu/programs/olin_center (visited Apr 22, 2004).

29 For a general discussion of methods for calculating existence value, see Donald $\mathbf{J}$. Boudreaux, Roger E. Meiners, and Todd J. Zywicki, Talk Is Cheap: The Existence Value Fallacy, 29 Envir L 765 (1999) (arguing that the notion of existence value is conceptually flawed). 
are typically ignored. In sum, predictive cost-benefit analysis overcomes the tension associated with conventional cost-benefit analysis between the dual goals of constraining agencies and allowing costbenefit analysis to be relatively inclusive.

This Article seeks both to identify information markets' potential technical problems and to consider their potential usefulness, assuming that these problems either do not exist or can be overcome. Part I offers a critical introduction to information markets. In addition to describing existing implementations and proposals for information market design, this Part considers information markets' accuracy. One of the most intriguing implementations of information markets is a conditional market, which is used to predict how a decision might affect some variable of interest. This Part, however, explains that the results of conditional markets must be cautiously interpreted because variance attributable to slight imperfections in market design might appear to represent market predictions of the effect of the decisions at issue. Part I also describes how problems associated with thin information markets can be overcome, and how a sponsor might subsidize an information market to improve participants' incentives to engage in research and analysis.

Part II discusses information markets' uses in administrative decisionmaking. The administrative markets' principal virtue is their objectivity, and this Part begins by explaining how an objective prediction tool could help overcome various problems of administrative decisionmaking. It then presents both the affirmative case that information markets are relatively objective and two concerns regarding their objectivity. The concerns are that interested parties might manipulate them, and that the market participants' unrepresentativeness might affect market results. There are some theoretical reasons to think that these dangers are small, but attempts at manipulation might foster suspicion and decrease market accuracy. With any market design, however, the impact of manipulation and unrepresentativeness is ultimately empirical, and this Part also explains how experiments might assess the extent of these problems.

Part II then describes various possible uses of information markets - none modest, though some more immodest than others-and evaluates how the various technical challenges in information market design might affect these uses. Among the possible applications is the one that officials found so problematic, the use of information markets to predict terrorist activity. In addition to acknowledging problems with that project, the Article will explain that worries that the project might have encouraged terrorism may have been overblown. 
While the terrorism information market presumably would have involved only a relatively small number of securities, it is possible to imagine information markets with large numbers of securities, one for each of a variety of entities to be studied. This Part illustrates such a phenomenon in discussing solvency regulation. The objectivity of information markets also makes them useful for resolving controversial forecasting problems, such as projection of budget deficits. Finally, Part II explains that information markets might support agency attempts to enact interim regulations pending final decisions, if information markets predict that the agency's final decision would be consistent with its interim approach.

Part III describes and defends predictive cost-benefit analysis. Because predictive cost-benefit analysis can result in a policy assessment regardless of the original decision, it does not suffer from selection bias and other technical problems that make conditional markets difficult to interpret. This Part also explains that although predictive cost-benefit analysis itself may be more costly than traditional costbenefit analysis, it offers significant benefits over the traditional approach. Predictive cost-benefit analysis is more objective than traditional cost-benefit analysis, and it thus provides a more reliable signal about the policies that an agency wishes to undertake. Indeed, this form of cost-benefit analysis could potentially satisfy both camps in various debates on regulatory theory.

\section{THE ECONOMICS OF INFORMATION MARKETS}

Part I.A explains the mechanics of simple information markets, and Part I.B reviews the limited literature assessing the accuracy of existing markets. Part I.C considers alternative means of structuring information markets to address particular challenges, identifying problems with "conditional markets" used to assess the effects of a possible policy and explaining how information markets can be constructed when thin trading is anticipated and when the government wishes to subsidize participation to ensure greater accuracy.

\section{A. The Mechanics}

A basic information market's operation is simple: The information market's sponsor issues one or more securities and provides some form of prospectus specifying how each security will eventually be redeemed. Each security's payout will be some function of a number or numbers that will become objectively verifiable by the time of redemption. The sponsor sells securities to those who wish to participate 
in the market, and participants subsequently can trade securities with one another. Typically, these trades are facilitated by a market maker who matches those wishing to buy and sell a particular security; trades occur when someone is willing to buy at a price greater than or equal to the price at which someone else is willing to sell, that is, when the largest bid price is greater than or equal to the largest ask price. ${ }^{30}$ The prices at which these transactions occur, as well as the bid and ask prices, reflect market predictions of the eventual payout and thus of the number or numbers on which that payout is based. ${ }^{31}$

The Iowa Electronic Markets, the only continuously operating information markets using real money that are legal in the United States, offer numerous examples. Most of the information markets operated by the Iowa Electronic Markets involve predictions of the results of political elections, ${ }^{33}$ although a few nonpolitical markets also exist. ${ }^{34}$ The election markets are of two types: vote-share markets and winner-take-all markets. In a vote-share market, a security corresponds to a particular candidate or political party and pays off the number of cents equal to the percentage of votes obtained. For example, each security corresponding to a candidate who wins 30 percent of the total votes would pay $\$ 0.30$. In a winner-take-all market, a security corresponding to a candidate or party pays off if and only if that candidate or party receives the most votes in the election.

30 Bid-ask spreads will be relatively large when there is a relatively large possibility that traders will have asymmetric information, such as in markets in which insider trading is possible. See James Harlan Koenig, The Basics of Disclosure: The Market for Information in the Market for Corporate Control, 43 U Miami L Rev 1021, 1030-31 n 47 (1989).

31 For a description of a number of information markets, see Saul Levmore, Simply Efficient Markets and the Role of Regulation: Lessons from the Electronic Markets and the Hollywood Stock Exchange 2-11 (July 29, 2003) (unpublished manuscript, on file with author).

32 Certain internet gambling sites based abroad have created information markets based on the results of sporting and political events. See, for example, http://www.tradesports.com (visited Apr 22, 2004) (providing information market services from Ireland). The Iowa Electronic Markets, by contrast, have received regulatory clearance for their activities. See Commodity Futures Trading Commission Letter No 93-66, Comm Fut L Rep II 25, 785 (available on Westlaw at 1993 WL 595741). Other real-money information markets are planned. See, for example, http://www.simonmarket.org (visited Apr 22, 2004) (planning to offer an information market for claims about science).

33 See http://www.biz.uiowa.edu/iem/archive (visited Apr 22, 2004) (providing an archive of closed markets and historical data). A recent study assesses antecedents of the lowa Electronic Markets, which allowed stock market-like betting on presidential candidates in the late nineteenth and early twentieth centuries. The markets were remarkably accurate, especially considering the absence of scientific polling at the time. See Paul W. Rhode and Koleman S. Strumpf, Historical Presidential Betting Markets 1 (working paper, Nov 2003), online at http://www.unc.edu/ cigar/papers/BettingPaper_10Nov2003_short2.pdf (visited Apr 22, 2004).

34 For example, a current market predicts interest rates set by the Federal Reserve Board. See http://www.biz.uiowa.edu/iem/markets/fedpolicyb.html (visited Apr 22, 2004). 
Consider, for example, Figure 1, which reports the last share price for securities in the vote-share market for the 2000 presidential election. The graph is relatively stable, with both the Democratic and Republican expected vote shares hovering near 50 percent. The data, however, show some variation. For example, as Democratic nominee Al Gore gained in the polls in early September, his vote share also rose, but by late October, Republican nominee George W. Bush had a slight edge. The contracts eventually paid off at virtually identical prices, with Democratic securities paying at $\$ 0.499$, Republican securities paying at $\$ 0.497$, and Reform securities paying at $\$ 0.004$, all calculated based on the vote totals and shares reporting on November 10, 2000 in the New York Times and the Washington Post. ${ }^{35}$

\section{FIGURE 1}

\section{The 2000 Presidential Election Vote-Share Market ${ }^{36}$}

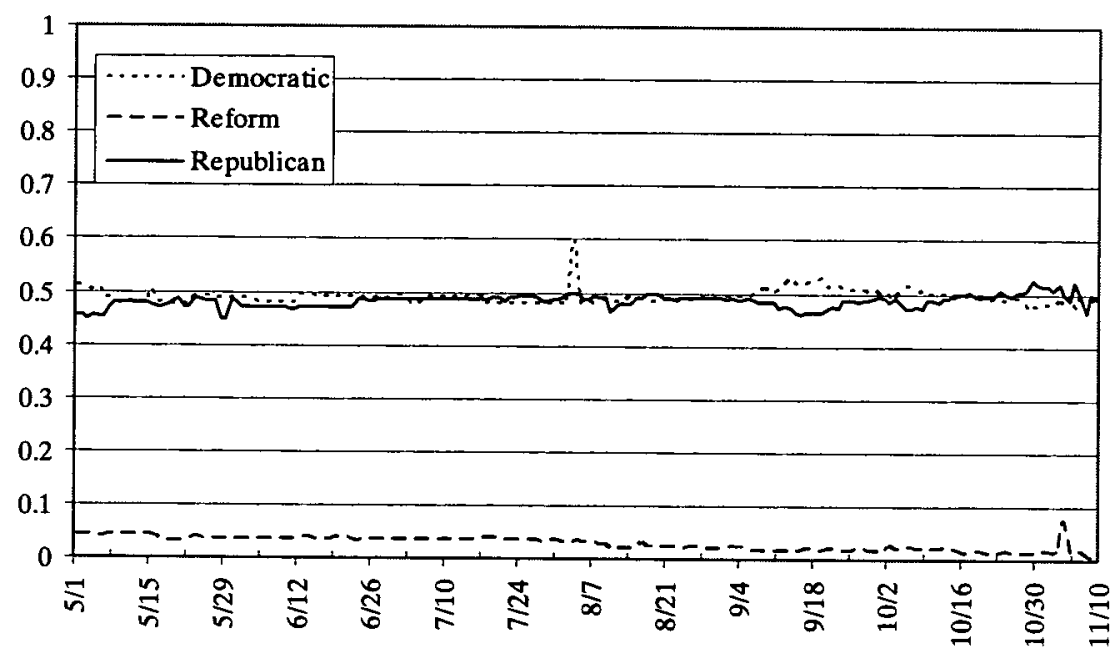

35 See http:/www.biz.uiowa.edu/iem/closed/pres00_vs.html (visited Apr 22, 2004); Dan Balz, Resolution Days Away as Bush's Lead Shrinks in Fla, Wash Post A1 (Nov 10, 2000) (reporting that Gore led in the popular vote by $49,059,936$ to $48,858,335$ ). The market defined vote shares as the vote shares among the three parties, so any votes received by other parties did not count. An alternative approach would have been to have an "other" security, representing the vote share of all parties other than those explicitly represented by securities.

36 This graph indicates the last price at which the securities in the Iowa Electronic Markets' 2000 presidential election vote-share market were traded on each day from May 1 to November 10 . 
For the most part, this chart provides a tentative indication that vote-share markets provide at least roughly rational predictions. The trading prices seem to reflect changes in the candidates' fortunes, as indicated by news reports and polls. Market prices, moreover, are far less volatile than in conventional stock markets. ${ }^{37}$ Shares of companies sometimes seem to move dramatically without explanation or at least disproportionately to the apparent significance of new information, but the Iowa Electronic Markets' predictions seem almost always to be at least close to what common sense would suggest. However, at least one anomaly is visible: The Democratic share price has a onetime dramatic spike to 0.60 on August $3 .^{39}$ This spike does not appear to reflect new campaign information, and it tellingly is not mirrored by a concurrent fall in the Republican share price. This price presumably only reflects the final transaction on August 3, and it may be the product of a foolish or manipulative trader. The lesson is that the last price traded may reflect an anomaly, at least in the absence of a sufficiently sophisticated automated market maker. ${ }^{40}$ This can be a problem even in relatively thick markets, ${ }^{41}$ but it is of greater concern in a market whose prices are being relied on for prediction. If one were relying on the market predictions for practical purposes, it might thus be advisable to ignore price spikes of very short duration and to consider inframarginal bid and ask prices, or average transaction prices over a series of transactions, as potentially better predictors than the share price of the last transaction.

37 Many of the causes of stock market volatility, such as economic uncertainty, seem unlikely to affect information markets. Consider Clifford W. Smith, Jr., Market Volatility: Causes and Consequences, 74 Cornell L Rev 953, 953-54 (1989) (discussing the causes of stock market volatility).

38 The 1987 stock market crash is a common example of volatility that did not appear to reflect any underlying changes in market fundamentals. See id at 954-56.

39 Another anomaly is less visible on the graph. The final trading prices of the securities on November 10 before the payout were 0.481 for Democratic, 0.004 for Reform, and 0.491 for Republican. This is slightly different from the ultimate payout, even though it appeared on November 9 that Gore would win the popular vote. See, for example, Akhil Reed Amar, The Electoral College, Unfair from Day One, NY Times A23 (Nov 9, 2000). This anomaly reinforces the point that in a market without much liquidity, very small price differences based on actual sales may not mean anything. The bid-ask spread at the end of November 10 may have been more sensible, but that information is unavailable.

40 See, for example, Morris Mendelson and Junius W. Peake, Intermediaries' or Investors': Whose Market Is It Anyway?, 19 J Corp L 443, 481-82 (1994) (discussing automated market makers). The mechanism by which trades are executed in the Iowa Electronic Markets is described in Robert Forsythe, et al, Anatomy of an Experimental Political Stock Market, 82 Am Econ Rev 1142, 1143-45 (1992).

41 See Gretchen Morgenson, Volatility in Closing Prices Worries S\&P, NY Times C1 (Jan 29,2004 ) (explaining that "[s]harp swings . . . in Nasdaq stocks at the end of the day's trading have raised concerns at the Standard \& Poor's Corporation"). 
Figure 2 presents the 2000 presidential election winner-take-all market and, with it, a surprise: Gore wins - at least as winning is defined by the prospectus for the security, which is tied to the winner of the popular vote as reported on November $10 .^{42}$ That definition is perhaps unfortunate, as a market dependent on the political party of the individual actually sworn in as President would have revealed the extent to which events like the Supreme Court's decision in Bush v Gore $^{43}$ surprised the market. The trends in this graph in any event correspond to those in Figure 1, but the effects are magnified. This is precisely what one would expect when polling numbers are relatively stable but the election is close. The slight lead that Gore had in the polls in September corresponds to a relatively large disparity in the probability that each candidate would win the popular vote. Similarly, although Bush had only a slight lead in expected vote share, that lead seemed sufficiently stable that his chance of winning the popular vote was above 70 percent shortly before the election. Of course, Bush ended up losing the popular vote, but the fact that unlikely outcomes sometimes occur does not by itself mean that the market's prediction was wrong. At least, the market's predictions seem to correspond with third parties' assessments of the likely result of the popular vote, and once it became clear that Gore would win the popular vote, the price line did an about-face. ${ }^{46}$

42 See http://www.biz.uiowa.edu/iem/closed/pr_Pres00_WTA.html (visited Apr 22, 2004). The prospectus makes explicitly clear that "[p]ayoffs are NOT affected by ... the outcome of the electoral college or any vote taken by the House of Representatives should such vote be necessary." Id.

43531 US 98 (2000).

44 The decision may have been motivated by concern that the market should produce an unambiguous winner. Suppose, for example, that the House of Representatives had initially deadlocked and then, as a compromise, chosen an independent as the next President or decided on joint rule by Bush and Gore. These possibilities are fanciful, but the market designers' possible desire to avoid these contingencies may reflect the notion that the markets will be most meaningful when they are entirely objective. See note 19 and accompanying text.

45 See, for example, Ronald Brownstein, Polls Show Victory Could Come Without Winning Popular Vote, LA Times A1 (Nov 3, 2000) (noting that Bush might win the popular vote and yet lose the electoral college).

46 There is another anomaly in this graph: The last trading price of the Democratic share was slightly below 1.0, and the last trading price of the Republican share was slightly above 0 . At least by the end of November 10, the outcome should have been entirely clear, since the prospectus defined the winner relative to the popular vote shares reported on November 10 . This again reinforces the conclusion that in a market with relatively low liquidity, very slight deviations in the prices at which shares are traded may not be meaningful. See note 39 . 
FIGURE 2

The 2000 Presidential Election Winner-Take-All Market ${ }^{47}$

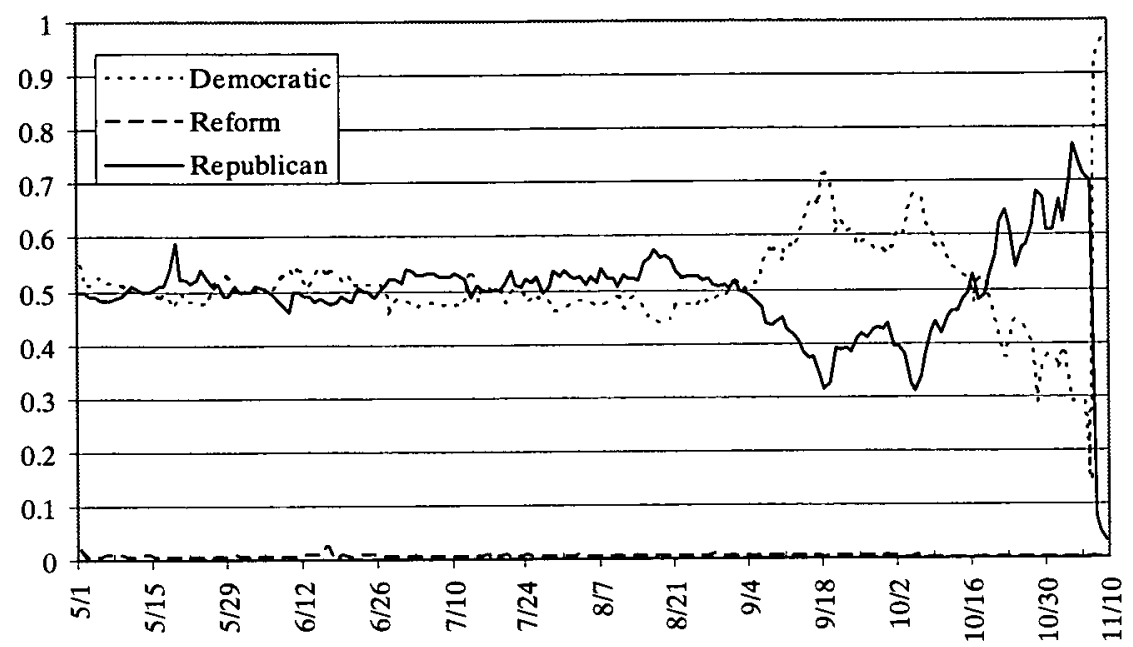

One distinguishing feature of the Iowa Electronic Markets is that the values of all the securities in any given market collectively add up to $\$ 1$. This is convenient because it allows for an easy way to sell the securities. For each dollar that a participant pays, the participant initially receives a bundle containing one of each security. ${ }^{48}$ This system ensures that the amount that the Iowa Electronic Markets pay at liquidation is equal to the amount contributed. As a result, the Iowa Electronic Markets avoid both the possibility of losing money and of gaining money, the latter of which might make the markets appear more akin to a casino than a stock market. There is nothing inherent in information markets, however, requiring security values to add up to a constant. For example, one can imagine a market in which a security would be deemed worth one cent for every million votes received by a particular candidate. Such a market would provide more information than the vote-share market, predicting total turnout as well as the share of the vote received by each security. ${ }^{49}$ The Hollywood Stock

47 This graph indicates the last price at which the securities in the Iowa Electronic Markets' 2000 presidential election winner-take-all market were traded on each day from May 1 to November 10.

48 See, for example, http:/www.biz.uiowa.edu/iem/markets/pr_Pres04_VS.html (visited Apr 22,2004 ) ("Fixed-price bundles consisting of one share of each of the contracts in this market can be purchased from or sold to the [Iowa Electronic Markets] system at any time. The price of each bundle is $\$ 1.00 . ")$.

49 A caveat is that prices in such a market might be affected by interest rates. If, for exam- 
Exchange is an information market structured along these lines, although it uses only "fake money." The Exchange allows for trading on securities corresponding to movies, including both those in production and those in theaters, with each movie security liquidated four weeks after the movie release for $\$ 1$ per $\$ 1$ million in box office gross.

\section{B. Accuracy}

The 2000 presidential election information markets alone provide some anecdotal evidence about the accuracy of information markets. The winner-take-all market's prediction on election eve that Bush had a 70 percent chance of winning the popular vote, for example, roughly corresponds to what we might have expected based on the evidence at the time. The price seems to reflect a reasonable consensus, even though it would have been more impressive if the market had predicted, against the apparent pre-election consensus, that Gore would win the popular vote. Forsythe, et al, provide a more complete analysis of the 1988 Iowa Electronic Markets, showing how the market prediction of the candidates' shares of the vote was more stable over the course of the election campaign than poll results. Perhaps more interesting, Forsythe, et al, argue that poll results did not drive market prices; that is, traders anticipated shifts in candidates' fortunes that were later reflected in polls before those polls were actually taken. ${ }^{53}$ The study thus suggests that information markets are not simply crude aggregators of other predictors, but manage to effectively incorporate difficult-to-interpret data. This conclusion should be treated with caution, however, as a study of a similar market used to predict an election in the Netherlands reached a different conclusion.

ple, traders expected a turnout of 50 million in an election a year away, they would be willing to pay no more than fifty cents for the security. There are several potential solutions to this problem, however. For example, all transactions could be cleared at the time the market is liquidated, regardless of when those transactions actually took place. Thus, if a participant made a purchase for fifty cents five months before the market closed, the fifty cents would be paid at the conclusion of the market.

50 See http://www.hsx.com/about (visited Apr 22, 2004).

51 See http://www.hsx.com/help/topics/whatcan.htm\#1 (visited Apr 22, 2004). Similarly, the Exchange offers StarBonds, corresponding to individual movie stars. These bonds are liquidated when a star's career ends, whether by unnatural causes, natural causes, or retirement, based on the average gross of the star's previous five pictures. See id.

52 Forsythe, et al, $82 \mathrm{Am}$ Econ Rev at 1150 (cited in note 40).

53 Id at 1153 ("Evidently, traders were able to find out about the mood of the electorate without relying on opinion polls. In this sense, polls are not 'news' to traders who have an incentive to seek out information from other sources.").

54 Ben Jacobsen, et al, (In)accuracy of a European Political Stock Market: The Influence of 
It is only over a number of markets that information markets' accuracy can be assessed. Because information markets purport only to give the best guesses possible based on available evidence, any single success or failure may reflect luck. Over a number of markets, however, it is possible to measure information markets' average performance. ${ }^{s 5}$ Berg, et al, for example, have considered the Iowa Electronic Markets' vote-share markets. In the five vote-share markets related to presidential elections, involving a total of twelve contracts, the markets had an average absolute error of 1.37 percent, meaning that on average each election eve prediction was off by 1.37 percent. ${ }^{37}$ In other U.S. elections, the average absolute error was 3.43 percent, largely because of two primary elections in which the markets exhibited unjustified confidence in Paul Tsongas. In non-U.S. elections, the markets had an average absolute error of 2.12 percent. ${ }^{88}$ Collectively, these data seem sufficient to establish that the markets' predictions were neither haphazard nor perfectly omniscient. ${ }^{\text {s9 }}$

The problem in assessing these data is the lack of a control group. A decisionmaker without any alternative estimate of the relevant variable would benefit from considering an information market prediction, but in real decision contexts, the choice is between relying on an information market and relying on one or more experts. One experiment, involving Hewlett Packard's printer sales predictions, provides evidence supporting the hypothesis that markets are better than experts. ${ }^{60}$ The market beat the official expert forecast six of eight

Common Value Structures, 44 Eur Econ Rev 205, 216-17 (2000) (concluding that polls did affect market prices in a similar study).

5s Formulas exist that make it possible to rate the accuracy of those who make repeated probability estimates, even though each individual probability estimate admits some uncertainty. See, for example, Glenn W. Brier, Verification of Forecasts Expressed in Terms of Probability, 78 Monthly Weather Rev 1 (1950) (offering an early example of such a formula).

56 Joyce Berg, et al, Results from a Dozen Years of Election Futures Markets Research (unpublished manuscript Nov 2000), online at http://www.biz.uiowa.edu/iem/archive/ BFNR_2000.pdf (visited Apr 22, 2004).

57 Id at 10.

58 Id.

59 The mean absolute error for the securities in the Netherlands study was 3.1 percent, which, though greater than the mean absolute errors that had been reported up to that time, still seems roughly consistent with this conclusion. See Jacobsen, et al, 44 Eur Econ Rev at 211 (cited in note 54). Jacobsen, et al, also argue that a form of the winner's curse led to overpricing of securities corresponding to parties with relatively small shares of the vote. See id at 224-27. For a general discussion of the winner's curse, see Richard H. Thaler, The Winner's Curse: Paradoxes and Anomalies of Economic Life 50-52 (Free Press 1992) (discussing the tendency of bidders to fail to take into account that if they win, this means others had lower valuations and they have overpaid). If this explanation is accurate, it seems unlikely to endure, given that others would have the opportunity to exploit this tendency once it is recognized.

so See Kay-Yut Chen and Charles R. Plott, Information Aggregation Mechanisms: Concept, 
times, ${ }^{61}$ even though the experts made their predictions after the markets closed. An analysis of the Hollywood Stock Exchange, however, shows that an expert predictor of movie returns, Brandon Gray of Box Office Mojo, ${ }^{62}$ slightly outperformed the market. ${ }^{63}$ The Hollywood Stock Exchange had an average error of 31.5 percent, while Box Office Mojo exhibited an error of only 27.5 percent. $^{64}$

Although these studies present conflicting results, they are relatively uninformative because the outcomes may depend on the setup of the particular experiment. Perhaps Hewlett Packard hired unusually bad forecasters to make the official prediction. Perhaps Gray got lucky, or perhaps the Hollywood Stock Exchange's imperfections can be traced to the use of fake rather than real money. The ultimate question is whether experts or markets are likely to outperform the other on average, assuming that equal resources are provided for each task. It would be possible to allocate some money amount either to hiring an expert or to subsidizing an information market. ${ }^{65}$ No set of even hypothetical experiments seems sufficient to provide a definitive answer, or at least one in favor of information markets, given the impossibility of finding an objectively superior process for hiring experts.

Perhaps the most that can be said on the basis of such experimental data is that information markets and well-motivated experts are roughly comparable. This alone is probably sufficient to justify further corporate and governmental experimentation with information markets. The more significant potential payoff from information markets results if there is reason to believe that some experts make systematic errors or are not well-motivated. This is possible in some corporate contexts; perhaps an internal market used to predict quarterly earnings would be less susceptible to optimism biases than more traditional approaches. ${ }^{66}$ It is in governmental decisionmaking, however,

Design and Implementation for a Sales Forecasting Problem 17 (California Institute of Technology Social Science Working Paper No 1131,2002), online at http://www.hss.caltech.edu/SSPapers/ wp1131.pdf (visited Apr 22, 2004) (discussing Hewlett Packard's use of an information market system to improve business planning). For a discussion of intracorporate experimentation with information markets, see Levmore, Simply Efficient Markets at 12-15 (cited in note 31).

61 Chen and Plott, Information Aggregation Mechanisms at 21 (cited in note 60).

62 See http://boxofficemojo.com (visited Apr 22, 2004).

63 David M. Pennock, et al, Extracting Collective Probabilistic Forecasts from Web Games, in Proceedings of the Seventh ACM SIGKKD International Conference on Knowledge Discovery and Data Mining (ACM 2001), online at http://portal.acm.org/citation.cfm ?id=502537\&dl=ACM\&coll=GUIDE (visited Apr 22, 2004).

64 Id at 177 table 1.

65 See Part I.C.3 (discussing subsidizing markets).

66 Optimism biases sometimes lead individuals to believe that they are more likely than most to avoid risks such as that of business failure. See, for example, David A. Dana, A Behavioral Economic Defense of the Precautionary Principle, $97 \mathrm{Nw}$ U L Rev 1315, 1325 (2003) 
where there is the greatest reason to be suspicious of experts, either because of external influence or because of ideological agendas. Information markets seem to have information aggregation capabilities that are at least good enough for government work. The question, to which I shall return below, is whether information markets are indeed objective, and whether a tool that allows the government to make objective forecasts would be useful in governmental decisionmaking.

\section{Market Design Challenges}

\section{Conditional markets.}

Perhaps the most ambitious information market form proposed by economists to date is a conditional market, ${ }^{68}$ which assesses the results of different choices that a decisionmaker might make. Such a market harnesses information about the anticipated effects of a decision on some number of interest to the market participants. Berg and Rietz used a version of the Iowa Electronic Markets in the 1996 presidential election campaign to demonstrate the power of information markets to assess conditional probabilities. ${ }^{69}$ The securities in the voteshare market included two securities for each potential Republican nominee conditional on that nominee's receiving the nomination. For example, one security represented the percentage of votes that Robert Dole would receive in the general election, while another represented the percentage of votes that the Democratic candidate would receive against Dole. At any time before the nomination, the sum of these two securities would have reflected the market's estimate of the probability that Dole would win the nomination. The relative values of these shares would indicate Dole's projected performance relative to Clinton assuming that Dole was the nominee. Berg and Rietz note that Republicans could have used the market prices to recognize that Dole was not the strongest possible candidate against Clinton. $^{70}$ The

("[P]eople may believe, even in the absence of any factual basis, that with time they will find a costless means to avoid future risks."); Barton H. Thompson, Jr., Tragically Difficult: The Obstacles to Governing the Commons, 30 Envir L 241, 264 (2000) ("[W]hen confronted by an uncertain future, most people assume that they will be able to avoid, reduce, or ameliorate future risks.").

67 See Part II.A.2.

68 See, for example, Robin D. Hanson, Conditional Markets (2002) (unpublished presentation, on file with author) (providing a careful analysis of such markets). See also Hanson, 14 IEEE Intelligent Sys at 16-18 (cited in note 19) (providing a brief overview of the possibility for using such markets).

69 See Joyce A. Berg and Thomas A. Rietz, Prediction Markets as Decision Support Systems, 5 Info Sys Frontiers 79 (2003).

70 Id at 80 . This particular result may not have been all that surprising. Other commenta- 
same conditional market approach is being used for the 2004 presidential election, and Table 1 shows a snapshot of market prices and what those prices indicated about the market's evaluation of candidates' relative prospects as of April 28, 2003.

\section{TABLE 1}

\section{The 2004 Presidential Election Conditional Vote-Share Market ${ }^{11}$}

\begin{tabular}{|c|c|c|c|c|c|c|}
\hline $\begin{array}{c}\text { Potential } \\
\text { Democratic } \\
\text { nominee }\end{array}$ & $\begin{array}{l}\text { Conditional } \\
\text { security for }\end{array}$ & Bid & Ask & Midpoint & $\begin{array}{c}\text { Chance of } \\
\text { winning } \\
\text { nomination }\end{array}$ & $\begin{array}{c}\text { Conditional } \\
\text { vote share }\end{array}$ \\
\hline \multirow{2}{*}{ H. Clinton } & Democrat & 0.016 & 0.02 & 0.018 & \multirow{2}{*}{0.058} & \multirow{2}{*}{0.31} \\
\hline & Republican & 0.032 & 0.048 & 0.04 & & \\
\hline \multirow{2}{*}{ R. Gephardt } & Democrat & 0.036 & 0.043 & 0.0395 & \multirow{2}{*}{0.096} & \multirow{2}{*}{0.411} \\
\hline & Republican & 0.056 & 0.057 & 0.0565 & & \\
\hline \multirow{2}{*}{ J. Kerry } & Democrat & 0.103 & 0.153 & 0.128 & \multirow{2}{*}{0.29} & \multirow{2}{*}{0.441} \\
\hline & Republican & 0.159 & 0.165 & 0.162 & & \\
\hline \multirow{2}{*}{ J. Lieberman } & Democrat & 0.042 & 0.045 & 0.0435 & \multirow{2}{*}{0.098} & \multirow{2}{*}{0.444} \\
\hline & Republican & 0.054 & 0.055 & 0.0545 & & \\
\hline \multirow{2}{*}{ Other } & Democrat & 0.206 & 0.209 & 0.2075 & \multirow{2}{*}{0.451} & \multirow{2}{*}{0.46} \\
\hline & Republican & 0.24 & 0.247 & 0.2435 & & \\
\hline
\end{tabular}

The calculations in Table 1 are straightforward largely because the securities in the conditional market are normalized so that the total payoffs are known, in this case $\$ 1$. This approach can be used to assess the extent to which a particular decision will affect some other

tors recognized Dole's weakness at the time, pointing to polling results involving hypothetical matchups between President Clinton and various Republican candidates. See David S. Broder, Many Still Making Up Their Minds; Shifting Loyalties Mark Final Days, Wash Post A1 (Feb 12, 1996). Of course, some Republican voters might have preferred Dole over a candidate with a better chance of winning because they preferred Dole enough to make it seem worth the risk.

71 The Table provides a snapshot of the 2004 presidential election market as of April 28, 2003 at noon. The first column lists each potential nominee, including one undeclared candidate (Hillary Clinton) and an "other" category, including such potential nominees as John Edwards. Two securities correspond to each potential nominee. The two securities corresponding to the eventual nominee will be liquidated based on the eventual two-party vote share in the election, with all other contracts liquidating at zero. The third, fourth, and fifth columns report the bid and ask prices, followed by the midpoint of these. The last two columns calculate the market's estimate of the chance of the candidate's winning the election and the vote share assuming the candidate is nominated based on these midpoints. For example, Hillary Clinton's 0.058 chance of winning the nomination is the sum of the bid-ask midpoints $(0.018$ and 0.04$)$ of the securities corresponding to her nomination. (Note that this measures her absolute chance of winning the nomination, not her chance of winning conditional on deciding to run.) Clinton's conditional vote share of 0.31 is equal to her bid-ask midpoint divided by her overall chance of winning the nomination. 
probability. Robin Hanson, for example, analyzes a hypothetical conditional market used to determine how a decision whether to move troops will affect the probability that a war will occur. ${ }^{2}$ The market involves four securities. The first will pay off $\$ 1$ if troops are moved and there is a war; the second, if troops are moved and there is no war; the third, if the troops are not moved and there is no war; the fourth, if troops are not moved and there is a war. From the securities' prices one could calculate both the market's estimate of the chance that a decision to move troops will be made and the market's estimate of the correlation between a decision to move troops and the probability that war will result from such a decision.

Hanson, however, also notes that conditional markets might be used to assess how specified decisions might affect non-binary variables, such as stock price, GDP per capita, or unemployment rates. The mechanics here become somewhat more complicated. Suppose, for example, that a conditional market is to be used to assess the effect of proposed airline safety regulations on the number of people who will choose to fly on airplanes in a particular year, because one anticipated effect of the regulations is increased consumer confidence. ${ }^{74}$ The government could issue a security that will pay off one cent per a specified number of passenger miles if the regulations are adopted and another that will pay off at the same rate if the regulations are not adopted. The values of these securities, however, would also depend on the market's prediction about whether the regulations are adopted. A simple solution would be to create an additional information market estimating the probability that the agency will indeed adopt the regulations, for example by issuing two securities, with one selected to pay off $\$ 1$ depending on whether the regulations are adopted. ${ }^{75}$ The

72 Hanson, Conditional Markets at slides 2-3 (cited in note 68).

73 Id at slide 4.

74 Of course, a market could also be used to measure the variable that is more obviously of interest, the number of anticipated deaths in airplane crashes. I use the passenger miles to place aside questions about the appropriateness of using an information market to predict deaths and about whether information markets might create a moral hazard problem by encouraging people to predict high death totals and then cause those deaths. See notes $182-84$ and accompanying text for discussion of these types of concerns.

75 An alternative solution would be for the government to provide that the transactions on the irrelevant market would be cancelled, with all investors in that market receiving refunds. For example, if the regulations were adopted, then the information market corresponding to nonadoption would be cancelled. Such a market would give no indication of the probability of adoption but would indicate the effect of adoption. A drawback of this approach is that if there is a very high probability of adoption or non-adoption, there might be very little incentive to trade on the market that will be cancelled, and its results may thus be unreliable. This may not be a large concern, however, since the very high probability would presumably indicate that the government is not expected to take into account the market prediction in any event. 
price of each security divided by the probability of the corresponding decision would then provide a prediction of the passenger miles in each scenario.

Information markets may produce misleading predictions, however, if there is a possibility that the eventual decisionmaker might have information unavailable to the market. Suppose that an airline safety market participant estimates, based on her own information, that there will be 500 billion passenger miles if the regulations are adopted and 490 billion otherwise, but the participant also knows that the decisionmaker has additional information that could allow for refinement of these estimates and therefore might affect the eventual decision. The decision itself thus might provide some indication of the content of this information. The market participant should reason that if the regulations are enacted, then the probability that the information is favorable to the regulations is higher than the participant's initial estimate, and vice versa if the regulations are rejected. As a result, the participant should price the security conditional on enactment as above the 500 billion level, and the security conditional on rejection as below that corresponding to 490 billion. Hanson, who has recognized this potential problem, suggests a possible solution: to allow decisionmakers to trade, so that there will be no information unavailable to the market. ${ }^{76}$ This solution is problematic, however, because decisionmakers might then be tempted to make decisions that would maximize their trading gains rather than social welfare. ${ }^{n}$

There are two additional reasons, besides this selection bias problem, suggesting that decisionmakers should hesitate before blithely accepting information market predictions calculated on the basis of differences in security values. First, conditional markets may lead to expenditure of effort on issues of little interest to the decisionmaker, as market participants may factor in a number of variables besides whether a particular decision is made. In the market used to predict the effect of proposed regulations on airline safety, for example, market participants might devote considerable resources to the overall

\footnotetext{
76 Hanson, Conditional Markets at slide 12 (cited in note 68).

77 Hanson responds, "I don't see the problem with decision-makers maximizing their trading gains, if they are trading on decision conditional predictions." Email from Robin Hanson (Aug 30, 2003) (on file with author). A decisionmaker, however, who invests in a security that will be redeemed conditional only on a particular resolution of a policy has an incentive to ensure that the policy is resolved in that way. Conditional markets can be structured so that investments are returned when the condition is not met. See note 21 . Even here, however, a decisionmaker who purchases securities might reason that the decisionmaker will have a chance to profit from the decision only if the condition is met.
} 
task of modeling passenger miles. If such a market were subsidized, ${ }^{78}$ market participants would be able to obtain a portion of the subsidy by improving predictions on any variable that might affect passenger miles, such as expected changes in weather patterns. Only a portion of the subsidy therefore would specifically incentivize the variable of interest, the effect of the regulations. If the regulations are expected to have a very small effect on consumer behavior, few if any resources would be spent on this portion of the analysis. There is no obvious way to determine how much effort market participants expended at calculating the effect of the regulations. Any incomplete evaluation of relevant information in effect adds noise to the estimate of the factor the market is designed to predict.

Second, slight differences in security prices could be a result of a different type of noise. If there is some noise in the data used to generate predictions, such as the last transaction price or the midpoint of bid-ask spreads, then that noise may overwhelm the variable of interest. If the increase in passenger miles caused by the regulation corresponds to a price effect that is smaller than the bid-ask spread, for example, traders might have insufficient incentive to arbitrage away any difference in price associated with the two securities. The greater the liquidity of the market, the more closely market variables such as transaction price are likely to reflect the actual consensus of market participants regarding the variables in question. As discussed below in more detail, ${ }^{79}$ in a relatively thin market, there could be significant deviation between price and consensus.

Each of these problems associated with conditional markets could significantly affect the calculation of the effect of the relevant decision on the variable of interest. The bias attributable to this selection effect, for example, might be slight relative to the overall prediction of passenger miles, but large relative to the predicted difference in passenger miles attributable to a particular decision. If the bias leads to security prices corresponding to 485 and 505 billion miles, for example, then the bias essentially doubles the conditional market's estimate of the effect of airline safety regulations. The resulting data might still be useful by showing that the regulations will be expected to have only small effects. In some cases, this might itself be sufficient to show that the regulations should not be enacted, assuming that consumer confidence rather than actual safety is the regulatory goal. But often in regulation even relatively small effects matter, and indeed an

See Part I.C.3.

79 See Part I.C.2. 
agency might consider effects on consumer confidence only because the issue is related to safety fundamentals. In that case, the government might want to know the market's exact prediction of the effect of enacting the regulations on the number of miles.

In sum, while information markets can make predictions that may be used as inputs in subsequent decisionmaking, the particular usefulness of conditional markets stems from their ability to predict the effect of hypothetical decisions on variables of interest. If the predicted effect of the decision can be determined only by analyzing multiple market prices, however, slight imperfections in information markets are magnified. Conditional markets are thus most likely to be useful where the decision is expected to have a substantial effect on the variables of interest. In that case, though, conditional markets are pointless: When a decision is expected to have a significant effect, the direction of that effect is probably already clear. These problems with conditional markets suggest that it is impossible to construct an information market that produces a useful evaluation of a potential decision. I will argue in Part III, however, that although predictive cost-benefit analysis shares some of the weaknesses of conditional markets, it successfully avoids many of their problems.

\section{Thin markets.}

Information markets are a tool for generating consensus predictions from a number of participants, but they may be less effective when markets are thin. In thin markets, trades occur relatively rarely, and there is a danger that the most recent transaction will not represent the market consensus. For example, even if all traders recognize that the value of the securities has changed, they may have no reason to buy or sell these securities. The problem may be particularly severe in an information market in which some traders may obtain significant information that others lack. The greater the degree of information asymmetry, the larger bid-ask spreads will be $\mathrm{b}^{80}$ and the less frequently transactions will occur. The Iowa Electronic Markets seem to have sufficient liquidity to enable frequent transactions, yet the relative thinness of even this market can make it hazardous to rely on the last transaction price. ${ }^{81}$ When dealing with an information market in which there are fewer likely traders and asymmetric information is more of a concern, the standard mechanism may prove more problematic.

81 See text accompanying note 40 . 
The central problem of thin information markets is that information markets rely on voluntary transactions to assess market consensus, but transactions will not occur with sufficient frequency to reach an accurate consensus under certain conditions. One can imagine many nonmarket mechanisms, however, that provide for compulsory transactions. Consider, for example, the following simple mechanism: An initial predictor makes a prediction of the variable of interest. Anyone can challenge the initial predictor to a bet, which the initial predictor is required to take. The challenger then announces a new prediction and can be challenged in turn. So, if $A$ predicts $5, B$ could bet $A$ that the amount will be higher and announce a new prediction of 6 . Then, $C$ could bet $B$ that the actual amount is 7 . Suppose the market then closes and the amount turns out to be 8 . If each unit of prediction corresponds to $\$ 1$, then $B$ would win $\$ 1$ against $A$, but $C$ would win $\$ 1$ against $B$. Such a simple betting scheme performs the same information aggregation function as a securities market, but it encourages the predictors to update their predictions to reflect new information lest they be challenged, and it allows those with new information to trade on that information even if others would prefer not to trade because of the informational asymmetry.

There are ways to integrate compulsory transactions into the market metaphor, including the enactment of a rule that requires a security holder to announce a price which then serves as an offer for anyone else to either buy the security at that price or sell an identical security to the holder at that price. ${ }^{83}$ The central point, however, is that the market metaphor is unnecessary. Information markets work because they allow market participants to profit when they correctly identify that the consensus prediction is inaccurate. The market metaphor is both useful and familiar, because we know that capital markets tend to aggregate predictions. The above compulsory betting procedure accomplishes much the same thing, and at least in one respect, is better than the traditional capital market, because it allows participants to make positive expected-value bets based on even small amounts of information. An additional virtue of this procedure is that it helps distinguish information markets from more conventional securities markets and the pathologies that behavioral finance scholars have identified within them. ${ }^{84}$ No one would casually use this form of

82 Because the initial predictor is required to take all bets, some incentive would need to be given for someone to become the first predictor.

83 See Michael Abramowicz, Trial by Market (2003) (unpublished manuscript, on file with author) (describing such a mechanism).

84 See note 11. 
the information market as an investment vehicle, given the risk of being subject to a bet.

Robin Hanson offers a similar proposal to overcome market thinness. ${ }^{85}$ Hanson builds on the literature on "scoring rules," which are rules that can be used to compensate individual experts to induce honest valuations from them. For example, suppose that I want to give an expert an incentive to estimate for me the average temperature this coming winter. I could ask for an estimate and agree to pay the expert based on the difference between the prediction and the eventual observed value, with a higher payment amount the closer the expert is. Somewhat more complicated scoring rules as described in the scoring rules literature can be used to generate predictions as to the probability of events. ${ }^{86}$ A scoring rule is similar to an information market in that participants have an incentive to predict the events of interest to the sponsor. It is, in effect, an information market that could be used in the thinnest of all possible markets, a market with just one participant.

Hanson suggests what he calls a "market scoring rule" as a way to provide a mechanism that works like a scoring rule when there are only a small number of participants and like a more traditionally structured information market when there are more participants. Under the market scoring rule, after the initial prediction, anyone else can make a subsequent prediction, as long as the subsequent predictor in effect agrees to pay off the current predictor when the market closes. The subsequent predictor thus receives a payment equal to the difference in the payments that the scoring rule would provide to the two predictors; if this number is negative, the subsequent predictor would pay money. ${ }^{88}$ This system is identical to the betting scheme dis-

85 Robin D. Hanson, Combinatorial Information Market Design, 5 Info Sys Frontiers 107 (2003) (suggesting improvements to current information aggregation techniques).

86 See, for example, Robert T. Clemen, Incentive Contracts and Strictly Proper Scoring Rules, 11 Test 167 (2002) (discussing scoring rules in the context of agency theory and game theory); Robert L. Winkler, Scoring Rules and the Evaluation of Probability Assessors, $64 \mathrm{~J}$ Am Stat Assn 1073 (1969) (comparing scoring rules to likelihood ratios as means of evaluating assessors).

87 Hanson, 5 Info Sys Frontiers at 110-11 (cited in note 85 ).

88 Suppose a market scoring rule is to be used to predict interest rates a year hence. A scoring rule for a market predicting interest rates might provide that the predictor will receive $\$ 12,000$ minus $\$ 1,000$ for each quarter point by which the estimate turns out to be inaccurate (and thus will have to pay money if the prediction turns out to be wrong by more than three percentage points). Suppose that Predictor 1 picks 2.5 percent; Predictor 2, 4.0 percent; Predictor 3, 3.25 percent; and the actual interest rate turns out to be 3.75 percent. The scoring rule would assign Predictor $1 \$ 7,000$; Predictor $2, \$ 11,000$; and Predictor $3, \$ 10,000$. With the market scoring rule, Predictor 1 receives $\$ 7,000$, Predictor 2 receives $\$ 4,000(\$ 11,000-\$ 7,000)$, and Predictor 3 pays $\$ 1,000(\$ 10,000-\$ 11,000)$. The example shows the possibility that there might be a windfall for the first predictor (or depending on the scoring rule, an expected liability, in which case no 
cussed above, except that each subsequent predictor's bet is with the house rather than with the previous predictor. The advantage of this approach relative to the betting scheme described above is that a potential predictor need only worry about coming up with a prediction that is likely to be better than that of the current predictor, but need not worry that a subsequent predictor will further refine his or her prediction. Given the risk, individuals might still choose not to act on very minor pieces of information, but there will be more of an incentive to do so than with the betting scheme.

\section{Subsidized markets.}

Although the Iowa Electronic Markets are not subsidized, subsidies would improve market participants' incentives to engage in research and analysis; markets that are less intrinsically interesting than the Iowa Electronic Markets may require additional subsidies to create sufficient interest. Hanson's market scoring rule provides an easy mechanism for subsidizing information markets. Recall that after the initial predictor, each subsequent predictor receives a sum equal to the amount by which the predictor achieved a better payout than her predecessor based on the scoring rule. The sponsor of the market therefore will end up paying the amount that the scoring rule would indicate that the last predictor should receive. However, there are two issues that the literature does not explicitly consider. First is how the initial predictor would be selected. Being the first predictor would provide a windfall, at least with any scoring rule that always produces a positive reward. ${ }^{89}$ The second issue is how large a subsidy should be provided.

One approach would be for the sponsor to make an initial prediction of the variable of interest. It could then announce a scoring rule that would produce a reward based on the amount by which the next prediction improved upon this initial one (or a penalty if the next prediction were less accurate). For example, in the airline safety regulation market described above, ${ }^{90}$ the government might announce a prediction of 500 billion miles and then announce that for each one billion improvement in predicting miles, the government would pay a total of $\$ 1,000$. If the eventual prediction were 505 billion miles and the

\footnotetext{
one would want to participate). See note 92 and accompanying text.

89 Some subsequent predictors might lose money with such a scoring rule, as in the example of Predictor 3 in note 88 , but that is only because they did not predict as accurately as their predecessors.

90 See notes 74-75 and accompanying text.
} 
total number of miles turned out to be 510 , the government would pay a total of $\$ 5,000$. $^{\text {. }}$

This does not identify a complete solution to the first problem identified above: the selection of the first predictor. Rather, there still might be a windfall to the second predictor, and thus a race to be that second predictor, if the initial market consensus is that the government's initial prediction was poor. A simple solution to this is to auction off the right to be the second predictor. ${ }^{2}$ If the government announced a prediction of 490 billion miles, but it were widely recognized even before research that 500 billion would be a more sensible initial estimate, then the government would receive nearly $\$ 10,000$ in auction revenues for the right to be the second predictor ${ }^{93}$ and then would end up paying $\$ 10,000$ back upon the close of the market. The incentives to improve on the prediction of 500 billion miles would exist as before, but the windfall would be eliminated.

Regardless of whether an auction is used to eliminate windfalls, an advantage of a subsidization scheme that provides a set reward for specified improvements in predictions is that the sponsor of the market can set the subsidy based on its assessment of how valuable improvements in the information would be. In this case, for example, potential participants will invest their time and resources into market participation whenever they believe that an investment of $\$ 1,000$ (including the risk associated with participation) will be expected to produce a refinement in the estimate by one billion passenger miles. It is difficult to know how valuable more accurate information is. Presumably, the subsidy should reflect the reliance the government is

91 Suppose, for example, after the government's initial prediction of 500 billion miles, $A$ predicts $503, B$ predicts $502, C$ predicts $518, D$ predicts 522 , and $E$ predicts 505 , with the actual total turning out to be 510 . The scoring rule would assign $\$ 1,000$ for each unit improvement in the prediction. Thus, the initial assignments of the scoring rule (before subtractions) would assign rewards of $\$ 3,000$ for $A, \$ 2,000$ for $B, \$ 2,000$ for $C,-\$ 2,000$ for $D$, and $\$ 5,000$ for $E$. The amount that each predictor actually receives, however, is the difference between the scoring rule amount for that predictor and the previous one. So, the final payments as determined by the market scoring rule would be $\$ 3,000$ for $A,-\$ 1,000$ for $B, 0$ for $C,-\$ 4,000$ for $D$, and $\$ 7,000$ for $E$.

92 Auctions are a commonly proposed approach to eliminating windfalls that would exist merely as a result of being first. See, for example, Julie Rubin, Auctioning Class Actions: Turning the Tables on Plaintiffs' Lawyers' Abuse or Stripping the Plaintiff Wizards of Their Curtain, 57 Bus Lawyer 1441, 1443-45 (1997) (advocating the use of class action auctions as a means of mitigating lawyer abuse); Robert G. Hansen and Randall S. Thomas, Auctioning Class Action and Derivative Lawsuits: A Critical Analysis, $87 \mathrm{Nw}$ U L Rev 423,428-29 (1993) (finding that in most class action lawsuits the court appoints as lead counsel the first attorney to file the lawsuit).

93 It would not receive quite this much back because of the risk associated with being the second predictor, given the inherent uncertainty about the prediction being made. The predictor, in effect, would demand some compensation for this risk by bidding less than $\$ 10,000$ even if the expected receipts from participating were $\$ 10,000$ with some variance. 
likely to place on the information market: the higher the subsidy, the greater the reliance the government is likely to place on the information market. This system has the virtue of allowing the market sponsor to consider the information's value directly, whereas other means of providing subsidies may obscure the question of how much research the sponsor is encouraging individuals to conduct. Despite this benefit, there may be occasions in which the sponsor wishes to provide a set subsidy for a particular market, for example, because it needs to be able to anticipate the cost of running the market. This would be a straightforward calculation, as the subsidy, plus any auction revenues, could be divided in proportion to the reward indicated by the market scoring rule.

\section{INFORMATION MARKETS AND ADMINISTRATIVE DECISIONMAKING}

Information markets in theory might be used in any decisionmaking environment, and corporations have experimented to determine how effectively information markets aggregate information. ${ }^{95}$ If the information aggregation benefits are relatively modest, however, then it might not seem worthwhile to experiment with information markets in governmental decisionmaking. For reasons of tradition and continuity, governments are hesitant to innovate with respect to decisionmaking structures, ${ }^{*}$ and the innovations that administrative agencies have undertaken are generally responsive to some government-specific

94 In the example in note 91 , suppose the preset subsidy were $\$ 10,000$. Then, the scoring rule would assign, instead of $\$ 1,000$ per unit improvement, one point per unit improvement. The market scoring rule would subtract each participant's points from the previous participant's and then distribute the subsidy in proportion to these points. The final payments would end up being exactly twice those listed in the hypothetical: $\$ 6,000$ for $A,-\$ 2,000$ for $B, 0$ for $C,-\$ 8,000$ for $D$, and $\$ 14,000$ for $E$.

The only complication would occur if the final prediction were worse than the initial prediction. In this case, the market scoring rule could be adjusted so that all positive rewards (that is, rewards corresponding to predictions that did move in the right direction) were multiplied by the constant that would result in the government's paying on net the amount of the subsidy. In the unlikely event that there were no predictions moving the market in the proper direction, then the government could distribute the subsidy so that those who caused the least damage received the most. For example, if $A$ 's market score were -1 and $B$ 's market score were -2 , then $A$ would receive two-thirds of the subsidy.

95 See note 60 and accompanying text. A company called Intellimarket offers services in establishing internal information markets for companies seeking to perform estimations. See http://www.wrsasc.com/default.cfm?fuseaction=tbAboutintellimarket (visited Apr 22, 2004).

96 Even in areas in which competitive federalism provides an incentive to improve regulatory structures, states still may hesitate to innovate. See Michael Abramowicz, Speeding Up the Crawl to the Top, 20 Yale J Reg 139 (2003) (explaining why there might be underinnovation in corporate law). 
need. ${ }^{\text {n }}$ If information markets are to become a particularly useful tool in governmental decisionmaking, it will not be because governmental decisionmakers themselves want to use the tool to improve their own decisions. Rather, information markets are best justified as a means for disciplining governmental decisionmaking. Part II.A explains why objective prediction tools might be particularly useful in an area as rife with agency problems as governmental decisionmaking, and it assesses the extent to which concerns about manipulation and unrepresentative traders undercut the possibility of objectivity. Part II.B then considers a few specific instances in which information markets might assist governmental decisionmaking, selecting examples that illustrate various design problems with information markets. Finally, Part II.C offers an assessment of the possible use of information markets in judicial review, if such markets existed and proved to be objective.

\section{A. The Objectivity of Information Markets}

1. Why objectivity matters.

Imagine that government researchers developed a crystal ball that allowed officials to see what the future would be like under any given set of policies. Would the government use the crystal ball? For some purposes, perhaps not; we might not want to know our individual destinies or those of our favorite sports teams. But it is hard to imagine an area of administrative law for which the crystal ball would not be useful. The Department of Homeland Security could anticipate terrorist attacks, and a Department of Precrime could intervene to stop murders before they occur. ${ }^{98}$ The Environmental Protection

97 A useful example of such an innovation is negotiated rulemaking, which provides a means of passing regulations when all principal constituencies can agree on what the rules should provide. See generally 5 USC $\$ 561$ et seq (providing the statutory foundation for negotiated rulemaking); Matthew J. McKinney, Negotiated Rulemaking: Involving Citizens in Public Decisions, 60 Mont L Rev 499 (1999) (arguing that negotiated rulemaking can solve a number of problems currently associated with traditional notice-and-comment rulemaking); Jody Freeman, Collaborative Governance in the Administrative State, 45 UCLA L Rev 1 (1997) (concluding that negotiated rulemaking has proved advantageous in the areas of health and safety and environmental regulation). Negotiated rulemaking would have limited applicability in corporate contexts, where hierarchical structures minimize the need to satisfy a broad range of constituencies.

98 See Minority Report (20th Century Fox 2002) (exploring such a scenario). The movie questions whether we would want to rely on such a system if it were the least bit uncertain, as represented by the occasional "minority report," or dissenting opinion as to the future. The concern is that we might end up arresting people for crimes that in fact they would not have committed, and an additional concern is that it might be morally problematic to arrest people for crimes that they would have committed but did not actually commit. Somewhat puzzlingly, however, the movie never considers the possibility that the system could be used to thwart crime but not to incarcerate the putative perpetrators. Perhaps the filmmakers felt an intrinsic discomfort 
Agency (EPA) could assess the effects of both global warming and the policies that might limit it. The Securities and Exchange Commission could consider which market rules would lead to the highest future stock prices. The U.S. Citizenship and Immigration Service could assess the effects of immigration on economic growth and crime. And on and on. None of these analyses would be sufficient to determine the course of policy, for in all of these areas, few if any policies are Pareto efficient. ${ }^{99}$ But a crystal ball surely would at least be useful by narrowing administrative decisionmaking to the selection of which world we would prefer.

Information markets are not a crystal ball. They cannot predict what will happen; rather, they can only give us probabilistic predictions. But let us suppose that information markets are accurate, in the sense that they aggregate information as well as alternative approaches, such as consulting experts, and that they are objective, in that they have no ideological or other biases and cannot be manipulated by government or outside agents. Suppose further that they are accepted as providing a best guess, so that an argument that information markets are inferior to other predictive approaches would receive little weight in policy discourse. While information markets cannot allow us to select a single future, with these assumptions they can permit us to select from probability distributions of possible futures, at least based on the variables that we select for the markets to predict. This still narrows agency decisionmaking down to normative assessments rather than to the task of making scientific and other predictions. Of course, these assumptions are not trivial, ${ }^{100}$ and ultimately information markets' usefulness depends on difficult evaluations of the extent to which these assumptions are correct.

The immediate question is why narrowing agency decisionmaking to normative questions would be useful. It might seem that if we set aside the possibility that information markets achieve better information aggregation than any comparably costly individual decisionmaker, it should not matter whether the government uses them. On this argument, information markets represent a privatization of government functions without resource savings and should thus be a mat-

with predictive legal tools. Or maybe they worried that acknowledging the distinction would have made the movie less interesting.

99 Pareto efficient policies are those that make at least one person better off and no one worse off. For a general discussion of Pareto efficiency, see Guido Calabresi, The Pointlessness of Pareto: Carrying Coase Further, 100 Yale L J 1211 (1991) (noting that few policies are Pareto efficient and considering bases for evaluating policies that are not).

100 See Part I.B (considering the accuracy assumption); Part II.A.2 (considering the manipulation and ideological bias assumptions). 
ter of indifference. The problem with this argument is that it focuses exclusively on different information aggregation technologies rather than on how agents might use or misuse such technologies. The danger is that administrative agencies might make factual assessments in order to support decisions that they would like to make for normative reasons. ${ }^{101}$ Deprived of the ability to announce misleading predictions, agency officials would need to defend their decisions with normative arguments alone. To the extent that these normative arguments are unpersuasive, agency officials might suffer the reputational costs that a decisionmaker bears when observers view a decision as nothing more than an ipse dixit, ${ }^{102}$ and the officials might also face an increased possibility of skeptical judicial review. ${ }^{103}$

Although information markets that generate predictions of objective variables are only precursors to subsequent normative agency decisions, they can help discipline the process of making those decisions. Another analytical tool, cost-benefit analysis, has often been identified as achieving a similar type of discipline. Commentators have emphasized that cost-benefit analysis helps to reduce cognitive errors and the effect of political factors, such as interest groups or ideology, on legal policy. The parallel is incomplete, as agency officials may have some ability to control the numbers produced by cost-benefit analysis that they would not have with information markets, but I will return to that problem later by showing how information markets might be

101 Joseph Smith and Emerson Tiller have shown empirically that judges who wish to achieve results in particular cases may act strategically in choosing an instrument that will achieve that policy goal, for example by deciding whether to reject a regulation on procedural or substantive grounds. See Joseph L. Smith and Emerson H. Tiller, The Strategy of Judging: Evidence from Administrative Law, $31 \mathrm{~J}$ Legal Stud 61 (2002). Smith and Tiller note:

Strategic judges anticipate the likely responses of other players and make choices that will ultimately maximize their own policy preferences under the given constraints. To the extent that the choice of a judicial instrument affects the ability of others to reverse the court, it becomes a strategic variable in the court's decision.

Id at 63. The point applies as much to agencies as to judges. Agency officials who wish to ensure that a policy is enacted may justify their decisions on predictions that are difficult for courts to dispute if they are concerned that courts might be skeptical of the normative considerations that in fact motivated the decision.

102 Some commentators doubt that reputation figures prominently in the judicial utility function. See Richard A. Posner, What Do Judges and Justices Maximize? (The Same Thing Everybody Else Does), 3 S Ct Econ Rev 1, 15 (1993) (arguing that reputation is not central to the judicial utility function of judges of "ordinary abilities," but may be a "dominating objective" for extraordinary judges). To the extent that judges do care about their reputations, however, judges presumably do not wish to appear result-oriented. See, for example, Richard A. Posner, The Meaning of Judicial Self-Restraint, 59 Ind L J 1, 8 (1983) (recognizing that "result-oriented" is used as a "pejorative").

103 See notes 226-31 and accompanying text (considering the possible use of information market predictions in judicial review). 
combined with cost-benefit analysis to reduce such control. ${ }^{104}$ The comparison, however, is useful, as information markets can increase the objectivity of predictive assessments in much the same way that cost-benefit analysis can increase the objectivity of normative assessments, as the following subsections explain.

a) Cognitive errors. The simplest defense of cost-benefit analysis is that it prevents bad policies, which are policies whose costs, if enacted, would exceed their benefits. ${ }^{105}$ Such a defense invites the question of why governmental officials would choose bad policies in the absence of cost-benefit analysis, a question to which Cass Sunstein poses one possible answer in Cognition and Cost-Benefit Analysis. ${ }^{100}$ Sunstein argues that "cost-benefit analysis is best defended as a means of overcoming predictable problems in individual and social cognition." ${ }^{, 107}$ By "predictable problems," Sunstein means the heuristics that cognitive psychologists have identified as producing systematic biases in human decisionmaking, ${ }^{108}$ as well as the social dynamics that can cause group decisionmaking to err. ${ }^{109}$ Cost-benefit analysis's methodology enforces a rigor that can help decisionmakers overcome such pitfalls, pointing them to what is really at stake in a decision.

As the most significant example, Sunstein cites the availability heuristic, ${ }^{110}$ which refers to the tendency of people to think that events are more likely to occur than the statistics suggest because they can recall past examples of such events. Writing with Timur Kuran, Sunstein has previously emphasized the danger that this heuristic will lead to "availability cascades," a vicious cycle in which an event leads individuals to overestimate a risk, in turn affecting public discourse, which then exacerbates the initial overestimation. ${ }^{1.2}$ As an example,

104 See Part III.

105 For a sophisticated exposition of what they term the "conventional view," see Matthew D. Adler and Eric A. Posner, Rethinking Cost-Benefit Analysis, 109 Yale L J 165, 176-94 (1999).

106 Cass R. Sunstein, Cognition and Cost-Benefit Analysis, 29 J Legal Stud 1059 (2000).

107 Id at 1060.

108 For a general discussion of such biases, see Daniel Kahneman, et al, eds, Judgment under Uncertainty: Heuristics and Biases (1982) (collecting many of the seminal cognitive psychology articles identifying such biases).

109 Sunstein himself has done considerable work on the dynamics of group decisionmaking. See, for example, Cass R. Sunstein, What's Available? Social Influences and Behavioral Economics, $97 \mathrm{Nw}$ U L Rev 1295 (2003) (examining society's impact on personal heuristics and biases); Cass R. Sunstein, et al, Predictably Incoherent Judgments, 54 Stan L Rev 1153 (2002) (analyzing how judges and juries decide the magnitude of civil and criminal penalties); Cass R. Sunstein, Deliberative Trouble? Why Groups Go to Extremes, 110 Yale L J 71 (2000) (discussing the propensity for group polarization during deliberations).

110 Sunstein, 29 J Legal Stud at 1065-66 (cited in note 106).

111 Kuran and Sunstein, 51 Stan L Rev at 683 (cited in note 17).

112 See id at 716 ("Public discourse shapes individual risk judgments, risk preferences, and 
Kuran and Sunstein cite the Love Canal episode, in which residents' concerns about environmental contamination from a toxic waste dump snowballed, eventually leading to mass relocations, ${ }^{113}$ even though there was no good scientific evidence validating their concerns. ${ }^{114}$ The ultimate effect, Sunstein suggests, was even more dramatic, leading to passage of the Superfund statute, ${ }^{115}$ which critics have suggested is one of the most expensive and least effective environmental statutes, ${ }^{116}$ given the relatively small risk posed by toxic waste dumps."

Cost-benefit analysis might have thwarted the Love Canal availability cascade by forcing governmental officials to make explicit estimates of risk based on scientific data. ${ }^{1.8}$ An information market might have a similar effect. For example, an information market might have been invoked to predict future cancer rates in various communities. A prediction that the cancer rates in communities near dumps would be comparable to the rates in communities lacking dumps would provide an objective datum indicating that there was an overreaction. Information markets might also be used for other availability cascades that Sunstein has perceived, such as the public overreaction that he believes followed the September 11, 2001 terrorist attacks. ${ }^{119}$ In that case, for example, an information market might have been used to predict future deaths from terrorism, possibly conditional on different governmental policies. ${ }^{120}$ Such a market might have produced an objective datum that the risk was small, or it might have suggested that the risk

policy preferences; and the reshaped personal variables then transform the public discourse that contributed to their own transformations.").

113 Id at 695

114 Id. For a different view of the episode, see Adeline Gordon Levine, Love Canal: Science, Politics, and People (Lexington Books 1982).

11542 USC $\$$ 9601-75 (2000).

116 Revesz and Stewart state that "Superfund is also widely regarded as a wasteful and inefficient program, plagued by high transaction costs, serious administrative deficiencies, and long delays in cleaning up sites.” Richard L. Revesz and Richard B. Stewart, The Superfund Debate, in Richard L. Revesz and Richard B. Stewart, eds, Analyzing Superfund: Economics, Science, and Law 3, 4 (Resources for the Future 1995).

117 See James T. Hamilton and W. Kip Viscusi, The Magnitude and Policy Implications of Health Risks from Hazardous Waste Sites, in Revesz and Stewart, eds, Analyzing Superfund 55, 56 (cited in note 116) (concluding that "the overwhelming preponderance of risk is to future populations for land uses that represent departures from current behavior").

118 See Sunstein, $29 \mathrm{~J}$ Legal Stud at 1065-66 (cited in note 106) ("Cost-benefit analysis is a natural corrective [to availability cascades], above all because it focuses attention on the actual effects of regulation, including, in some cases, the existence of surprisingly small benefits from regulatory controls.").

119 See Cass R. Sunstein, The Cost-Benefit State: The Future of Regulatory Protection 26 (ABA 2002).

120 Indeed, this is one of the tasks for which FutureMAP was intended. See Part II.B.1. 
was quite large, especially if the danger of nuclear terrorism were taken into account. ${ }^{121}$ At the same time, an information market preceding September 11 might have suggested that insufficient attention was being paid to the dangers of terrorism.

A significant caution is in order here. Just because an information market exists does not mean that it will stop an availability cascade, even assuming that it makes an accurate prediction. Public officials might well ignore the results of an information market, downplaying any data that seem inconsistent with public concerns. This is, however, a limitation of cost-benefit analysis and other objective guides to policy as well. ${ }^{122}$ Any methodology for improving governmental decisionmaking can be successful only to the extent that it is followed. Administrative agency officials might seek to institute information markets as a way of preventing availability cascades from emerging, ${ }^{123}$ but officials might also like to play on public fears, either to seem responsive or because they prefer a greater amount of risk regulation than a wellinformed public would choose.

There are at least two possible routes that could lead the government to make decisions consistent with approaches like costbenefit analysis and information markets. One is general acceptance. Such acceptance has eluded cost-benefit analysis, ${ }^{124}$ perhaps in part because of legitimate claims that it favors particular values over others. ${ }^{12}$ Even if information markets do prove to be accurate and objective, the public may be skeptical of their results. Their relative lack of

121 See, for example, Martin J. Rees, Our Final Hour: A Scientist's Warning (Basic Books 2003) (arguing that nuclear war and other potential disasters present a strong possibility of destroying civilization).

122 As Kuran and Sunstein emphasize, a blue-ribbon panel on Love Canal "endorsed none of the reports of serious health effects," but "its evaluation had no appreciable influence on subsequent events." Kuran and Sunstein, 51 Stan L Rev at 695 (cited in note 17).

123 Information markets may not succeed in eliminating information cascades altogether. See, for example, Werner F.M. De Bondt and Richard H. Thaler, Do Security Analysts Overreact?, 80 Am Econ Rev 52 (1990) (indicating that even professional security analysts may behave irrationally). See also Colin F. Camerer and Robin M. Hogarth, The Effects of Financial Incentives in Experiments: A Review and Capital-Labor-Production Framework, $19 \mathrm{~J}$ Risk \& Uncertainty 7 (1999) (indicating that increasing monetary stakes does not eliminate persistent irrationalities). Markets, however, at least provide incentives for participants to trade based on existing irrationalities, and the better we understand cascade effects, the better markets should be at overcoming them. Cascade effects should also be less likely to emerge in information markets than in more traditional securities markets because casually informed traders may be less likely to participate in information markets.

124 Sunstein himself has documented a recent case in which a cost-benefit analysis recommendation was controversial. See Cass R. Sunstein, The Arithmetic of Arsenic, 90 Georgetown L J 2255, 2261-63 (2002) (discussing the controversy surrounding the Bush administration's decision to suspend the Clinton administration's arsenic regulation).

125 See notes 284-85 and accompanying text. 
prominence makes acceptance of their predictions particularly unlikely, although in the long term, their focus on predictions rather than on values may encourage their acceptance, especially if they prove prescient and their accuracy is publicized. The second route is to enact a set of rules requiring that administrative agency decisionmakers engage these methodologies and factor them into their decisions. ${ }^{126}$ Attempts to institutionalize cost-benefit analysis have been at least moderately successful, ${ }^{127}$ though the courts have held that some agencies cannot use cost-benefit analysis. ${ }^{128}$ I will consider the role that information markets might play in judicial review below. $^{129}$

b) Politics. A separate virtue of cost-benefit analysis is that it may allow for easier monitoring of agencies by their principals, the President and Congress. Eric Posner has argued that cost-benefit analysis may help to overcome informational advantages that agencies have over the President and Congress by forcing an agency to convey information about projects. ${ }^{130}$ Cost-benefit analysis thus produces not only better projects from the perspective of social welfare, but also better projects from the perspective of the President, ${ }^{131}$ who Posner assumes can veto agency plans. ${ }^{132}$ Perhaps surprisingly, Posner's model suggests that cost-benefit analysis will lead to enactment of more regulations, as the President will trust the agency more once it must back up its recommendations with cost-benefit analysis, and the agency in turn will propose more projects that the President otherwise would have rejected. ${ }^{133}$ Posner extends the analysis to situations in which Congress is the principal or Congress and the President are both principals, concluding once again that cost-benefit analysis helps the agency transmit information.

126 See, for example, Kuran and Sunstein, 51 Stan L Rev at 746-61 (cited in note 17) (considering a variety of correctives to prevent availability cascades).

127 The Office of Management and Budget has standardized cost-benefit analysis in Circular A-94. See Office of Management and Budget, Circular A-94 (Oct 29, 1992), available at Guidelines and Discount Rates for Benefit-Cost Analysis of Federal Programs, 57 Fed Reg 53519 (Nov 10,1992).

128 See Whitman v American Trucking Associations, Inc, 531 US 457, 486 (2001) (finding that the EPA cannot consider costs under certain sections of the Clean Air Act).

129 See Part II.C.

130 See Eric A. Posner, Controlling Agencies with Cost-Benefit Analysis: A Positive Political Theory Perspective, $68 \mathrm{U}$ Chi L Rev 1137 (2001). Posner explains that an "[a]gency's informational advantage is due to its institutional expertise." Id at 1149.

131 Id at $1156-57$.

132 Id at 1148.

133 Id at 1157.

134 Id at 1171. 
Critical to Posner's model is that cost-benefit analysis provides an objective datum about the efficiency of projects. ${ }^{135}$ Posner recognizes the possibility of agencies "bias[ing] the outcomes in their own favor" to move policy closer to their ideal level of regulation, ${ }^{136}$ but his model depends at least on the possibility that cost-benefit analysis might provide a means of overcoming an informational asymmetry and allowing a principal to monitor an agent. Whether cost-benefit analysis in fact provides such a function, information markets would, assuming that they are generally objective. ${ }^{137}$ Just as cost-benefit analysis allows an agency to reassure the principal that a particular project moves regulation in the principal's preferred direction, so too could information markets assure the principal that the regulation will be an improvement based on the principal's policy preferences. For example, a cost-benefit analysis showing that a regulation is expected to save many lives could help assure a President who is more skeptical than agency officials of interventionist government that there is indeed reason to believe that the regulation will produce considerable bang for whatever bucks are being expended.

Posner's model helps to underscore a straightforward point that is as applicable to information markets as it is to cost-benefit analysis: Any tool that provides an objective reflection on an agency's decision makes it easier to separate the claimed and real justifications for agency decisions. As a result, agencies are less likely to pursue policies when the real justifications would be insufficient to persuade those who have some power over the agencies. Yet agencies will be better able to pursue policies in which the claimed justification would in fact be sufficiently persuasive, because information markets can reduce the informational asymmetry and thus help to reduce distrust.

Perhaps the most significant implication is that information markets may help limit the role of interest groups. Posner notes that "interest groups sometimes help government principals control agencies

135 Posner complicates this assumption by suggesting that the agency can "fake" a plausible cost-benefit analysis for some additional cost. Id at 1161. Although Posner does not elaborate the nature of this cost, it might be thought of as the reputational hit that the agency may suffer as a result of faked analyses. Posner does note that if this cost is relatively low, the President might not believe the agency's cost-benefit analysis. Id. See also Eric A. Posner, Cost-Benefit Analysis as a Solution to a Principal-Agent Problem, 53 Admin L Rev 289, 292 (2001) ("If the agency's costbenefit analysis is based on implausible data, or uses flawed calculations, then the President has the necessary information for disciplining the agency as well as for rejecting the project.").

136 Posner, 68 U Chi L Rev at 1178-79 (cited in note 130).

137 See Part II.A.2.

138 As conceived so far, the information market measures only the bang and does not consider the buck. But see Part III (explaining how predictive cost-benefit analysis would allow for an overall assessment of legal policy). 
by disclosing information to the principals," ${ }^{139}$ specifically by announcing endorsement of or opposition to a particular regulation. Although such signals may have an effect similar to cost-benefit analysis in reducing informational asymmetry, a consequence is that interest groups may bias agencies' project choices. ${ }^{140}$ By neutralizing the informational advantage, cost-benefit analysis eliminates the potential for such bias. Information markets can do much the same thing. ${ }^{141}$ But they can also do something that cost-benefit analysis cannot do. As Posner acknowledges, "interest groups retain a hidden influence on the location of the other players' ideal points," but cost-benefit analysis does not change this. ${ }^{122}$ Information markets may frustrate agency officials' ability to credibly claim illusory benefits from policies that are in reality special interest giveaways. Information markets can thus lead agency officials concerned with their credibility to act in a manner more consistent with the ideal points that they would prefer to project to the public, who constitute the principal that they ultimately may care most about.

\section{Are information markets objective?}

The affirmative case for information markets' objectivity is that they provide financial incentives for honest predictions. When individuals are asked to make predictions in the absence of a financial incentive, they might announce what they wish would happen or what they would like to be seen as believing rather than what they truly believe. ${ }^{143}$ Financial incentives aimed at accurate prediction may be sufficient to override these factors. Even if these incentives are inadequate for some traders, other traders will have an incentive to trade against these financially unmotivated traders, whose willingness to lose money for expressive purposes will ordinarily be limited. Depending on the amount of money at stake, traders may even have an incentive to gather information not previously publicly available to better inform their trading decisions.

139 Posner, 68 U Chi L Rev at 1174 (cited in note 130).

140 Id.

141 A variety of reforms of administrative agencies might limit outside influence on agency decisionmakers. One danger, however, is that reforms that seek to insulate decisionmakers might effectively cut out only public participation, leaving industry and other special-interest groups in a relatively stronger position. See, for example, David A. Dana, Setting Environmental Priorities: The Promise of a Bureaucratic Solution, 74 BU L Rev 365, 379 (1994) (noting the possibility of "uneven depoliticization").

142 Posner, 68 U Chi L Rev at 1175 (cited in note 130).

143 See note 254 and accompanying text (discussing "position taking"). 
There are, however, two significant caveats to this proposition, each considered in the following subsections. The first danger is that some market participants might affirmatively attempt to manipulate an information market because they have extrinsic reasons, including possibly financial ones, to care about the results of that market. If attempts at manipulation are successful, then the information markets may be biased, unless attempts by opposing factions happen to cancel each other out. The second danger is that the demographics of the trading population may influence results. For example, if traders happen to be on average conservative, they may have honestly different beliefs, and thus predictions, with respect to certain questions than those of a more demographically diverse group. It may not be enough for information markets to produce honest predictions if the honest predictions are those of a homogeneous group. Although there are theoretical reasons to believe that both these dangers will be small, resolution of these issues ultimately requires more empirical evidence.

a) Market manipulation. The Iowa Electronic Markets have appeared relatively immune to attempts at market manipulation, and indeed one attempt to bid up the securities corresponding to Patrick Buchanan had only a transient effect on prices. ${ }^{144} \mathrm{~A}$ possible explanation for this immunity, however, is that the Markets' only effects are on the participants themselves. Imagine, however, a world in which a large number of voters based their actual election votes on the outcome of the Iowa Electronic Markets. This is somewhat fanciful, ${ }^{145}$ but the hypothetical allows us to consider what might occur if the government were to use information markets as factors in its own decisionmaking. In the election hypothetical, there would then be many individuals, from the candidates themselves to special interest groups, who might be willing to accept some trading losses if their trading activity had an effect on the market price and thus on the election. Similarly, in an information market used as a basis for agency decisionmaking, anyone with an interest in the ultimate decision might

144 See Erica Klarreich, Economists Explore Betting Markets as Prediction Tools, 164 Sci News 251 (Oct 18, 2003), online at http:/www.sciencenews.org/20031018/bob9.asp (visited Apr 22, 2004) ("Buchanan prices briefly spiked, but well-informed traders then seized the opportunity to profit off the manipulative traders and by the end of the day, the effect of the investments had virtually vanished.").

145 Some voters prefer to vote for the candidate whom they expect to win, a phenomenon called the "bandwagon effect." See, for example, Roger B. Myerson and Robert J. Weber, A Theory of Voting Equilibria, 87 Am Polit Sci Rev 102, 102 (1993). If the Iowa Electronic Markets became widely recognized as accurate predictors of election results, supplanting polls in press assessments of elections, market prices might affect some voters' decisions. Moreover, market prices might affect campaign contributions, thus becoming self-fulfilling prophesies. 
trade with the primary goal of manipulating market prices, even if such manipulation resulted in financial loss for the trading party. ${ }^{16}$

The possibility of such manipulation, particularly if it had more than a trivial effect on market prices, would weaken the case for the objectivity of information markets. Market manipulation is likely to be impossible, however, whenever market participants can detect that the manipulation has changed asset prices in an objectively unjustifiable way. Consider, for example, a hypothetical version of the Iowa Election Markets, where Bill Gates seeks to pour money into the securities corresponding to the Green Party in order to drive up their prices. This would create an immediate opportunity for arbitrageurseven those with no knowledge of the security's true value-because the price of the various securities would add up to more than $\$ 1$. By investing $\$ 1$, an arbitrageur could receive one of each security, selling them all at market prices, and this activity would drive down the price of the Republican and Democratic securities. Fundamental values traders, however, would recognize that the Republican and Democratic securities were undervalued, and they would thus purchase these securities, driving their prices back up. ${ }^{147}$ This market activity would attract other arbitrageurs and fundamental value traders, and eventually even Gates would run out of money.

Gates, in this hypothetical, is effectively offering to make obviously losing bets. If Gates announced that he would give his money to anyone who asked, it would disappear quickly; it would disappear with almost equal speed if he announced that he would bet anyone and everyone $\$ 1$ that the Green Party would win the presidency. An information market structured similarly to the Iowa Electronic Markets - where traders can purchase bundles from the Exchange at par value at any time-ensures the same dynamic. Some additional protection against manipulation would be needed in an information market in which the number of securities is constant. If, for example, there were a fixed number of Green Party securities, Gates could buy all of these securities, sell one of them to a friend for $\$ 1$, and then refuse to enter into any additional transactions. There are, however, a number of possible solutions to this problem; a simple one is employing mar-

146 Hanson characterizes the incentive by noting that interested parties might seek to trade according to criteria other than fundamental security values because "[d]ecision gains might outweigh trade losses." Hanson, Conditional Markets at slide 13 (cited in note 68).

147 If it were possible to sell short on the Iowa Electronic Markets, the fundamental value traders also might sell the Green Party short. Current rules on the Iowa Electronic Markets prohibit short sales. See http://www.biz.uiowa.edu/iem/faq.html\#shortsales (visited Apr 22, 2004). The rules note, however, that it is possible to achieve the functional equivalent by holding onto all securities in the bundle except the one that a participant wishes to "short." Id. 
ket scoring rules. ${ }^{148} \mathrm{By}$ allowing anyone to displace the current predictor with a new prediction, this approach would in effect allow market participants to take bets against anyone repeatedly entering unsupportable predictions. ${ }^{199}$ This approach should thus similarly allow the market to counter manipulation fairly quickly.

Quickly, however, may not be fast enough in certain cases. We have seen at least one blip in the Iowa Electronic Markets data. What if such a blip occurred in an information market used to support a decision at exactly the moment that the market terminated? That could happen for reasons other than pure coincidence. If there is a fixed point at which a snapshot of market prices is to be taken for decision purposes, potential manipulators would have an incentive not to make a manipulative trade until just before this point. There is, however, a potential antidote to this problem. Instead of setting a fixed point at which the market would end, the sponsors of an information market might leave the exact end time ambiguous, even if there is some period in which the market is assured to be open. ${ }^{150}$ Moreover, the market sponsor might provide that the market will close only after some period of time during which there has been relatively little market activity that may signal market manipulation. Signaling activity might be defined as an unusually high volume of trading or unusually large shifts in market price.

This analysis provides strong reason to believe that as long as it is clear that a trader's activity has moved a security price away from its fundamental value, market forces should respond. Robin Hanson reaches this conclusion as well, ${ }^{\text {ist }}$ but he properly recognizes that this

148 See Part I.C.2.

149 Even with heterogeneous trader predictions, predictions would likely converge quickly, as rational market participants would adjust their predictions based on others', while seeking to distinguish honest predictions from attempts at manipulation. More experimentation is needed, however, to verify that this convergence would occur. Even if predictions failed to converge, the market could be useful, as long as the market prediction were defined as some average prediction over a period of time.

150 For this to work, the market sponsors could not announce the latest date at which the market would necessarily close; if they did, the risk of manipulation in the period just before the announced date would be high. Instead, the sponsors might assign a "half life" to the market at some point, so that in each succeeding period, there is only some relatively small probability that the market will close regardless of how many such periods have occurred. See Michael Abramowicz, Cyberadjudication, 86 Iowa L Rev 533, 568-69 n 93 (2001) (describing such an approach in an analogous context). Even with such a system, if the half life is sufficiently short, there is a high probability that the relevant market will close quickly. An alternative approach is for the market-clearing price to depend on the average price over some period.

151 See Hanson, Conditional Markets at slide 18 (cited in note 68). For a recent, more developed version of the argument that manipulation attempts are unlikely to affect information market prices, see Robin Hanson and Ryan Oprea, Manipulators Increase Information Market Accuracy (draft Mar 2004), online at http://hanson.gmu.edu/biashelp.pdf (visited Apr 22, 2004). 
will not always be the case. In information markets for which asymmetric information is relevant, traders will be uncertain whether trades reflect genuine insider information or a trader's attempts at market manipulation. If traders underestimate the extent to which a trade is based on an attempt at manipulation, the attempt may partly succeed. ${ }^{152}$ On the other hand, Hanson argues, if traders overestimate the extent to which a trade is based on a desire to bias, then the attempt may backfire. ${ }^{133}$ Allowing interested parties to trade, Hanson argues, will not increase the danger of successful manipulation, as long as market participants know which parties are potentially interested, because other market participants remain free to conclude that an interested trader's activity reflects nothing about the security's underlying asset value. ${ }^{1.4}$ The possible existence of interested parties does not seem likely to produce systematic bias, but there is concern that trading by such parties could add considerable noise to market predictions.

Information markets in any event might be relatively efficient at distinguishing between trading based on information and trading based on desires to bias the results. Some traders will presumably earn reputations for acting reliably on the basis of private information, which may include private information that they have paid other parties to access. In a world with many information markets, the market will trade against traders lacking such reputations, and they will thus be unable to influence the market. Perhaps initial experiments with information markets will not be sufficient in duration to allow such reputations to build, but there would be strong long-term incentives for traders to build and monitor reputations. Traders who fail to produce reputable information will often be unsuccessful in convincing others.

The success of attempts to manipulate may depend on the context. For example, one goal of FutureMAP was to determine whether information markets could effectively combine both public and classified information. ${ }^{155}$ If all participants in a market have access to the same classified information, or even if there is known to be a critical mass of traders who have such access as well as information about

Hanson and Oprea show that attempts at manipulation can increase information market accuracy by increasing the returns to informed trading.

152 See Hanson, Conditional Markets at slides 16-21 (cited in note 68).

153 Id.

154 See id at slide 22.

155 See http://web.archive.org/web/20030401131233/www.darpa.mil/iao/FutureMap.htm (visited Apr 22, 2004) ("A market that addresses defense-related events may potentially aggregate information from both classified and unclassified sources."). 
who else has such access, such markets may work well. But in a market in which individual traders may have access to classified information that they cannot convey to other traders, market participants will give some credence to any trades by someone who may have such information, especially if participants have no way of determining which traders have access to relevant information. That credence would be counterbalanced by the estimates of market participants about the extent of that individual's biases due to desired policy outcomes. It is unclear how these competing calculations would affect the accuracy of market predictions. By contrast, in a market that depends primarily on public information, or even on private information that market participants could share with reputable parties who could verify it, traders seem likely to place only minimal weight on the views of traders without reputations for objectivity if they do not produce persuasive analyses in support of their positions.

Ultimately, the effect of possible manipulation on the accuracy of markets where such incentives exist is an empirical question. An experiment involving a large number of securities could be used to address this question: For example, some individuals could be given incentives to care about the prices of randomly selected securities. The experiment could also compare the effects of incentives to manipulate that are conveyed privately to one trader or announced publicly. Until such experiments verify that there is some means of structuring information markets to minimize problems associated with manipulation, government agencies will need to exercise caution in relying on the results of such markets.

b) Unrepresentative decisionmakers. Another potential objection to relying on information markets for governmental decisionmaking is that such reliance means that an unrepresentative group of traders is effectively making decisions for society as a whole. This objection may come in two distinct flavors. The first is that even if traders were excellent predictors, relying on traders is democratically illegitimate because the traders are not democratically elected. This objection identifies an instinctive discomfort that democratic theorists have to private entities governing the public, but this discomfort may be out of place here: It arises from the concern that private entities may act on behalf of their own interests rather than those of society as a whole, ${ }^{156}$ a concern that disappears if market predictions are indeed

156 See, for example, Jody Freeman, The Private Role in Public Governance, 75 NYU L Rev $543,549(2000)$ (arguing that although privatization increasingly results in private firms making public decisions, "alternative accountability mechanisms ... can allay our concerns about the particular risks posed by arrangements of public and private actors, while capitalizing on their 
unbiased. If democratically selected officials depend on unbiased information when making decisions, it should not matter whether the voting behavior of those producing the unbiased information suggests that their policy preferences are consistent with or contrary to the results they produce. ${ }^{157}$

The second flavor of the objection concedes this counterargument but worries that the results of information markets might reflect an unintentional bias. The argument is that even if a market is not manipulated by any individual participant or set of participants, the market outcome might be affected by the aggregate composition of the participants. Information market participants are not likely to be representative of the population as a whole. Aside from having more expertise in the relevant area, they might be wealthier or have consistently different political views. Suppose, for example, that the participants in the hypothetical market measuring the effects of airline safety regulations on passenger miles generally tend to be more sympathetic to market-oriented solutions and skeptical of government mandates than airline safety experts in general or than the population as a whole. If true, one might worry that predictions by this market might be systematically different from predictions produced by a hypothetically more representative group because of the market participants' generally lower confidence in regulation's ability to instill consumer confidence.

The limited experimental evidence produced by the Iowa Electronic Markets suggests that this is not likely to be a problem. Cognitive psychologists have identified in other contexts a "false consensus effect," in which individuals overestimate the number of others who share their views. ${ }^{138}$ Such an effect would be troubling for an information market if the false consensus effect existed among participants and affected market prices. Robert Forsythe and his co-authors conducted an experiment suggesting that the effect did exist among

\footnotetext{
capacities").

157 Assuming, of course, that attempts to manipulate the market are unsuccessful. See Part II.A.2.a.

158 See, for example, Clifford E. Brown, A False Consensus Bias in 1980 Presidential Preferences, $118 \mathrm{~J}$ Soc Psych 137, 137 (1982) (confirming that voters in a presidential election reflect a false consensus bias by estimating support for their preferred candidates at higher levels than other voters); Thomas Gilovich, Differential Construal and the False Consensus Effect, $59 \mathrm{~J}$ Pers \& Soc Psych 623, 632-34 (1990) (describing four studies of the false consensus effect illustrating that larger false consensus effects are obtained on items that permit greater latitude for subjective interpretation); Lee Ross, David Greene, and Pamela House, The False Consensus Effect: An Egocentric Bias in Social Perception and Attribution Processes, 13 J Exper Soc Psych 279, 279-81 (1977) (demonstrating a bias related to the false consensus effect existing in participants' social inferences about the commonness and revealing nature of other participants' responses).
} 
many participants but did not affect market prices. They studied the participants in the 1988 presidential vote-share market and collected, through polls, information on traders' political preferences. ${ }^{159}$ The market performed quite accurately, with election eve predictions coming within about one percentage point ${ }^{160}$ even though the traders consisted entirely of individuals affiliated with the University of Iowa, including a disproportionate number of business students, producing a trading population that identified as Republican and favored George Bush somewhat more than the population as a whole. ${ }^{161}$ On the whole, traders tended to buy shares associated with their preferred candidates. ${ }^{162}$ The authors, however, isolated one group of traders, whom they called marginal traders, who exhibited little to no judgment bias. These traders were identified by the fact that they placed limit orders at prices slightly different from the market price, while biased traders placed either market orders or limit orders at prices far from the market price. ${ }^{163}$ In effect, the marginal traders determined the market price and ensured that judgment bias did not affect the market, ${ }^{164}$ even though these marginal traders were less demographically representative than traders as a whole. ${ }^{165}$

Though cause for optimism, there are at least two reasons that this study is not a conclusive repudiation of the possibility that traders' demographic characteristics might affect market prices. First, the closeness of election eve predictions to the actual result does not disprove the possibility of bias; perhaps the market prediction was slightly biased but by chance the bias coincided with an election day surprise. ${ }^{166}$ An experimental design that might more clearly control the

159 See Forsythe, et al, 82 Am Econ Rev at 1142 (cited in note 40).

160 Id at $1148-49$.

161 Id at 1146 (noting, for example, that 46 percent of traders identified themselves as Republican, compared with 31 percent in a national poll).

162 Id at 1155-56 (finding that 62 percent of the Bush supporters bought more Bush stock than they sold while 68 percent of Dukakis supporters bought more Dukakis stock than they sold).

163 A market order is an order to buy or sell a security at the best available price, while a limit order is an offer to buy or sell only if the price reaches a certain level. See generally Puneet Handa and Robert A. Schwartz, Limit Order Trading, 51 J Fin 1835, 1837-41 (1996) (explaining the rationale for limit orders).

164 See Forsythe, et al, 82 Am Econ Rev at 1156-60 (cited in note 40) (describing how marginal traders had a greater influence on the outcome of the market).

165 Id at 1158 (noting that all marginal traders were male and that 60 percent favored Bush after the third debate). The marginal traders also tended to have higher investments than other traders. Id.

166 Forsythe, et al, recognize this possibility, noting that they might have just been "lucky." They find this explanation unlikely, however, in light of the success of subsequent studies. Id at 1156-57. 
effect of traders' demographic composition would involve implementation of a number of simultaneous markets, for example predicting vote shares in large numbers of congressional races, varying the composition of those permitted to trade in these markets randomly across markets. ${ }^{167}$ A demonstration that groups of Democratic traders were no more likely to be biased toward Democrats than other groups would bolster the Forsythe findings. If, however, it turns out that group composition matters, then the further question, also potentially testable, is to what extent group composition matters in open markets in which anyone may participate. ${ }^{168}$ One possibility, supported indirectly by the experiments indicating that a small percentage of informed traders is sufficient, ${ }^{169}$ is that as long as there is some minimal participation by a range of individuals, the results do not depend on the traders' exact composition.

Second, the conclusion that some trader diversity will ensure objectivity is not necessarily generalizable to other forms of information markets, particularly those involving complex models that individuals with different political views might view with different levels of acceptance. Traders may recognize that others will have different political views, but not give credence to alternative models relevant to the immediate prediction. It is one thing for traders to recognize that their preferred candidate may not win the election, but quite another for them to grant equal weight to others' views about economic policy. Conservative traders skeptical of command-and-control regulation, for example, might apply a discount to lives saved by an air safety regulation that liberal traders who believe government is relatively efficient might not apply. A market with only conservative traders might reach a different result from one with only liberal traders, even if the two groups would reach similar results in a market that, for example, predicted whether a candidate who supported the command-andcontrol approach would win an election.

This too is potentially empirically testable with an experimental design using a large number of information markets operating simul-

167 With a large number of markets, thin trading is potentially a concern. See Part I.C.2.

168 A possible experimental methodology would examine predictions in sports information markets. See note 32 and accompanying text. If group composition matters, one might expect the markets to predict stronger performance from relatively popular teams. Such a finding would not necessarily be dispositive in other contexts, because participants might derive more utility from betting on the home team than from making a prediction consistent with a particular political orientation. It is possible, though, that such preferences can be arbitraged away, providing a strong indication that information markets are not influenced by what traders on average would like to see happen.

169 See note 164 and accompanying text. 
taneously. For example, a number of markets might be used to predict economic performance in a variety of different states or localities contingent on passage of some presidential initiative, such as a tax-cut proposal, ${ }^{170}$ with markets again randomly assigned to allow only those with Democratic preferences, only those with Republican preferences, or a mix, to participate. Perhaps each individual group will contain a sufficient number of marginal traders who are able to put their own views aside, and thus traders' demographic composition will not matter; but the experiment may show that because Democratic traders simply think differently than Republican traders, the markets with more Democratic traders would be more skeptical of the benefits of a Republican tax cut proposal.

Evidence indicating that demographic composition can affect the predictions of information markets may justify placing less weight on these markets in some contexts, but it does not necessarily mean that these markets should be ignored altogether. Even an assessment by a biased group may prove useful in governmental decisionmaking, especially when the group's prediction runs opposite its identified bias. The effects of any bias may be small, and the magnitude of the effects may depend on the type of information that the market is predicting. Demographic and ideological characteristics seem less likely to matter, for example, in an information market predicting election returns than in an information market predicting the economic consequences of the adoption of a particular proposal, even assuming comparable analytical complexity in these two predictive problems. Evidence that a trader personally believes that a particular proposal will be good for the economy does not necessarily mean that the trader would then assume that others will recognize the wisdom of the proposal and vote for the candidate associated with it. ${ }^{17}$

The more complex and controversial the relevant models are, and the greater the disparity between the models' evaluations and the individuals' political beliefs, the greater the danger that the traders' composition could matter. Yet the situations in which information

170 A potential problem here is the determination of whether the tax cut proposal in fact passed. See note 213.

171 Party officials, of course, will offer positive spin on how election news is good for their preferred candidate, but few of us believe that the officials actually believe what they are saying. See Michael Kinsley, True Lies, New Yorker 48, 50 (Sept 26, 1994) (pointing out how the insistence by two prominent political "spin control" artists that they never lie looks hollow in the face of the stories they tell describing their great "spin control" victories), reviewing James Carville and Mary Matalin, All's Fair: Love, War and Running for President (Random House 1994). But we are less likely to doubt party officials' claims that they in fact prefer the candidate they are working for to the alternatives. 
markets may be least objective are the same as those in which governmental decisionmaking is likely to be least objective. A controversial market, such as one that estimates the effects of global warming, ${ }^{12}$ might show a greater improvement in objectivity over traditional costbenefit analysis than would an information market making a noncontroversial prediction. ${ }^{173}$ Presumably, in considering a controversial policy, an agency would find that the inherent difficulty of the projection would make it easier for the agency to make projections in accordance with its normative views. An information market at least eliminates cheap talk, ${ }^{174}$ forcing those who take positions on controversial matters to back up their predictions with money. ${ }^{175}$ The relative advantage of information markets is thus likely to be greatest where talk is cheapest. Any lack of objectivity from information markets may be of greater concern than a comparable lack of objectivity by agency officials, because such officials are at least selected by democratic processes. But almost any tool that agencies use in their decisionmakingincluding more traditional means of consulting experts ${ }^{176}$ - can introduce subjectivity without a solid democratic pedigree into the administrative decisionmaking process. Just because information markets seek to increase decisionmaking's objectivity does not render fatal any failure to obtain a perfectly objective decisionmaking process.

172 Compare, for example, Bjørn Lomborg, The Skeptical Environmentalist: Measuring the Real State of the World 258-322 (Cambridge 2001) (expressing skepticism about models predicting global warming), with Laurence Pringle, Global Warming: The Threat of the Earth's Changing Climate (SeaStar Books 2001) (arguing that global warming does present a threat).

173 Such a market, however, is unlikely to have any immediate political consequences. See text accompanying note 255 .

174 See Jason Scott Johnston, Communication and Courtship: Cheap Talk Economics and the Law of Contract Formation, 85 Va L Rev 385, 412 (1999) ("Formally, cheap talk is defined as a message that does not directly affect the payoff of either the message's sender or receiver.").

175 Without an information market, the government can take a position on global warming to support other goals. For example, if the Bush administration is concerned that environmental regulation may be too expensive, it might claim skepticism on global warming. See Eric Pianin, Group Meets on Global Warming, Wash Post A8 (Dec 4, 2002) (noting the Bush administration's skepticism about the causes and effects of global warming, along with environmentalists' response that adequate evidence exists). Of course, the same possibility could occur in reverse; an administration sympathetic to environmental concerns could discount any doubts about global warming because it would like to minimize air pollution in any event. Information markets will not reflect information that participants wish were true, but will reflect information that participants believe to be true. Markets are thus potentially not objective only when people have trouble separating the two.

176 Groups of experts themselves may not be random samples of the population. Those who decide to obtain training in environmental policy, for example, may be on average more liberal than the population at large and thus produce different policy recommendations than environmental experts would in a hypothetical world where educational choices were uncorrelated with political beliefs. 


\section{B. Some Potential Governmental Uses for Information Markets}

This Part describes potential governmental uses for information markets. This is a very partial list. ${ }^{17}$ Every administrative agency makes policy decisions, and such decisions are almost always based implicitly on predictions about what the future will bring or how different decisions will affect the future. The examples here are not information markets' most straightforward applications; to the contrary, they illustrate a range of design challenges. Nor are they chosen for political viability, though given the FutureMAP controversy, no information market proposal is likely to be viable in the near future.

Part II.B.1 addresses the direct goal of the FutureMAP program, considering whether information markets might help recognize security vulnerabilities, and identifies problems with the particular application that reinforce the proposition that information markets must be carefully designed. Part II.B.2 provides an example involving information markets with very large numbers of securities, assessing the extent to which such markets might help regulators assess the solvency of individual financial institutions. Part II.B.3 shows how information markets might help provide objective forecasts, in this case with respect to budget deficits, and overcome partisan disputes about methodology. Finally, Part II.B.4 shows how an information market might be used to predict a future governmental decision and help administrative agencies enact interim regulations while they consider longterm solutions.

1. Homeland security vulnerabilities.

One of the goals of the FutureMAP program was to use information markets to improve homeland security. An information market could be adapted toward identifying degrees of vulnerability. An initial test market was used to predict the number of days in a month corresponding to each threat level providing the public with a prediction of the average threat level expected over the month. ${ }^{178}$ This market received no public attention, but the example illustrates a modestly useful application of information markets. The government does not predict future threat levels, but Americans might want to consider

177 As the New York Times reported, "Once you get the idea, the possibilities are endless." Hal R. Varian, Economic Scene; Can Markets Be Used to Help People Make Nonmarket Decisions?, NY Times C2 (May 8, 2003).

178 See Homeland Threat Level Market, Neotek/MarTek Demonstration Market, online at http://www.marteksys.com/markets/ThreatLevel_home.html (visited Apr 22, 2004) (describing the test market and listing trading prices). 
the anticipated threat level, whether in making personal travel plans or in corporate and local governmental planning. An information market would provide some guidance without requiring the government to release supporting information. Of course, the market would incorporate only information known to its participants, so it might not have much predictive power. Even if employees with security clearances were prohibited from participating, however, the market at least could have provided a summary of what experts without clearances anticipated about threat levels.

The Policy Analysis Market presented a much more complex set of political and technical challenges. This market was designed to predict indices of political and economic stability in Middle Eastern countries, along with "global" variables such as U.S. GDP and Western terrorist deaths. The market also included a "miscellaneous" category to be defined later, and speculation about what securities would be traded in this category proved controversial. ${ }^{179}$ Various extensions could focus on specific terrorism-related concerns. For example, an information market might be used (though no such plans were made) to predict the total amount of property damage from cyberterrorism attacks in a particular year. At the end of that year, the government would estimate the amount of property damage, and that estimate would be used to liquidate the market. Similarly, such markets might be used to predict the number of people killed from attacks on the water supply or to assess the vulnerability of particular targets, such as the Sears Tower ${ }^{180}$ or the Palo Verde Nuclear Plant. ${ }^{181}$ A comprehensive program might allow trading on all conceived possible means of attack and all prominent individual targets, using markets predicting damage from "other means" and to "other targets" to develop a comprehensive picture of terrorist threats.

Politically, the principal problem with such a threat-specific approach was its distastefulness-which perhaps explains why no such targeted approach was ever authorized. Senator Hillary Clinton, for

179 News reports indicated that the claims would include "whether Palestinian leader Yasser Arafat would be assassinated, or Jordan's King Abdullah II would be overthrown." See Jeremy Kahn, Is a Futures Market on Terror Outlandish?, Fortune.com (July 30, 2003), online at http://www.fortune.com/fortune/investing/articles/0,15114,471785,00.html (visited Apr 22, 2004). These, however, were merely hypothetical applications of the miscellaneous category, not approved securities. See email from Robin Hanson (Aug 30, 2003) (on file with author) (explaining that the system was not set up to predict individual terrorist acts).

180 See generally Robert L. Kaiser, Taking America's Pulse inside Sears Tower, Chi Trib C1 (Sept 8, 2002) (reporting on concerns about the Sears Tower's vulnerability to terrorist attacks).

181 See Bill Gertz and Jerry Seper, Nuclear Power Plant a Potential Target, Wash Times A13 (Mar 20,2003) (describing the deployment of National Guard troops to protect a nuclear power plant in Arizona). 
example, criticized the program as "a futures market in death." ${ }^{182}$ This criticism may reflect intuitive revulsion, or a belief that futures markets commodify and destroy personhood. ${ }^{183}$ Such concerns cannot, however, be dispositive unless we are willing to do away with many of our fundamental economic practices. After all, we tolerate similar "commodification" in other contexts: Life insurance companies set prices based on assessments of when people will die, and providers of annuities and viatical companies in fact benefit when people die. ${ }^{184}$ Along the same lines, the law calculates the economic value of a reversionary interest in a life estate according to a person's age.

The promise of such a market is that it might help expose imbalances in resource allocations, especially those associated with salient threats. Suppose, for example, that the United States has paid excessive attention to safeguarding air travel and insufficient attention to certain other threats. An information market prediction indicating greater risk from other threats would be consistent with that claim, although these predictions alone would be insufficient to justify a policy conclusion. In theory, the marginal decrease in risk associated with the last dollar of spending to combat each of a variety of threats should be equal, ${ }^{185}$ but the information markets measure only the risk side of the equation, not the extent to which spending can address that risk. Conditional markets are a possible solution here, though the caveats about such markets discussed above ${ }^{186}$ are compounded by the non-binary nature of the decision of how much money to allocate to each risk. Given the wide range of policy responses to potential terrorist risks, it might be difficult to create information markets that would sufficiently assess the full range of policy options.

182 See Bets Off on Terror Futures Market, AP News Wire (July 29, 2003), online at http://www.wired.com/news/politics/0,1283,59813,00.html (visited Apr 22, 2004) (reporting congressional criticism of the Terrorist Information Awareness program).

183 See generally Margaret Jane Radin, Contested Commodities (Harvard 1996) (developing commodification theory).

184 See generally Russell J. Herron, Note, Regulating Viatical Settlements: Is the Invisible Hand Picking the Pockets of the Terminally Ill?, 28 U Mich J L Ref 931 (1995) (urging greater consumer protection of the terminally ill who name a viatical settlement company as beneficiary under a life insurance policy in exchange for a lump sum payment).

185 A caveat is that it may make sense to spend extra on risks that cause the most anxiety. See Frank B. Cross, The Public Role in Risk Control, 24 Envir L 887, 924-26 (1994) (considering "dread risks").

186 See Part I.C.1.

187 It might be possible to have conditional markets for each of a number of different possible levels of spending. The greater the segmentation of conditional markets, however, the lower the subsidy for each information market, and the greater the noise in the market price, making differences between prices of conditional securities less meaningful. See text accompanying note 78 . 
In the absence of an adequate conditional market, an additional problem is the danger of circularity. ${ }^{188}$ Suppose, for example, that a trader identifies a new security vulnerability that terrorists might exploit, but one that the government could address and eliminate if the market price rose to reflect the risk. The information suggests that the security is undervalued, but if the trader drives up the price of the security, it will then be overvalued as the government response reduces the risk back to its initial level. It is difficult to predict how the market would equilibrate. Traders might find that the optimal strategy was to trade on securities only up to a price just below the level that would trigger a government reaction. Information markets would then reflect only information about which the markets expected nothing could or would be done, considerably reducing their usefulness. ${ }^{189}$ Maybe the optimal way to avoid this problem would be for information markets to have a relatively short time horizon, perhaps estimating different risks over a period of about a month. ${ }^{100}$ Such an approach would allow estimates of current risk levels while still providing data to facilitate long-term responses. In the short term, the information market would in effect be predicting risks that the govern-

188 For an explanation of the circularity, see Daniel Gross, Bookmakers for the BombMakers, Slate (July 29, 2003), online at http://slate.msn.com/id/2086315 (visited Apr 22, 2004) (describing the controversy surrounding the Pentagon's Policy Analysis Market and offering additional criticism).

189 Tyler Cowen argues that this will not be any more of a problem than it is in all securities markets:

The fact that a government could look at such markets and then (maybe) stop a terrorist attack does not worry me. Think about the stock market. If a company's stock price falls, they might fire the CEO and try to correct matters, thus raising the share price again. No big problem, it doesn't stop useful arbitrage.

Tyler Cowen, Read This Defense of "Terrorism Futures," online at http://volokh.com/ 2003_07_27_volokh_archive.html\#105965731715456167 (visited Apr 22, 2004). Cowen is correct as long as there is some positive probability that the government will not move to correct an identified problem. If that probability is sufficiently small, however, anticipation of a terror attack would trigger only very small movements in prices, and these movements might be so small that they are dismissed as mere noise.

190 A complication is that the probability estimates would likely be very small. This presents two potential problems, the second more serious than the first. First, cognitive psychology experiments indicate that people generally are not as good at estimating small probabilities. See Daniel Kahneman and Amos Tversky, Prospect Theory: An Analysis of Decision under Risk, 47 Econometrica 263, 281 (1979) (concluding that very low probabilities are generally overweighted by decisionmakers). At least some market participants, however, would likely be sophisticated enough to rely on formal models rather than intuitive probability estimations to guide trading in such a market. Second, it may be that the relative prices of securities, reflecting the relative risk of different types of attacks, would be the focus of attention. To make comparisons of security prices meaningful, the government would need to promise a relatively large payment in the event of an actual terrorist attack, so that traders would have incentives to investigate the levels of different risks and factor them into trading decisions. 
ment cannot avoid. Though not providing a signal to the government to take action, such a market would signal to the public about where risks lie.

The problem upon which many critics of FutureMAP focused is the danger that insider trading profits might encourage terrorist acts. Insider trading in information markets generally should be encouraged, because the purpose of such markets is to encourage consideration of all potentially relevant information. ${ }^{191}$ Indeed, information markets in theory could even provide a means of implementing antiterrorism bounty programs. ${ }^{192}$ There is, however, a concern that terrorists might trade on their acts just before implementing them and thus profit from terrorism. Worse, information markets could create a moral hazard problem, ${ }^{193}$ encouraging individuals who otherwise would not have been terrorists to commit terrorist acts for profit.

191 The same argument can be made for traditional securities markets, and indeed Henry Manne has argued that insider trading should generally be permitted, as insider trading will promote market efficiency. See generally Henry G. Manne, Insider Trading and the Stock Market (Free Press 1966). See also Dennis W. Carlton and Daniel R. Fischel, The Regulation of Insider Trading, 35 Stan L Rev 857 (1983) (building on Manne's general thesis); David D. Haddock, Academic Hostility and SEC Acquiescence: Henry Manne's Insider Trading, 50 Case W Res L Rev 313 (1999) (commenting on Manne's work and its influence). Whatever the merits of Manne's claim as applied to the stock market, it seems powerful in the context of an information market. An information market's sole purpose is to encourage the release of information, and the welfare of market participants is not a significant concern. Thus, the strongest counterarguments to Manne's theory do not apply. For example, Michael Manove has argued that insider trading may discourage corporate investment, but corporate investment is not an issue here. See Michael Manove, The Harm from Insider Trading and Informed Speculation, 104 Q J Econ 823, 824 (1989). To be sure, insider trading might discourage trading by non-experts, but an information market loses little from having trading primarily by those in the best position to make predictions.

192 The State Department currently sponsors a "Rewards for Justice" program that promises to pay individuals who provide information that thwarts terrorist acts. See Rewards for Justice, online at http://www.rewardsforjustice.org (visited Apr 22, 2004). See also 22 USC \& 2708 (2000) (providing the statutory basis for the program). It would be possible to use an information market as a means of providing the reward. An information market might be used, for example, to determine whether the government uncovers a terrorist plot of a particular type during a given time period. By trading on such a market and then releasing information to the government, an informant could assure a trading profit. Though such a market overcomes problems of circularity, the challenge in such a market would be for the government to develop a reliable mechanism for calculating the magnitude of terrorist acts averted, a number that government officials might have a strong incentive to exaggerate. Note that the market could not be used to predict successful terrorist attacks, however, for then trading that succeeds in alerting the government to a terrorist attack would not be profitable.

193 In the insurance context, "[m]oral hazard is the ... tendency of an insured to underallocate to loss prevention after purchasing insurance." Kenneth S. Abraham, Distributing Risk: Insurance, Legal Theory, and Public Policy 14 (Yale 1986). This context provides a more direct and troubling form of moral hazard that insurance law generally worries about only in the life insurance context. 
The amount of money that could be made in this way, however, would be relatively small, unless the government poured millions of dollars into such a market. Moreover, trading activity might leave a paper trail that could lead to the terrorists' apprehension and that might prevent terrorists from cashing in on the appreciation in share value. The government could require that traders be identified, perhaps even subject to background checks, and that government payouts be made and transactions cleared only after it is determined that traders did not themselves participate in any terrorist acts. With appropriate regulation, an information market would become an extremely unlikely venue for this type of scheme. It would be far easier to make money by trading on conventional securities markets, ${ }^{14}$ or even by bribing a basketball player to shave a few points in a game. Nonetheless, even if the possibility of such side effects is remote, the worst case scenario may be so serious that even the probability-adjusted costs might outweigh any benefits of such a program.

\section{Solvency regulation.}

Information markets might prove more directly useful for governmental tasks that are explicitly predictive and involve processing massive amounts of information. A useful example, though in the end perhaps not practicable, is solvency regulation. The federal agencies that share responsibilities for regulating depository institutions regularly monitor those institutions' financial performance to prevent insolvency. ${ }^{195} \mathrm{~A}$ principal justification for such monitoring is that with federal deposit insurance, institutions in danger of insolvency have an incentive to take excessively risky bets in a last desperate effort to avoid losing their investments. ${ }^{196}$ States engage in a similar form of monitoring of insurance companies, seeking to ensure that insurance companies will be able to meet their obligations even in the

194 Indeed, there were reports after September 11 that the terrorists might have profited by trading on options markets before the attacks, though subsequent investigations indicated that they did not do so. See Erin E. Arvedlund, Chance, Not Terror, Was behind Suspicious Deals, Asian Wall St J W2 (Feb 1, 2002) (describing government investigations into suspiciously timed stock trading).

195 For an overview of bank solvency regulation, see George J. Benston and George G. Kaufman, Risk and Solvency Regulation of Depository Institutions: Past Policies and Current Options, Federal Reserve Bank of Chicago Staff Memo No 88-1 (1988); Michael P. Malloy, Bank Regulation 229-62 (West 1999) (discussing the regulation of failing financial institutions).

196 See R. Mark Williamson, Regulatory Theory and Deposit Insurance Reform, 42 Cleve St L Rev 105, 120-21 (1994) ("Moral hazard is present with deposit insurance because banks which increase the riskiness of their portfolio will capture all upside profits while bearing only part of the downside losses."). 
event of unexpectedly high liabilities. ${ }^{197}$ The regulatory regimes are complicated, with regulators focusing on several indicia of safety, such as reserve ratios and other capital standards.

Simple information markets could be used to provide some form of political feedback. For example, a market might be used to predict the number of depository institutions that will be expected to go insolvent in a particular year or the total dollar amount of the federal government bailout corresponding to such failures. Such a market might have led to earlier recognition of the savings and loan crisis in the 1980 s. $^{198}$ Although such recognition presumably would not have averted closures, it might have prevented some of the high-risk activity that exacerbated the problem. ${ }^{199}$ The more challenging task for information markets, however, would be to perform the monitoring of individual institutions. The goal, after all, of these regulatory regimes is to make individualized predictions about the likelihood of insolvency and the corresponding likelihood of either consumer or governmental losses, or both, in the event of insolvency. Such markets could foster more objective decisionmaking. Given the criticism that special interests have affected monitoring in the past, ${ }^{200}$ objective predictions might be a considerable improvement.

The large number of institutions at issue should not be a significant problem for such a market, as long as a different security is issued for each one. Just as traders in the Hollywood Stock Exchange, or any other information market, have incentives to consider each security individually, ${ }^{201}$ so too would traders in an insolvency information market, assuming that there was a sufficient financial incentive. The greater challenge is overcoming traders' limited access to relevant information. Although mandatory reporting requirements furnish some publicly available data, governmental inspections are a key aspect of

197 See Kenneth S. Abraham, Insurance Law and Regulation: Cases and Materials 98-104 (Foundation 3d ed 2000) (describing state solvency monitoring of insurance companies).

198 For a general discussion, see Carl Felsenfeld, The Savings and Loan Crisis, 59 Fordham L Rev S7 (1991) (providing an overview of the federal savings and loan system and discussing specific reasons for the collapse of the system in the 1980s).

199 See Joseph A. Grundfest, Lobbying into Limbo: The Political Ecology of the Savings and Loan Crisis, 2 Stan L \& Pol Rev 25, 30 (1990) (describing how late discovery by Congress and the Reagan administration led to further high-risk behavior by the banks).

200 See, for example, Mark Seidenfeld, A Civic Republican Justification for the Bureaucratic State, 105 Harv L Rev 1511, 1567 (1992) (identifying special interest lobbying of Congress as a factor in loose monitoring of endangered thrifts).

201 Each security in the Hollywood Stock Exchange is liquidated based on the performance of a particular film. See text accompanying notes 50-51. While it might be profitable to trade on a number of securities based on information expected to affect filmgoing generally, traders typically profit by finding errors in the market's pricing of individual films. 
such regulatory regimes. ${ }^{202}$ Privacy considerations presumably would prevent traders from obtaining the full access that governmental officials enjoy. Traders would thus need to base their predictions on publicly available information and any other information that they are able privately to obtain.

That information alone, however, may be sufficient to enhance the monitoring process. Whistleblowers with particular knowledge of problems at depository institutions have an incentive to trade on the information and thus reveal the problems, assuming that the law creating the market explicitly exempted such traders from insider trading liability. Moreover, if depository institutions would suffer some adverse consequence from even a temporary information market prediction of a high insolvency probability, they would have some incentives to open up their files to private parties that will independently verify their financial information, lest traders infer from a lack of cooperation that the institutions are hiding information. ${ }^{203}$ Theory alone is insufficient to predict the extent to which these dynamics will affect information markets' success at incorporating private information. Even a financially modest experiment, publicly or privately financed, could provide traders with sufficient incentives to develop models predicting the probability of insolvency based on public information, ${ }^{204}$ and such models might help overcome any loopholes in current governmental accounting rules that may allow institutions in danger to clear government benchmarks. In theory, if such an experiment proved success-

202 Critical to the programs are the randomness of inspections, since banks and insurance companies may be able to make temporary changes to conceal weaknesses. See Andrew Chin, Spoiling the Surprise: Constraints Facing Random Regulatory Inspections in Japan and the United States, $20 \mathrm{Nw}$ J Intl L \& Bus 99, 99-100 (1999) (describing a scandal in Japan involving governmental officials tipping off banks as to the dates of their inspections).

203 Once some institutions reveal information, an adverse selection effect increases the pressure on other institutions to do so as well. Because an institution will have an incentive to allow inspections whenever it believes that traders are overly suspicious of it, the best of the institutions that initially do not reveal information will have a strong incentive to do so. This dynamic can produce an unraveling effect, so that even institutions that fear that inspections will reveal negative information will allow such inspections lest traders infer that the situation is even worse than it actually is. See generally Paul Milgrom and John Roberts, Relying on the Information of Interested Parties, 17 RAND J Econ 18, 22-24 (1986) (providing a model of how adverse selection may force information release). Of course, this dynamic would not exist until there was sufficient confidence in information markets so that institutions cared about their predictions. Even with institutional concern about predictions, the unraveling might be incomplete, especially if some fraction of institutions would be expected to ignore an adverse prediction, perhaps even to reduce confidence in the market's ability to make predictions about that institution.

204 Such an experiment might be particularly successful if regulators were allowed to trade, given that regulators have the best information. If the markets were significant enough, the chance of trading profits in effect would become part of the governmental officials' compensation and would motivate them to scrutinize institutions carefully. 
ful, governmental agencies could consider as a next step incorporating market predictions into governmental formulas determining the extent of governmental intervention.

\section{Budget forecasts.}

The examples so far have involved areas in which the application of information markets may be controversial, but the policy issues corresponding to the relevant predictions are generally uncontroversial. Information markets could be used in more controversial areas, although they might offer little other than academic value in such contexts. For example, it would be straightforward, if macabre, to use a conditional market to assess the deterrent effect of the death penalty, by creating securities whose redemption value would depend, for a particular geographic area, on both the number of executions in a specified time period and the number of murders in the next time period. ${ }^{205}$ Such a market would likely play only a peripheral role in the policy debate for two reasons. First, although deterrence figures largely in debates on the death penalty, people's views on the death penalty may depend more on their belief in retributive justifications for punishment. ${ }^{206}$ Second, an information market prediction does not resolve the underlying question, but provides at most a best guess. An information market is thus akin to event studies in corporate law, serving as a sophisticated form of opinion poll that might prove incorrect. ${ }^{207}$ An educated analyst might still rationally disagree with the prediction.

Information markets on controversial issues would most likely be relevant when competing parties have some incentive to commit to the outcomes of the markets in advance. One area in which this might be true would be in budget forecasting; for example, the market would predict the size of government deficits in future years conditional on the enactment of legislation. ${ }^{208} \mathrm{~A}$ desire to have relatively objective

205 A recent study considers the deterrent effect of the death penalty by examining retrospectively the crime rate shortly before and after such executions. See Hashem Dezhbakhsh, Paul H. Rubin, and Joanna Shepherd, Does Capital Punishment Have a Deterrent Effect? New Evidence from Post-moratorium Panel Data 29-30 (unpublished manuscript 2003), online at http://papers.ssrn.com/id=259538 (visited Apr 22, 2004) (finding that allowing executions has "been associated with significant reductions in homicide").

206 See Dan M. Kahan, The Secret Ambition of Deterrence, 113 Harv L Rev 413, 437-38 (1999) (arguing that deterrence arguments have little effect on citizens' views, even if they are common in public discourse).

207 See Jill E. Fisch, Picking a Winner, 20 J Corp L 451, 465 (1995) (noting that reliance on an event study may produce bad policy if the market has processed information irrationally).

208 For an example of deficit forecasts given existing policies, see Congressional Budget Office, Current Budget Projections, online at http://www.cbo.gov/showdoc.cfm?index=1944 
data has led Congress to create the Congressional Budget Office (CBO), which generally is viewed as seeking to guard its independence and thus the integrity of its estimates. ${ }^{209}$ Budget projections, however, can still become political, in part because the majority party appoints the leadership of the $\mathrm{CBO}{ }^{210}$ In addition, controversies can arise over proper methods. A prominent example is whether budget forecasters should employ "dynamic scoring," "211 a method that assumes tax cuts will increase economic growth, and how much dynamic scoring they should allow. ${ }^{212}$ Disagreements about the accuracy of different methodologies may imperil the legitimacy of budget forecasts, and both parties might be amenable to a solution that depoliticizes both methodologies and forecasts.

Information markets offer a straightforward solution, which might, for example, incorporate dynamic considerations to an extent that falls between its most ardent proponents and detractors. A simple approach would tie securities to ex post evaluations of the deficit and use conditional securities to assess the effects of different policy choices. ${ }^{213} \mathrm{~A}$ possible concern here is that there may be subjectivity even in such retrospective assessments, for example because ambiguities in accounting rules allow for some degree of discretion..$^{214}$ As long as the identity and party affiliation of the budget officials who will make the assessments are unknown, however, information markets

(visited Apr 22, 2004) (listing projected government revenues, outlays, deficits, and surpluses).

209 See generally Philip G. Joyce and Robert D. Reischauer, Deficit Budgeting: The Federal Budget Process and Budget Reform, 29 Harv J on Legis 429, 431-33 (1992) (discussing the origins of the $\mathrm{CBO}$ ). Even with the independent CBO, however, Congress often finds ways of masking its spending decisions. See Cheryl D. Block, Pathologies at the Intersection of the Budget and Tax Legislative Processes, 43 BC L Rev 863, 869, 897-98 (2002) (discussing a practice known as "directed scorekeeping," in which Congress orders the Office of Management and Budget to perform its accounting in a specified way).

210 See 2 USC $\$ 601$ (a)(2) (2000) ("The Director shall be appointed by the Speaker of the House of Representatives and the President pro tempore of the Senate.").

211 The Reaction, Economist 28-29 (Jan 18, 2003) (discussing the attempt by Republicans to implement dynamic scoring).

212 See generally Alan J. Auerbach, Dynamic Revenue Estimation, $10 \mathrm{~J}$ Econ Persp 141 (1996) (considering methodological and implementation issues associated with dynamic scoring).

213 The concern about selection bias with conditional markets, discussed in notes 76-77 and accompanying text, is not salient here, because Congress is unlikely to have substantial private information relevant to the market's assessment of deficits conditioned on the enactment of a particular policy. The most significant challenge with such a market would be developing suitable definitions for the relevant conditions because almost no particular budget proposal will be adopted in its entirety. One solution might be to have the conditional market estimate the deficit based on the specified tax rate.

214 Theodore Seto has emphasized the manipulability of budget forecasts in arguing that a balanced budget amendment to the Constitution would need an "independent scorekeeper" to make deficit assessments. See Theodore P. Seto, Drafting a Federal Balanced Budget Amendment That Does What It Is Supposed to Do (and No More), 106 Yale L J 1449, 1511-15 (1997). 
will predict an average of what different officials might be expected to decide, ${ }^{215}$ thus effectively stripping political bias out of the estimate. To ensure anonymity, assessments should be scheduled for a significant period of time, perhaps ten years, after the launch of the market, even if the budget being predicted is for a fiscal year that is close to the market launch date. This is a critical point, to which I will return in discussing predictive cost-benefit analysis: ${ }^{216}$ The possibility of subjectivity in determinations of market payouts is not a problem as long as the ultimate decision is postponed and as long as a prediction of how an average decisionmaker would make the assessment is sufficient for the relevant purpose.

\section{Interim regulation.}

That predictions in a budget forecasting information market actually predict future governmental assessment does not make that market unique. Any information market requires that some individual, whether or not governmental, make a final assessment of the predicted value. Information markets, however, might be used to predict not only governmental assessments made specifically for the purpose of concluding the markets, but also governmental decisions on issues of regulation. Agencies often lack sufficient resources to address all of the regulatory questions they face. For example, the EPA is notoriously slow in determining whether to classify particular chemicals as pollutants. ${ }^{217}$ Similarly, the Food and Drug Administration has often faced criticism for the amount of time that it takes to conduct drug trials. ${ }^{218}$ An information market that predicted the decision that the agency will eventually reach might be useful in fashioning an interim regulatory regime.

In the EPA context, for example, an information market might include a number of securities corresponding to different chemicals, with the security to be liquidated at a set value if the chemical eventually is classified as a carcinogen. Without conducting any scientific research on its own, the agency might enact rules regulating such carcinogens. For example, the EPA might decide to limit expanded use of

215 See text accompanying note 249.

216 See Part III.

217 See John P. Dwyer, The Pathology of Symbolic Legislation, 17 Ecol L Q 233, 258-59 (1990) (describing the six-year process to determine whether vinylidene chloride was a hazardous air pollutant).

218 For an evaluation of a federal statute that seeks to expedite the process, see Deborah G. Parver, Comment, Expediting the Drug Approval Process: An Analysis of the FDA Modernization Act of 1997, 51 Admin L Rev 1249, 1258-64 (1999) (concluding that the statute will allow new drugs to enter the market at a faster pace). 
chemicals for which the information market indicated a significant probability of ultimately being labeled a carcinogen. A more elaborate information market might predict the "dose-response" curve corresponding to a particular chemical. ${ }^{219}$ In such a market, the securities would predict the effect of each chemical on humans at various levels of exposure. Although these are notoriously difficult assessments, ${ }^{220}$ the market at least would provide an objective prediction of the EPA's later determination. The information market alone cannot determine the best interim legal regime, ${ }^{211}$ but it can provide an agency with limited data that it can use pending its own investigation. Such an information market could at least help an agency decide which decisions to prioritize.

\section{Judicial Review}

Some critics of the administrative process complain that it is "ossified," , with the cumbersomeness of notice-and-comment rulemaking preventing administrative agencies from enacting useful regulations. ${ }^{223}$ Although the Administrative Procedure Act allows an agency

219 For a definition of "dose/response assessment," see Robert A. Pollak, Regulating Risks, $33 \mathrm{~J}$ Econ Lit 179, 183 (1995) ("Dose/response assessment estimates the relationship between the amount, intensity, or duration of exposure and the risk of a particular outcome (e.g., . . a worker's lifetime probability of contracting leukemia).").

220 See Sunstein, 90 Georgetown L J at 2279-80 (cited in note 124) (discussing doseresponse curves and the difficulties of calculating them).

221 In the FDA context, a relevant question would be whether drugs should be provisionally allowed when there is a prediction that they ultimately will be approved. An argument for such a rule is that many people may die while waiting for a drug to be approved, and an information market prediction at least provides some assurance that the drug company is not seeking to deceive consumers by peddling snake oil. See Department of Health and Human Services, Investigational New Drug, Antibiotic, and Biological Drug Product Regulations, 53 Fed Reg 41516, 41516 (1988) (amending 21 CFR $\S \S 312,314$ ) (noting the FDA's goal of "speed[ing] the availability of new therapies to desperately ill patients, while preserving appropriate guarantees for safety and effectiveness"). A contrary argument is that the government might find it difficult to eliminate supplies of the drug should it ultimately decide not to approve it.

222 See Thomas O. McGarity, Some Thoughts on "Deossifying" the Rulemaking Process, 41 Duke L J 1385, 1387-96 (1992) (describing the increasingly rigid and burdensome nature of rulemaking).

223 The Administrative Procedure Act appears to require relatively little information by agencies in the rulemaking process. See 5 USC $\$ 553$ (b)(3) ("The notice shall include ... either the terms or substance of the proposed rule or a description of the subjects and issues involved."). The D.C. Circuit, however, has interpreted administrative notice provisions aggressively, for example by requiring agencies to release background documents that might be necessary for parties to make informed comments on the rules. See Portland Cement Association v Ruckelshaus, 486 F2d 375, 384-86, 402 (DC Cir 1973) (rejecting a Notice of Proposed Rulemaking under the National Environmental Policy Act, even though the agency had provided the text of the proposed rule in draft form). See also Gary Lawson, Federal Administrative Law 254 (West 2d ed 2001) ("[Portland Cement] did not formally hold that notices of proposed rulemak- 
to skip the notice-and-comment process for "good cause," courts have been reluctant to allow agencies to count the interim nature of a rule as sufficient good cause. ${ }^{225}$ Such reluctance is understandable, given the danger that agencies might abuse such a prerogative by regulating through successive series of interim rules. An information market used to predict an ultimate agency decision, however, can provide the agency with some data to support the view that it will indeed eventually find sufficient evidence to act in a particular way. Perhaps this data would be sufficient to convince courts that interim regulation is appropriate.

Should information markets exist on topics relevant to particular administrative decisions, no amendments to the Administrative Procedure Act would be necessary for courts to take them into account in checking the rationality of judicial policy decisions. Under the "hard look" doctrine, one of the means by which courts assess whether agency actions are "arbitrary" or "capricious," courts closely analyze administrative agencies' justifications for their policy choices. ${ }^{227}$ In $\mathrm{Mo}$ tor Vehicle Manufacturers Association v State Farm Mutual Automobile Insurance $\mathrm{Co}^{228}$ for example, the Supreme Court scrutinized the National Highway Traffic Safety Administration's interpretation of studies on the effect of seatbelt usage, noting that the agency's prediction of less than a five percentage point increase in safety belt usage failed to take into account distinctions between two types of belts. ${ }^{229}$ Similarly, a court might vacate an administrative action when an agency has failed to produce an adequate explanation of why that decision is justified given a particular prediction by an information market. This is a limited power, as the court can guarantee only that the agency

ings must reveal all relevant underlying studies and data in the agency's possession, but it was taken to mean that by just about everyone.").

2245 USC $\$ 553(\mathrm{~b})(\mathrm{B})$.

225 See, for example, Tennessee Gas Pipeline Co v FERC, 969 F2d 1141, 1144-46 (DC Cir 1992 ) (rejecting two rationales for application of the "good cause" exception).

2265 USC $\$ 706(2)(A)$ (requiring the reviewing court to "hold unlawful and set aside agency action, findings, and conclusions found to be ... arbitrary, capricious, an abuse of discretion, or otherwise not in accordance with law").

227 Though firmly entrenched, the hard look doctrine remains controversial. See, for example, Richard J. Pierce, Jr., The Unintended Effects of Judicial Review of Agency Rules: How Federal Courts Have Contributed to the Electricity Crisis of the 1990s, 43 Admin L Rev 7, 19-29 (1991) (exploring the effect of hard look review on substantive regulatory outcomes in the electricity regulation context).

228463 US 29 (1983) (holding that the National Highway Traffic Safety Administration's rescission of a passive restraint requirement was "arbitrary and capricious").

229 Id at 54 ("[T]his and other statements that passive belts will not yield substantial increases in seatbelt usage apparently take no account of the critical difference between detachable automatic belts and current manual belts."). 
conducts a "reasoned analysis," among a variety of reasonable conclusions that which the court thinks best. The more objective data that courts have to assess administrative agency reasoning, however, the more effectively courts will be able to conduct this task. Because the hard look assessment is open-ended, traditionally considering any studies that might be relevant to the enactment of the regulation, there is no legal bar to incorporation of information market predictions into the analysis, at least provided that further evidence suggests that information markets are indeed reliable predictors. ${ }^{231}$ Of course, if information markets are susceptible to manipulation when the stakes are sufficiently high, judges should not rely on them, for the same reason that they might hesitate to rely on an industry-financed study that lacked indicia of objectivity.

In the State Farm case, then-Justice Rehnquist's separate opinion suggested that the National Highway Traffic Safety Administration's about-face on passive restraint policy should be allowed in part because the change in policy was the result of a change in presidential administrations. ${ }^{232}$ Rehnquist's realist approach may have been admirably candid, but critics insisted that although politics may affect agency policy decisions, courts should not simply abdicate their review responsibilities when confronting such decisionmaking. ${ }^{233}$ Despite Rehnquist's view, courts do not yield to politics. Instead, they seek to ensure public participation, consistency of regulations with statutory requirements, and careful consideration of policy decisions by agency officials. Doctrine, however, renders judicial review relatively deferential. $^{2.4}$ Part of the explanation for deference may be a Rehnquist-like theory of winner's spoils. Yet more often deference is justified by rela-

230 Id at 57 (holding that a "reasoned analysis" is sufficient even when an agency is changing its policy course).

231 In principle, courts might even consider the results of a privately run information market, just as they might consider private studies. Interestingly, private parties have vowed to recreate a version of the Policy Analysis Market even without government subsidy. See Mark Gongloff, Middle East Futures Market Returns, CNNMoney.com, online at http://money.cnn.com/ 2003/11/17/news/terror_futures (visited Apr 22, 2004).

232 See State Farm, 463 US at 59 (Rehnquist concurring in part and dissenting in part) ("The agency's changed view of the standard seems to be related to the election of a new President of a different political party. ... A change in administration brought about by the people casting their votes is a perfectly reasonable basis for an executive agency's reappraisal of the costs and benefits of its programs and regulations.").

233 See, for example, William F. Funk, To Preserve Meaningful Judicial Review, 49 Admin L Rev 171, 177-78 (1997) (concluding that political input to the regulatory process should be balanced by real judicial scrutiny).

234 See, for example, Chevron USA Inc v Natural Resources Defense Council, Inc, 467 US $837,865-66$ (1984) (providing for deference to agency legal conclusions where those conclusions are reasonable). 
tive institutional competence; ${ }^{235}$ that is, by a conclusion that agencies make policy better than courts.

Agencies' general superiority at policymaking need not leave courts without a role. If doctrine grants agencies too much deference, agencies may adopt policies that thwart congressional intent or represent ideological agendas that most of the population would reject. On the other hand, if it grants too little, judges may do the same. The balance depends in part on the effectiveness and the objectivity of the tools that courts use to assess agency action. The only tool that courts currently use is plain old logical reasoning, as judges assess whether agencies have offered responses to significant counterarguments ${ }^{236}$ and whether agency interpretations are consistent with statutory authority. ${ }^{237}$ Reasoning is a powerful tool but an inherently subjective one, and while judges presumably seek to avoid writing opinions that appear disingenuous, ${ }^{238}$ reputation furnishes only a limited constraint. The extent of deference that doctrine affords agencies thus reflects the difficulty of monitoring judges and the danger of government by judiciary.

To the extent that information markets provide for objective analysis, information markets both provide decisionmakers an opportunity to avoid poor decisions and offer others a metric by which to assess the decisions that are made..$^{2.9}$ Information markets serve these two purposes for both agencies and courts. Just as an information market can help an agency avoid a decision based on a poor prediction, so too can it help courts avoid their own errors. An information market might lead judges to uphold policies that they would have struck down based on their own normative lights, or to strike down agency actions that they otherwise would have found to be within

235 See Richard J. Pierce, Jr., Chevron and Its Aftermath: Judicial Review of Agency Interpretations of Statutory Provisions, 41 Vand L Rev 301, 307-08 (1988) (arguing that agencies should have the dominant role in policymaking when the choice is between agencies and courts).

236 Judges consider agency reasoning both under the hard look doctrine and under 5 USC $\S 553$, which sets forth the requirements for notice-and-comment rulemaking. See generally Merrick B. Garland, Deregulation and Judicial Review, 98 Harv L Rev 505, 526-31 (1985) (discussing the relationship between hard look and procedural review).

237 Courts also often invoke canons of construction to assess the reasonableness of agency interpretations, but judges sometimes disagree about their relevance and scope. See, for example, Babbitt $v$ Sweet Home Chapter of Communities for a Great Oregon, 515 US 687 (1995) (providing an example of a case in which both sides used canons of construction to support their positions).

238 See note 102 and accompanying text.

239 Information markets thus respond to Lisa Bressman's recent call for developing administrative law tools that reduce arbitrariness, rather than merely promoting accountability. See Lisa Schultz Bressman, Beyond Accountability: Arbitrariness and Legitimacy in the Administrative State, 78 NYU L Rev 461, 527-44 (2003). 
agencies' broad discretion. Equally importantly, just as an information market can allow courts and other governmental actors to assess agency officials, so too can such a market allow for scrutiny of judicial decisions. Although no court would be expected blindly to follow information market predictions and recommendations, information markets could make ideologically driven judicial reasoning more apparent, leading judges who care about their reputations for neutrality to hesitate before acting on their own political views. Used judiciously, information markets thus have the potential to improve the incentives and decisions both of agencies and of the courts reviewing them.

\section{PREDICTIVE COST-BENEFIT ANALYSIS AND BEYOND}

A principal challenge in creating information markets, hinted at above, is determining what information the markets should be constructed to predict. ${ }^{240}$ The information must be sufficiently important to bear on the decision, but even once a clearly relevant type of information is predicted, governmental decisions will often depend on a variety of additional factors. The information markets described so far can provide inputs into governmental decisions, but they cannot provide comprehensive assessments of the decisions themselves. ${ }^{241}$ Predictive cost-benefit analysis provides at least a solution to these dilemmas, by creating an information market to predict the outcome of a cost-benefit analysis. A cost-benefit analysis can incorporate, at least in theory, all of the costs and benefits of a particular decision, and therefore does not have to define the relevant contours of a decision. By incorporating all costs and benefits, the market produces bottomline assessments of potential government decisions. Existing information markets predict information that can be objectively verified ex post. What makes predictive cost-benefit analysis a useful tool is its

240 In the cyberterrorism context, for example, the difficult questions are which terrorist activities to predict and over what time frame. See Part II.B.1. The problem is especially acute for conditional markets, which also require a definition of the condition upon which the markets will depend.

241 Robin Hanson has described a use of information markets that also would result in bottom-line analysis of decisions. See Robin Hanson, Futarchy: Vote Values, But Bet Beliefs (Aug 2000), online at http://hanson.gmu.edu/futarchy.html (visited May 31, 2004) (proposing a new form of government where "[e]lected representatives would formally define and manage an after-the-fact measurement of national welfare, while market speculators would say which policies they expect to raise national welfare"). This approach, however, would require the government to announce in advance by statute weights for all potential policy outcomes, such as effects on Gross National Product, economic distribution, and so on. A limitation with this approach is thus that the legislature must recognize all the values that policies might implicate in advance and come to agreement on them. 
potential to enable comprehensive analysis of individual policy decisions.

Predictive cost-benefit analysis is attractive not only because it accommodates virtually any form of governmental action. It is also responsive both to concerns about information markets and to concerns about traditional cost-benefit analysis. Furthermore, it improves on conditional markets, which, although useful for assessing individual decisions, present technical problems that make their results difficult to interpret. On the other hand, a disadvantage of predictive costbenefit analysis compared to other information markets is that predictive cost-benefit analysis predicts only what people will say their opinions are, and sometimes this might deviate from their true opinions. In most contexts, however, the most significant virtue of predictive costbenefit analysis renders this disadvantage inconsequential.

This virtue is that predictive cost-benefit analysis assesses how an average, as opposed to an identifiable, evaluator, would rate a particular policy. Unlike traditional cost-benefit analysis, predictive costbenefit analysis will not vary based on the happenstance of which political party or which particular individuals happen to be in control of an agency at the time of the analysis. A proponent of traditional costbenefit analysis might protest that it would be worse to have politically moderate analysts all of the time than to have politically more extreme analysts from opposite sides of the ideological spectrum sharing power across time. Allowing Democrats free reign for a few years and Republicans for another few years might be better than having moderates always control policy, because experimentation with different approaches is likely to produce useful feedback into the political process. ${ }^{242}$ This perspective sees the abrupt shifts in power following elections as inherently desirable rather than as the mere byproduct of a political system that seeks to enshrine the preferences of a hypothetical median voter but can do so only approximately and only in fits and starts.

As important as this objection is, it does not affect my thesis, which is simply that predictive cost-benefit analysis is a more useful tool than traditional cost-benefit analysis, not that agencies necessarily should be required to follow its recommendations. The more decisionmakers can manipulate cost-benefit analysis to reflect their own preferences, the less valuable cost-benefit analysis becomes as an in-

242 This position dates at least to President Jackson. See John F. Duffy, The FCC and the Patent System: Progressive Ideals, Jacksonian Realism, and the Technology of Regulation, $71 \mathrm{U}$ Colo L Rev 1071, 1138-39 (2000) (discussing how President Jackson limited agency officials' tenure to promote rotation in office). 
put into administrative decisionmaking. ${ }^{2.3}$ Eventually, at an extreme of manipulability, cost-benefit analysis becomes useless, providing meaningless positive evaluations of every administrative action. The very motivations that lead agencies to employ cost-benefit analysis, such as providing clear signals to other policy actors, should create a preference for more objective forms of cost-benefit analysis, at least if the cost of increasing objectivity is not significantly higher and if others recognize the increase in objectivity. If information markets generally are indeed relatively objective ${ }^{244}$ predictive cost-benefit analysis also will be more objective than traditional cost-benefit analysis, in the sense that it will be less sensitive to the identity of the policymaker.

The increased objectivity and transparency of predictive costbenefit analysis could appear to be a vice, for example if it facilitates third-party manipulation of regulatory outcomes. Suppose that the government were using predictive cost-benefit analysis to determine whether to impose a costly regulation on industry, and it appeared that the ultimate market prediction would be close to zero-in other words, that costs were roughly equal to benefits. Industry might respond by voluntarily addressing the problem targeted by the proposed regulation. ${ }^{245}$ It is possible that such behavior could produce the best outcome. But it is also possible that the costs of voluntary industry action might exceed its benefits, even if these benefits would thwart the proposed regulation by nudging the regulation from the net benefit to the net cost side of the ledger.

This hypothetical demonstrates that a second-best argument might exist in which we should not seek to improve the objectivity of tools like cost-benefit analysis for fear that they might be misused, either by the agency or in this case by private parties, especially if the agency were required to follow the results of the analysis. In this preliminary account of predictive cost-benefit analysis, though, I will assume that if cost-benefit analysis does exist, it might as well be as objective as possible. If noise were desirable, that could always be added in randomly at the end; if that possibility seems unattractive, the second-best argument against predictive cost-benefit analysis should seem unattractive as well.

243 See text accompanying notes 135-37.

244 See Part II.A.2.

245 This is an example of a more general point offered by Saul Levmore: Interest groups may be most able to act when social choice problems such as the danger of cycling are present. See Saul Levmore, Voting Paradoxes and Interest Groups, 28 J Legal Stud 259, 261-63 (1999). Reliance on a relatively transparent system of cost-benefit analysis may in effect provide third parties with greater agenda control and thus facilitate rent-seeking behavior. 
Indeed, agencies already seek to improve the objectivity of their analyses by providing rigid ex ante rules for measuring costs and benefits. Ex ante rules become unnecessary with predictive costbenefit analysis because such analysis provides an alternative means of assuring objectivity. By doing so, it blunts the criticism that ex ante rules merely mask subjectivity, moving discretion from the evaluators of individual policies to those who determine the ex ante rules. This complaint is at the heart of many debates about cost-benefit analysis and about regulatory policy more generally, and Part III.B.2 will explain why predictive cost-benefit analysis should appease both sides in many such debates, even if considerable debate persisted about whether the results of predictive cost-benefit analysis should affect agency action. Before that, Part III.A will describe the mechanics of predictive cost-benefit analysis, and Part III.B.1 will compare it to other information markets.

\section{A. The Mechanics}

The mechanics of predictive cost-benefit analysis are straightforward, once an infrastructure for creating information markets exists. Suppose, for example, that the government wished in 2004 to conduct a predictive cost-benefit analysis of a proposed policy to reduce arsenic in the water. The information market would be initiated at that time, with a final prediction taken at some designated time, say September 1, 2004; the government could then consider that prediction in deciding whether to enact the proposed policy. Then, at some far later point, say September 1, 2014, the government would perform a costbenefit analysis of the policy, regardless of whether it in fact had been implemented. If the policy had been adopted, that cost-benefit analysis would estimate the costs and benefits that had occurred as well as any that might still result, discounting all to 2004 dollars; if it had not been adopted, the analysis would estimate what the costs and benefits would have been, discounting once again. The 2014 cost-benefit analysis would not have any direct policy effect; it would only determine prices at which securities from the 2004 information market would be liquidated.

The case for predictive cost-benefit analysis is largely the same regardless of how the information market component itself is constructed. Auctioning off the right to be the first participant helps solve a technical complication. ${ }^{246}$ The result of a cost-benefit analysis might

246 See note 92 and accompanying text. 
be a positive number (net benefits) or a negative one (net costs) ${ }^{247} \mathrm{~A}$ security liquidated at a negative number would mean that the holder of the security would pay money to the government, so there should be no difficulty allowing trading of such a security. In effect, the buyer receives money from the seller. ${ }^{248}$ But no one would want to be the initial holder of the security. An auction, however, could allow negative bids, and when net costs are expected, the highest bidder would be the one with the least negative bid. The government would then pay to that bidder the corresponding amount to compensate for holding a security that ultimately is expected to result in payments to the government. The risk associated with holding the security would make this amount more than the expected eventual payment back to the government, with the difference between these amounts being the government's expected cost from running the information market. Such a market could be subject to the market scoring rules described above, but would not necessarily need to be. This structure would, however, prevent the market from functioning in the same way as the Iowa Electronic Markets, with bundles of securities covering all contingencies ensuring predictable payouts.

The information market would produce a prediction of what an average decisionmaker would be expected to decide. If, for example, the market consensus is that Republicans would assess a regulation as having net costs of $\$ 50$ million and that Democrats would assess net benefits of $\$ 100$ million, then, assuming that it is equally likely that Republicans and Democrats will be in power ten years later, the market prediction would be net benefits of $\$ 25$ million. This assignment of probabilistic weights to different contingencies occurs in traditional securities markets as well. The stock price for a company that may be acquired, for example, incorporates the expected value of the company if it is and if it is not acquired and the probability of acquisition. ${ }^{24}$ Much the same result would occur if the market scoring rule described above were used. ${ }^{250}$ While the incentive of participants is to come as

247 An alternative approach would be to have two information markets, one used to estimate benefits and one used to estimate costs. This leads to various definitional questions, however, as some considerations may be seen either as reducing benefits or as imposing costs.

248 The market-scoring rule eliminates the need for such transactions to occur formally. See Part I.C.2.

249 Finance scholars have developed methods of inferring probability distributions of future stock prices based on the prices of options. See generally Jens Carsten Jackwerth and Mark Rubinstein, Recovering Probability Distributions from Contemporary Security Prices, $51 \mathrm{~J}$ Fin 1611 (1996) (deriving underlying probability distributions of European options on the S\&P 500 index); Stephen A. Ross, Options and Efficiency, 90 Q J Econ 75 (1976) (creating a mathematical model for options contracts).

250 See note 88 and accompanying text. 
close as possible to the eventual prediction, risk-averse participants will seek to minimize the risk associated with deviation from predictions and thus choose intermediate predictions rather than extreme ones.

Generating a prediction of an average expert's analysis is the chief purpose of having the actual cost-benefit analysis performed well into the future. However, there might be other mechanisms for accomplishing the same goal. For example, if a group of potential decisionmakers with a range of ideologies existed and were available to decide such cases, then a decision to select a random decisionmaker from the group shortly after the initial cost-benefit analysis would also achieve an averaging effect. Pushing the decision into the future eliminates the need to assemble such a body, a task that presumably could not be left to any single presidential administration.

Even if an adequate contemporary body can be formed, delaying the decision might still be useful, because more information about the relevant problem may emerge in the intervening time period. The question is a close one, however, and not just because participants in an information market would demand a premium above the market interest rate for the additional risk that delay would entail. To the extent that new information would not have been available to any market participants initially, incorporation of this information into the ex post analysis does not help discipline the market, and it may even decrease market efficiency by further increasing participant risk.

On the other hand, it is desirable to give market participants full incentives to take into account all information that they do have. If the ex post evaluation were performed shortly after the prediction, a market participant who is convinced that certain information will prove relevant over the long term may nonetheless disregard that information if the market participant believes that the current ex post evaluators would not adequately incorporate the information. This consideration may be sufficiently weighty to justify pushing analysis to the future even aside from the tendency of future analysis to neutralize ideological biases. An alternative approach might be to allow future decisionmakers to consider only information actually available to market participants originally, but that would require difficult assessments of what information was available and what information was

25I If such risk aversion were insufficient, the market scoring rule could be modified to provide incrementally greater rewards the closer the prediction. A simple scoring rule with this property would square the difference between the prediction and the actual result. For example, if the actual result turns out to be $\$ 50$, then a prediction of $\$ 30$ would count as four times further away from the result than a prediction of $\$ 40$. 
not. Some market participants might not trade on information that they will not be able to reveal before the close of the market, because they would worry that the retrospective decisionmakers might wrongly decide that the information was available only after the close of the market. Tentatively, we can conclude that any increased risk premium attributable to allowing retrospective decisionmakers to take into account information developing after the market close would be worth the cost. This risk premium should be no greater than the premiums that attach as a result of uncertainties in the performance of traditional securities like stocks.

Because the information market predicts what an average analyst would find, it is not quite so important here as in traditional regulatory contexts to ensure that the actual retrospective decision be highly accurate. ${ }^{252}$ As long as there is no systemic bias in the retrospective decisions, any limitations of the decisionmakers will only have the effect of increasing the risk premium that the government effectively pays to investors. That alone may well be enough of a consideration to justify substantial efforts to make the retrospective decisionmaking process a reliable one, but noise in decisionmaking at least will have less of an effect than noise would have in prospective decisionmaking, where it has a direct effect on regulatory outcomes.

\section{B. Comparisons}

Objectivity is the chief virtue of information markets, and a particular type of objectivity, independence from the current administration's political and ideological biases, is the chief virtue of the normative markets represented by predictive cost-benefit analysis. This independence represents the principal advantage of predictive costbenefit analysis over information markets used to make predictions of objectively verifiable numbers and over traditional cost-benefit analysis. The following will examine some possible disadvantages that normative markets possess vis-à-vis these other methods and then go on to explain the advantages that independence gives normative markets relative to these other methods.

252 A corollary is that it is less important here than in traditional regulatory contexts that the decisionmaker be highly qualified. Less qualified decisionmakers are likely to be less predictable, with a greater variance of cost-benefit assessments. Such variance is of immediate concern in traditional administrative decisionmaking, because anomalous decisionmaking has a policy effect. With predictive cost-benefit analysis, however, the ex post evaluation has no direct policy effect, and thus the possibility that some will err too high and others too low is of little concern. The optimal qualification level of a decisionmaker will also be lower the further into the future the decision is made, because the more the decisionmaker can rely on actual experience, the easier the assessment will be. 
1. Normative versus positive markets.

Suppose an administrative agency is considering a nationwide regulation that would ban citizens from carrying concealed handguns. Robin Hanson has suggested that a conditional market would be an ideal tool for evaluating the effect of such a policy change, allowing a prediction to emerge about how the policy would affect the murder rate or the number of deaths involving handguns. ${ }^{233}$ It would be equally straightforward to use a predictive cost-benefit analysis to assess how experts would evaluate the policy retrospectively. True, neither approach can guarantee the "correct" answer, as both reflect only traders' predictions. An advantage of the objective approach, however, is that it gives traders an incentive to predict the actual effects of the policy rather than what decisionmakers will claim they believe the effects of the policy to be. If retrospective cost-benefit analysis is merely a form of "position taking,", in which decisionmakers announce what they would like others to think they believe rather than what they truly believe, then predictive cost-benefit analysis will reflect anticipated positions on policy effects rather than the policy effects themselves. A positive information market might predict whether a concealed weapons ban would save or cost lives; a normative information market can predict only whether the retrospective decisionmakers will say what the effect of the ban was, and this may be quite different especially in controversial areas where decisionmakers may prefer to project certain beliefs to others.

This objection suggests that predictive cost-benefit analysis may fail to uncover universal truths on the nation's most controversial policy issues. But an information market that predicted an objectively verifiable number would be equally unlikely to determine government policy on such issues, ${ }^{255}$ because political actors are unlikely to yield to a prediction on a controversial issue, even an objective one. A positive information market might influence public opinion and thus indirectly political parties' positions, but an agency is unlikely to ignore the ad-

253 See Hanson, 14 IEEE Intelligent Sys at 16 (cited in note 19).

254 "Position taking" is defined in the political science literature as the "public enunciation of a judgmental statement on anything likely to be of interest to political actors." David $\mathbf{R}$. Mayhew, Congress: The Electoral Connection 61 (Yale 1974). When engaging in "position taking," legislators are motivated by a desire to appeal to constituents or others, rather than by their underlying views on the issues. Whether legislative behavior constitutes position taking is often controversial. See, for example, Keith Krehbiel and Douglas Rivers, Sophisticated Voting in Congress: A Reconsideration, 52 J Polit 548, 564-65 (1990) (describing the changeability of legislators' positions with respect to a civil rights bill). With retrospective cost-benefit analysis, the more the expert is expected to engage in "position taking," the less the underlying merits will matter.

255 See text accompanying note $205-07$. 
ministration's positions on a fundamental issue like gun control solely because of an information market prediction. Even if predictive costbenefit analysis reflects average political preferences as well as hardnosed analysis, this is more a virtue than a vice in the political process. Predictive cost-benefit analysis will recommend against policies that all retrospective analysts are expected to conclude had net costs, even if such conclusions are expected to be politically motivated rather than genuine. ${ }^{256}$ Such policies would elude enactment in any event, and a tool that recommended them would lack credibility in the political process. Along the same lines, predictive cost-benefit analysis can verify whether an agency's support for a policy is idiosyncratic, providing a politically useful signal to the President, Congress, and the courts, rather than just providing objective analyses that in the long run might affect voters.

At any rate, disingenuous policy evaluation should prove less dangerous with predictive cost-benefit analysis than with traditional administrative decisionmaking. One reason is that disingenuousness will often roughly cancel out; an average expert is less likely than a partisan to read evidence selectively. More significantly, the retrospective assessor will be less susceptible to political and other forms of pressure than an administrative agency official making an actual policy decision. The only effect of an assessment is on the traders, and, at least for most analyses, there would not be sufficient money at stake to cause traders to seek to influence the process. ${ }^{257}$ Because the analy-

256 When the subjective assessments predicted by predictive cost-benefit analysis point in a direction opposite from what a positive information market would recommend, additional values besides whatever the objective market directly measures may be at stake. Suppose, for example, that a positive information market would predict that allowing concealed weapons would reduce murders, but that a predictive cost-benefit analysis would nonetheless anticipate greater costs than benefits. The discrepancy might reflect that lives may not be the only relevant variable in a cost-benefit analysis. For example, the discomfort that many would feel from living in a world that formally allows individuals to carry tools for ending lives might count as a cost of allowing concealed handguns. If these concerns are sufficiently powerful to affect conclusions about the net benefits of a concealed weapons ban, then perhaps they should influence policy. For an argument that allowing concealed weapons may save lives, see John R. Lott, Jr., More Guns, Less Crime: Understanding Crime and Gun-Control Laws (Chicago 2d ed 2000).

257 If a sufficiently large amount of money is at stake, there must be some means of preventing or minimizing trader influence over the eventual expert. A simple approach would be to ensure that the experts are independent. For example, Article III judges rather than political officials might themselves choose the decisionmakers, at least if the decisions are appealable to the courts. See, for example, Freytag v Commissioner of Internal Revenue, 501 US 868, 881-82 (1991) (finding that special trial judges were inferior officers, who under the Constitution may be appointed by the heads of departments or by Article III judges); Landry v FDIC, 204 F3d 1125, 1130-34 (DC Cir 2000) (finding that administrative law judges were not inferior or principal officers, and thus not subject to the requirements of the Appointments Clause at all). In addition, the experts might serve single, nonrenewable terms, and rules of procedure might prevent ex 
sis has no direct policy effect, interest groups should have far less interest in retrospective evaluations of decisions made a decade before than in the original decisions, and retrospective evaluations will receive less attention than actual decisions from other agency officials, the public, the President, and Congress. On some issues, of course, partisans of one position or another will seek to influence retrospective decisionmakers, even if only to achieve symbolic victories. But we do have institutions like courts that are relatively successful at insulating decisionmakers from direct and indirect sources of outside influence, and a carefully designed retrospective evaluation process could minimize the extent of the rent-seeking problem.

The incentives of ex post evaluators would be similar to the incentives of judges, such as maintaining a reputation for high-quality work. At times, evaluators might seek to demonstrate solidarity with the present or past positions of a particular political party, or to use the retrospective valuations as a vehicle for advancing a world view. But unless evaluators from one party or associated with one view are more likely to act in this way than others, such tendencies will have no effect on predictions. Like judges, indeed perhaps even more than judges because judges have a direct influence on policy, ${ }^{258}$ retrospective evaluators may care about demonstrating careful and competent analysis. ${ }^{259}$

The predictions of a normative information market ordinarily should not differ greatly from those of a positive information market if they evaluate the same effect of a policy. The predictions of information markets are themselves informed opinions, and informed opinions about future expressed opinions of a policy's effect will rarely deviate greatly from informed opinions about the policy effect itself. This is especially true for run-of-the-mill administrative issues that elicit little passion in the present, and can thus be expected to attract virtually no attention when retrospectively assessed in the future. There may be occasions when there is little need to undertake the cost of a retrospective cost-benefit analysis, because there is widespread agreement

\footnotetext{
parte contacts between traders and experts.

258 A leading group of judicial politics scholars contend that judges tend to vote their "attitudes." See Jeffrey A. Segal and Harold J. Spaeth, The Supreme Court and the Attitudinal Model Revisited 86-97 (Cambridge 2002). Retrospective evaluators might suppress their attitudes more, given the inability actually to affect policy. On the other hand, the absence of policy consequences might liberate the evaluators to entertain even extreme positions.

259 See Sidney A. Shapiro and Richard E. Levy, Judicial Incentives and Indeterminacy in Substantive Review of Administrative Decisions, 44 Duke L J 1051, 1053-54 (1995) (identifying "craft" and "outcome" as two goals that judges seek to achieve). See also Brett G. Scharff, Law as Craft, 54 Vand L Rev 2245 (2001) (analogizing legal decisionmaking to other craft traditions).
} 
about what variable the agency should seek to optimize and there already exists a mechanism for measuring that variable. Most policies, however, have numerous effects, and no objective algorithm exists to convert all of them to a single scale. Predictive cost-benefit analysis avoids the subjectivity of the ex ante determination of what weight to assign different variables in assessing regulation by averaging the costs and benefits that different experts are expected to assign to various effects of a regulation. In practice, a policymaking process that uses predictive cost-benefit analysis may be less prone to subjective influences than one that uses positive information markets.

The most significant advantages of predictive cost-benefit analysis over positive information markets, however, are technical. First, with predictive cost-benefit analysis, there is less of a danger that the demographics of traders will have a significant influence on the market outcome. Traders' ideologies are more likely to affect trading behavior when the proper valuation depends on ideologically contested assumptions. The task of predicting individuals' preferences, however, is not necessarily ideologically charged, even if the preferences themselves are largely ideological. Liberal and conservative traders might have different views about whether government takeover of electricity generation would lead to lower prices and more reliable service, but they might nonetheless largely agree on how decisionmakers on average would assess those costs. Methodologies for measuring and predicting public opinion may be controversial, but such controversies tend to become ideological only in debates in which opponents each seek to claim public approval. Predictive cost-benefit analysis does not solve the problem of ideological influence entirely; traders may wrongly assume that others will agree with their own views, ${ }^{260}$ and they may believe that the passage of time will prove their perspective correct to the retrospective evaluator. It lessens the problem considerably, however, and the effect seems likely to be quite small as long as there is some ideological diversity among the traders.

Second, predictive cost-benefit analysis reduces the danger of spurious interpretations of effectively random phenomena. Conditional markets require a comparison of two closely related securities, so any noise in price determinations that randomly affects the two securities differently may be misinterpreted as reflecting the market's consensus about the effect of the relevant condition. ${ }^{261}$ Predictive costbenefit analysis requires the issuance of only one security, so noise

260 See note 158 and accompanying text.

261 See text accompanying note 79. 
should not be a factor. Even if such analysis proceeded with two securities, one to measure costs and the other to measure benefits, there is no overlap between what the two securities measure, so the price difference is meaningful. There will be some instances, of course, in which the evaluation of a regulation is so close that whether predictive or traditional cost-benefit analysis anticipates slight net benefits or slight net costs is essentially random. ${ }^{262}$ With conditional markets, however, noise may be of a magnitude comparable to the effect being predicted, rather than just a small factor that may on occasion prove to be the decisive difference.

Third, predictive cost-benefit analysis avoids the selection bias problem, even if agency decisionmakers have information unavailable to traders. A conditional market tends to exaggerate the effect of the relevant condition because traders will reason that if the agency adopts the policy, it may have information indicating that the policy will in fact be successful. ${ }^{263}$ This effect will occur only with securities that have value contingent solely on the government decision. With predictive cost-benefit analysis, whether the policy is adopted does not affect whether the retrospective assessment will occur, so selection bias is eliminated. Traders' assessments might still depend slightly on their estimate of the probability of adoption should they believe that retrospective cost-benefit analyses will be kinder to a regulation that is adopted than one that is not, all else being equal. ${ }^{204}$ Such an effect would make the government seem modestly wiser than the traders' views warrant and prevent predictive cost-benefit analysis from being entirely independent of the present administration. ${ }^{265}$ Predictions,

262 The policy decision is not necessarily unimportant in such cases. There may turn out to be very large net benefits or costs even if the average decisionmaker's evaluation would be very close to zero. When net benefits or costs are close to zero, however, there is little significance in whether there are a few dollars of net benefits or of net costs, because in such cases the probability that the regulation should be enacted will be close to 50 percent either way. As an analogy, the outcome of the 2000 presidential election might be seen as essentially random, in that very slight changes in conditions such as advertising expenditures could have made either candidate the clear winner. Though the decision itself is of obvious importance, in advance of an election, it may be far more important to ensure that election processes and machinery produce the "correct" winner when the population is split 75-25 percent than when it is split 50.01-49.99 percent, since in the latter case the outcome is essentially a tie. For a general discussion of a near-tie situation, see James W. Ceasar and Andrew E. Busch, The Perfect Tie (Rowman and Littlefield 2001) (providing political scientists' perspectives on the 2000 election).

263 See notes 75-76 and accompanying text.

264 This might be true if the retrospective decisionmakers are prone to a status quo bias. See Russell Korobkin, The Status Quo Bias and Contract Default Rules, 83 Cornell L Rev 608, 625-30 (1998) (discussing experimental evidence of such a bias). A status quo bias, of course, also affects other political decisionmaking, and information markets should not make the effects of such a bias any more severe than they already are.

265 A partial antidote would be to combine predictive cost-benefit analysis and a condi- 
however, would still be of retrospective cost-benefit analyses, and predictive cost-benefit analysis would still be far less dependent on the identity of current agency decisionmakers than cost-benefit analysis of the more traditional sort.

Despite the advantages possessed by normative information markets, I do not mean to suggest that a normative information market should always be preferred to a positive market. There are, in sum, a number of considerations relevant to the comparison. Where position taking seems to be a particularly strong concern, a positive information market might be preferred. Where a single predictable variable encompasses the policy effects of a particular regulation, a positive information market might be a simpler solution than predictive cost-benefit analysis. Where a large number of predictions must be made, such as in the bank insolvency example, ${ }^{266}$ a positive information market might be a less cumbersome approach. At the same time, conditional markets might be useful when the danger of information asymmetry is low and when the effects being assessed are likely to be sufficiently large that noise is not a significant concern.

\section{Predictive versus traditional cost-benefit analysis.}

The principal disadvantage of predictive cost-benefit analysis relative to traditional cost-benefit analysis is the cost of the procedure itself. Predictive cost-benefit analysis may well be more expensive than traditional cost-benefit analysis, because the government must both subsidize the information market itself and then pay for a retrospective cost-benefit analysis. Theoretically, however, this balance is indeterminate, for at least three reasons. First, the total cost will depend on how often retrospective analysis turns out to be necessary. Second, the retrospective component of predictive cost-benefit analysis might be cheaper or more expensive than prospective analysis. ${ }^{267}$ Third, and most importantly, the government can choose the level of

tional market, that is, to create a market predicting a cost-benefit analysis should a policy be enacted, and a separate market predicting a cost-benefit analysis should a policy be rejected. These two predictions could be given equal weight, so the status quo biases should roughly cancel out. Note that this conditional market would not have the technical limitation of other conditional markets, because it would not be used to consider the difference between the prices of the two conditional securities.

266 See Part II.B.2.

267 If the policy is adopted and costs and benefits become easily ascertainable, it might be cheaper. On the other hand, it might be more expensive for two reasons. First, actual measurement may be more costly than speculation, depending on how carefully each is done. Second, when the policy is not adopted, it may be more complex and thus expensive to imagine a counterfactual world than it would have been to imagine a possible future world. 
market subsidization. Should the government invest little in a predictive cost-benefit analysis, then predictive cost-benefit analysis might be cheaper than traditional cost-benefit analysis. Of course, the government can decide how much to invest in traditional cost-benefit analysis as well, with greater resources improving the report's accuracy and reliability. ${ }^{2.8}$

Determining the precise amount of funding needed to achieve accuracy in an information market comparable to traditional costbenefit analysis will require empirical analysis. If enough money is at stake, each predictor will have an incentive to spend as much time considering every line item in the cost-benefit calculation as carefully as a traditional practitioner would. That degree of incentive may not be necessary to achieve comparable accuracy; even if each individual predictor has less knowledge than the practitioner of traditional costbenefit analysis, the collective prediction that emerges may be equally accurate. Even to create this lower level of incentives may cost more than traditional cost-benefit analysis because of the redundancy of having multiple traders study the same information. ${ }^{269}$ Implementation costs are already important concerns in debates about traditional costbenefit analysis, as executive orders require cost-benefit analysis only for sufficiently important regulations. ${ }^{270}$ Predictive cost-benefit analysis may magnify those concerns. ${ }^{271}$

A comprehensive assessment would provide a cost-benefit analysis of the different types of cost-benefit analysis. A numerical comparison of costs and benefits, however, is not yet possible, and the above analysis suggests that the benefits may be a function of the costs. To focus the analysis on the benefit of predictive cost-benefit analysis, assume that it is funded at a sufficient level so that it is as accurate as a typical traditional cost-benefit analysis, and retain the assumption that predictive cost-benefit analysis is objective. Predictive cost-benefit analysis's benefit with these assumptions is that the signal it provides depends less on the identity of the current agency officials. The supe-

268 By "reliability," I mean the extent to which different practitioners of cost-benefit analysis would reach the same result.

269 Similar costs of redundant evaluation have long been recognized in the context of traditional securities markets. See, for example, Jack Hirshleifer, The Private and Social Value of Information and the Reward to Inventive Activity, 61 Am Econ Rev 561, 563-67 (1971).

270 President Reagan's original executive order required regulatory impact analyses only for "major rules." Executive Order 12291, 46 Fed Reg 13193, 13193 (1981).

271 Relatedly, if predictive cost-benefit analysis is expensive, it may magnify concerns about administrative ossification. See, for example, McGarity, 41 Duke L J at 1400-07 (cited in note 222) (describing problems resulting from the imposition of judicial, congressional, and federal analytical requirements on agencies). 
riority of predictive cost-benefit analysis along this dimension does not necessarily mean that this improvement is worth the expense, or that predictive cost-benefit analysis is sufficiently better than traditional cost-benefit analysis to justify greater reliance upon it in the regulatory process. Nor is this advantage necessarily sufficient to overcome what can be a healthy governmental reluctance to discard the procedures that it has traditionally employed. These are critical issues, but my ambition is only to explain the significance of predictive cost-benefit analysis's production of a signal that is relatively independent of agency officials' policy preferences.

The defenses of cost-benefit analysis generally described above provide a straightforward preliminary explanation of why a tool that makes cost-benefit analysis relatively more ideologically neutral represents an improvement. To allow for a clean comparison, consider two extremes, which we may call purely ideological and purely objective means of conducting cost-benefit analysis. With purely ideological cost-benefit analysis, agency officials do not consider the underlying merits at all, except insofar as the merits are their actual ideological concerns. With purely objective cost-benefit analysis, agency officials' ideological preferences have no effects on the outcome of the costbenefit analysis. Sunstein should prefer the purely objective approach, both because it thwarts heuristics to the extent that those heuristics have become impounded into agency decisionmakers' ideology, ${ }^{222}$ and because it eliminates the possibility that agency officials will exploit heuristics of members of the public to achieve ideological ends. Eric Posner should prefer it as well, because a purely ideological costbenefit analysis would have no credibility with the President, Congress, and the courts, and it would thus fail to reduce the skepticism about agency motives that he identifies as limiting agency action. ${ }^{273}$ Of course, predictive and traditional cost-benefit analysis do not repre-

272 Sunstein seems to assume that heuristics affect agency decisionmakers as much as the public. See Sunstein, The Cost-Benefit State at 9 (cited in note 119) (suggesting that cost-benefit analysis helps prevent agency decisionmakers from acting like "intuitive toxicologists"). But see Michael Abramowicz, Toward a Jurisprudence of Cost-Benefit Analysis, 100 Mich L Rev 1708, 1715-16 (2002) (arguing that well-informed decisionmakers are likely to be relatively unaffected by heuristics, but that they might seek to take advantage of the heuristics of others), reviewing Sunstein, The Cost-Benefit State. To the extent that heuristics do affect such decisionmakers, they might not affect decisionmakers of all ideologies equally. For example, liberals who are generally pro-environment might be more susceptible to an availability cascade resulting from an environmental catastrophe, because even an exaggerated policy response will generally be in the policy direction that they prefer. Similarly, conservatives who are generally pro-national security might be more affected by an availability cascade resulting from a terrorist incident, because the incident confirms their own fears.

273 See Posner, 53 Admin L Rev at 292 (cited in note 135). 
sent these extremes of purely objective and purely ideological analysis, but the comparison reveals that cost-benefit analysis will increase in effectiveness as its results are separated from the ideology of its practitioners.

This conclusion should be no surprise. To the extent that the results of cost-benefit analysis represent anything other than the merits or how people on average will view the merits, it becomes a noisier and less valuable measure. If a computer randomly added variance to cost-benefit measurements, the new measure would be less useful than the old one. Ideological perspectives and idiosyncratic views are not random, of course, but mixing cost-benefit measures with these factors is even worse. The regulatory system does not need an indication that agency officials favor a particular regulation; that is obvious from the agency's decision to adopt it. More worrisome, agency officials have the greatest incentive to shade the results of cost-benefit analysis in those cases in which others are least likely to share their views. Thus, to the extent that predictive cost-benefit analysis isolates average assessments rather than particular assessments, it improves the enterprise.

To some critics of cost-benefit analysis, making cost-benefit analysis more useful should count as a deplorable development, for the same reason that an environmentalist might not welcome a new piece of heavy equipment that makes it easier to pave over wetlands. ${ }^{27}$ This critique is beyond my scope here, as my ambition is to show only that predictive cost-benefit analysis can be a better tool than traditional cost-benefit analysis, not to defend more broadly the rise of cost-benefit analysis. ${ }^{27}$

274 Alternatively, cost-benefit analysis could be irrelevant to agency decisions, in which case a superior approach to cost-benefit analysis accomplishes nothing. Matthew Adler and Eric Posner make this point:

Suppose, for example, that the public has no influence on political decision making and that all regulations are approved if and only if interest groups that benefit from them have more political power than interest groups that are harmed by them. Under these circumstances, it is hard to imagine a normative argument in favor of using cost-benefit analysis. The results of cost-benefit analysis performed by agencies would not influence their choice of regulations, and it is hard to see why any political actors would want agencies to use cost-benefit analysis in the first place.

Matthew D. Adler and Eric A. Posner, Cost-Benefit Analysis: Legal, Economic, and Philosophical Perspectives - Introduction, 29 J Legal Stud 837, 839-40 (2000).

275 This Article advocates the use of information markets and predictive cost-benefit analysis as complements to, rather than replacements for, traditional decisionmaking forms. There are strong reasons for fitting new tools into existing legal frameworks. An interesting question, however, is whether it would be democratically illegitimate for the government to be required to follow the results of predictive cost-benefit analysis in all cases. Does democratic legitimacy depend on the representativeness of the decisionmakers, or just on the representativeness of the 
Predictive cost-benefit analysis, however, may facilitate a reform that would mute at least some of the concerns raised by critics of costbenefit analysis. The reform would consist of loosening the rules and norms underlying the practice of cost-benefit analysis, ${ }^{276}$ such as the requirements of OMB Circular A- $94,{ }^{2 \pi}$ leaving practitioners of costbenefit analysis free to make their own decisions about how to measure and discount costs and benefits. For example, such a reform would permit practitioners to count distributional effects of governmental regulations explicitly as benefits or costs, rather than merely discussing such effects, as required by Circular A-94, ${ }^{278}$ which effectively made the controversial Kaldor-Hicks criterion ${ }^{279}$ the lodestar of cost-benefit analysis if not of regulatory policy more generally. ${ }^{200}$ Similarly, practitioners might choose whether to measure deaths by the total number

decisions? This question is not ordinarily asked since existing forms of decisionmaking require representative decisionmakers to achieve the goal of producing representative decisions. While the question is beyond the scope of this Article, it illustrates that predictive cost-benefit analysis can serve as a conceptual heuristic that sharpens analysis of the purpose of representative bodies.

276 Some agencies develop their own guidelines for cost-benefit analysis. See, for example, Office of Air Quality Planning \& Standards, Regulatory Impact Analyses for the Particulate Matter and Ozone National Ambient Air Quality Standards and Proposed Regional Haze Rule $\S 12.7 .3 .1$ at $12-36$ to $12-37$ (1997), online at http://www.epa.gov/ttn/oarpg/naaqsfin/ria.html (visited Apr 22, 2004) (describing methodologies for calculating willingness to pay).

277 See Circular A-94, 57 Fed Reg 53519 (cited in note 127). The Circular could provide far more detailed guidance than it does, and much of the text consists of statements that are relatively uncontroversial. See, for example, id § 7.a at 53522 ("Economic analyses are often most readily accomplished using real or constant-dollar values, i.e., by measuring benefits and costs in units of stable purchasing power."). Other requirements, however, appear to be attempts to standardize administrative practice through choices with which some reasonable people might disagree. See, for example, Revesz, 99 Colum L Rev at 978 (cited in note 27) (suggesting that the Circular's approach to discount rates "can produce perverse results").

278 The Circular provides:

The principle of maximizing net present value of benefits is based on the premise that gainers could fully compensate the losers and still be better off. The presence or absence of such compensation should be indicated in the analysis. When benefits and costs have significant distributional effects, these effects should be analyzed and discussed, along with the analysis of net present value.

Circular A-94 § 10,57 Fed Reg at 53524 (cited in note 127).

279 For a critique of the Kaldor-Hicks approach, see Jules Coleman, The Normative Basis of Economic Analysis: A Critical Review of Richard Posner's The Economics of Justice, 34 Stan L Rev 1105, 1106-12 (1982).

280 The existence of regulatory effects that cost-benefit analysis does not consider has led some proponents of cost-benefit analysis to acknowledge that there may be sound reasons for agencies to ignore the recommendations of cost-benefit analysis. See Sunstein, The Cost-Benefit State at 22 (cited in note 119) ("[R]egulators might reasonably decide that the numbers are not decisive if, for example, children are mostly at risk, or if the relevant hazard is faced mostly by poor people, or if the hazard at issue is involuntarily incurred or extremely difficult to control."). 
of lives lost or the total number of life-years, ${ }^{281}$ rather than having that choice dictated by a general policy.

It may at first seem perplexing that allowing such flexibility should be considered a reform given the preceding analysis. After all, guidelines constraining the practice of cost-benefit analysis seek to limit manipulation by agency officials to achieve their regulatory goals. In addition, guidelines seek to ensure consistent analysis among different agencies ${ }^{232}$ and thereby to improve coherence in a regulatory regime that critics have complained lacks rational inter-agency priority setting. ${ }^{283}$ Guidelines thus advance the same goal as predictive costbenefit analysis, reducing the influence of those performing the analysis. Yet, this is precisely why predictive cost-benefit analysis can relax these standards. To the extent that predictive cost-benefit analysis succeeds in divorcing results from the identity of particular agency decisionmakers, predictive cost-benefit analysis renders guidelines constraining the practice of cost-benefit analysis less necessary. Flexibility in the retrospective cost-benefit analysis that would survive in a predictive regime does not present the same danger as flexibility in traditional cost-benefit analysis. Because the retrospective decisions do not directly affect policy, predictive cost-benefit analysis would result in predictions about how average decisionmakers would resolve any issues for which the retrospective decisionmakers will have discretion.

281 See Richard H. Pildes and Cass R. Sunstein, Reinventing the Regulatory State, $62 \mathrm{U}$ Chi L Rev 1, 83-85 (1995) (advocating consideration of "quality-adjusted life years"); Tammy O. Tengs, et al, Five-Hundred Life-Saving Interventions and Their Cost-Effectiveness, 15 Risk Analysis 369 (1995) (recommending independently discounting each year of life saved); Richard Zeckhauser and Donald Shepard, Where Now for Saving Lives?, 40 L \& Contemp Probs 5, 11-15 (Autumn 1976) (considering use of quality-adjusted life-years rather than lives). The EPA recently decided to end its practice of considering life-years rather than lives when senior citizens groups complained that this approach devalued the lives of the elderly. See John J. Fialka, EPA to Stop 'Death Discount' to Value New Regulations, Wall St J D3 (May 8, 2003). That is, of course, exactly what using life-years does, but society may be justified in spending more to prevent the accidental death of a six-year old than of a ninety-six-year old. In both cases, the agency is merely delaying death, but with the six-year old, it is presumably delaying it much longer. Considering lives rather than life-years in effect values each year of elderly people's lives at more than other people's.

282 Existing guidelines, however, are in many instances not sufficiently detailed to avoid considerable inconsistencies. See Matthew D. Adler and Eric A. Posner, Implementing CostBenefit Analysis When Preferences Are Distorted, 29 J Legal Stud 1105, 1146-47 (2000) (producing tables indicating differences in agencies' valuation of life and selection of discount rates). Compare Edward R. Morrison, Comment, Judicial Review of Discount Rates Used in Regulatory Cost-Benefit Analysis, 65 U Chi L Rev 1333, 1336 (1998) ("OMB's guidelines appear to have had little effect on the discount rates that agencies actually use.").

283 The critique is made most prominently by Stephen Breyer, Breaking the Vicious Cycle: Toward Effective Risk Regulation 21-33 (Harvard 1993) (finding that inconsistencies within agencies create a vicious circle inhibiting rational regulation). 
That predictive cost-benefit analysis produces restraining effects similar to guidelines explains only why the loss of guidelines need not be mourned. There are sound reasons, however, that their elimination should be celebrated. The guidelines are not neutral; they necessarily impound value choices. The guideline against factoring distributional effects directly into cost-benefit analysis may well be sensible in existing practice, given the semantic awkwardness of calling a particular redistributive effect a "cost" or a "benefit."284 Perhaps the omission of distributional effects makes cost-benefit analysis seem more value neutral than would a hypothetical set of rules indicating that monetary effects on the wealthy should count only at some prespecified fraction of those on the poor. ${ }^{255}$ But any appearance of value neutrality from the omission of such rules is an illusion. Whenever the rules of cost-benefit analysis prevent an effect of governmental policy from being weighed in the balance, that decision carries a practical consequence, making the omitted variable less important in the practice of cost-benefit analysis itself.

Predictive cost-benefit analysis would not eliminate debate of controversial methodological issues, but it would allow the practice of cost-benefit analysis to continue without unanimous resolution. Consider, for example, the recent debate about relative position and costbenefit analysis. Robert Frank and Cass Sunstein argued that by basing costs and benefits on individuals' willingness to pay, cost-benefit analysis substantially undervalued certain regulatory benefits. ${ }^{286}$ Individuals, they noted, care not only about their own economic wellbeing, but also their position relative to those they know. ${ }^{2 \pi}$ Relative position matters more for some goods, like sports cars, than for others, like health care, ${ }^{288}$ so an individual might be favorable to a regulation mandating a benefit for everyone even if the amount of income workers will lose as a result is greater than what individuals would be willing to pay in the absence of the regulation. ${ }^{299}$ Thomas Kniesner and

284 For an extended criticism of incorporating distributional concerns into cost-benefit analysis, see W. Kip Viscusi, Risk Equity, 29 J Legal Stud 843 (2000).

285 For an argument that cost-benefit analysis unjustifiably biases policy toward the rich, see David Copp, The Justice and Rationale of Cost-Benefit Analysis, 23 Theory \& Decision 65, 74-77 (1987).

286 See Robert H. Frank and Cass R. Sunstein, Cost-Benefit Analysis and Relative Position, 68 U Chi L Rev 323 (2001).

287 Id at 336-47 (reviewing survey and behavioral evidence).

288 Id at 326 (arguing that income is a positional good while health care is a nonpositional good).

289 Id at 372-73 (arguing that a nonwaivable right would make workers who care about relative position better off in regards to that right, but not worse off economically relative to other workers). 
W. Kip Viscusi offer a detailed response, ${ }^{200}$ arguing in part that Frank and Sunstein overestimate the importance of relative position. ${ }^{291}$ Equally importantly, they argue that factoring relative position into cost-benefit analysis is not practicable, given the methodological difficulties in assessing how much relative position matters. ${ }^{22}$ They accordingly reject the incorporation of positional concerns and conclude that "the most important refinements one could make in the area of regulatory evaluation would be for agencies involved to adhere more to the framework of what is generally considered a carefully done costbenefit study."293

A potential counter to Kniesner and Viscusi's complaint about the methodological difficulty of measuring the significance of positional effects is that the difficulty does not justify a conclusion that the effects are zero. The government should attempt, this counterargument suggests, to calculate the magnitude of positional effects as best it can, adjusting for different contexts and different groups of workers to the extent possible. Perhaps anticipating this counterargument, Kniesner and Viscusi argue that "the fact that the estimates are based on real market data for life and death choices rather than hypothetical thought experiments is a major contributing factor" to the acceptance of cost-benefit analysis. ${ }^{224}$ Although omission of a consideration from cost-benefit analysis as a practical matter constitutes a value judgment, the observation might be correct as a matter of public relations. Nuanced attempts by agencies to account for subtleties might make the value-laden nature of cost-benefit analysis more glaring. ${ }^{295}$ By

290 Thomas J. Kniesner and W. Kip Viscusi, Why Relative Economic Position Does Not Matter: A Cost-Benefit Analysis, 20 Yale J Reg 1 (2003).

29. Id at 12-16.

292 Id at 12-15. For example, Kniesner and Viscusi offer the following critique:

[S] uppose we consider the effects of others' incomes on my behavior, and my true reference group is only my neighbor living in the house to the east. The researcher cannot know that only the income of one neighbor enters my decisions. Therefore, a statistical model incorrectly identifying all the houses on my block as my reference group will find that the average income on my block is statistically significant to my behavior because incomes are positively correlated across houses nearby.

Id at 15 (footnotes omitted).

293 Id at 2. See also id at 19-22.

294 Id at 23. They continue: "Moreover, given the sensitivity of the concerns [associated with the valuation of statistical lives], it is noteworthy that implicit value of life estimates derive from the value workers themselves place on risks of death as reflected in their labor market decisions." Id at 23-24.

295 Viscusi himself, however, has considered many subtleties affecting the valuation of life. See, for example, Viscusi, Value of Life at 3 (cited in note 28) (using job fatality data to construct a fatality risk variable that should make refined estimates of the value of life more easily obtained); W. Kip Viscusi and Joseph E. Aldy, The Value of a Statistical Life: A Critical Review of 
omitting a variable, an agency can plausibly claim that it wishes to simplify the process of cost-benefit analysis and avoid making value judgments on a case-by-case basis.

Predictive cost-benefit analysis, however, provides a means through which a factor like positional effects can be considered without any ex ante agreement about the extent to which it should be a factor. Traders would seek to anticipate the importance that an average decisionmaker would attribute to positional effects, and an agency would not need to take a position on the value of positional effects in advance. The anticipated hypothetical average decisionmaker, of course, might not give positional effects precisely the weight that either camp in the debate believes to be appropriate. Predictive costbenefit analysis, though, appears to satisfy the procedural concerns of both camps. First, it provides a mechanism by which positional factors, and more broadly any factors that some decisionmakers are likely to consider important in cost-benefit analysis, can be counted. If positional concerns receive less weight than Frank and Sunstein recommend, that would be because traders anticipate that decisionmakers on average would give these concerns less weight. Second, it avoids both giving agency officials an additional parameter that they can use to obtain the results that they seek and the appearance problem associated with such discretion. Kniesner and Viscusi could complain that predictive cost-benefit analysis would heighten the regulatory community's awareness of disagreement about cost-benefit analysis and thus perhaps undermine support even for a form of it that effects a compromise on such disagreements. Even if we find admissible arguments that we should hide the public from the sausage factory in which policy is made, this argument is of a more tenuous sort, suggesting that we should not improve the workings of the sausage factory lest the public realize that it is sausage they are eating.

By leaving the technicalities of cost-benefit analysis to predictors and retrospective decisionmakers, predictive cost-benefit analysis answers some broad critiques of cost-benefit analysis. Lisa Heinzerling,

\footnotetext{
Market Estimates throughout the World 15-16 (NBER Working Paper No 9487, 2003), online at http://www.nber.org/papers/w9487 (visited Apr 22, 2004) (considering whether a statistical method used to measure the value of life from wage data should apply the logarithm of wages). Perhaps Kniesner and Viscusi are skeptical of Frank and Sunstein's recommendation for estimating the statistical value of life not so much because they are opposed to complex methodologies that are difficult to verify, but because they believe that confidence in cost-benefit analysis will be undermined by any techniques not focusing on revealed preferences. Although this distinction may have technical merit, it seems unlikely that the public will tolerate some methodologies for calculating costs and benefits but not others, given the general lack of public awareness of methodological issues.
} 
for example, has criticized cost-benefit analysis and numerical assessment of regulation more generally, ${ }^{2 \%}$ arguing that numbers tend to obscure regulatory debates rather than elucidate them. ${ }^{297}$ As Sunstein points out in response to a critique of a specific cost-benefit analysis that she offers in a separate article, ${ }^{298}$ Heinzerling has no principled objection to considering costs and benefits in the abstract, but only to particular approaches that agencies have taken to counting them under a false claim to scientific truth. ${ }^{2 x 9}$ Predictive cost-benefit analysis creates an ongoing discussion, both among predictors and among retrospective assessors, about the appropriate measurement of costs and benefits. It results in a final number, but this number will reflect a compromise among various experts' anticipated views, rather than serve as a pseudo-objective justification for policy.

Predictive cost-benefit analysis also answers critiques that costbenefit analysis focuses excessively on narrowly economic values, to the exclusion of aesthetic and other significant values. ${ }^{300}$ Proponents of cost-benefit analysis have developed techniques for considering such values, such as contingent valuation, which relies on surveys to assess how much citizens would pay to save a species or preserve a forest. ${ }^{30}$ Such surveys, however, are notoriously vulnerable to framing effects, with the amount that surveyed individuals indicate they would pay to save a forest bearing little relation to the size of the forest. ${ }^{32}$ Predictive

296 See Lisa Heinzerling, Regulatory Costs of Mythic Proportions, 107 Yale L J 1981 (1998).

297 Heinzerling argues:

[S]ome, probably many, people will be fooled into believing that numerical estimates of risks, costs, and benefits are impartial reflections of factual reality, in which case the likely result of increased reliance on quantification in setting regulatory policy will be that the side that best obscures the value choices implicit in its numbers will prevail. This will not produce more sensible regulation, but it will produce a more dishonest debate about regulation.

Id at 2068.

298 See Lisa Heinzerling, Markets for Arsenic, 90 Georgetown L J 2311, 2312-13 (2002) (responding to an earlier article by Sunstein, 90 Georgetown L J 2255 (cited in note 124)).

299 See Cass R. Sunstein, In Praise of Numbers: A Reply, 90 Georgetown L J 2379, 2383 (2002) ("Heinzerling's attack on cost-benefit analysis seems to be based not on a belief that costs and benefits are irrelevant, but on the willingness-to-pay criterion, which she identifies with costbenefit analysis.").

300 See, for example, Thomas O. McGarity, Regulatory Analysis and Regulatory Reform, 65 Tex L Rev 1243, 1294-95 (1987) (noting opponents' concerns that cost-benefit analysis cannot accurately monetize health, environmental, and aesthetic values).

301 See generally Jerry A. Hausman, ed, Contingent Valuation: $A$ Critical Assessment (NorthHolland 1993) (collecting studies on contingent valuation). For a critique of the conceptual basis of these methods, see generally Boudreaux, Meiners, and Zywicki, 29 Envir L 765 (cited in note 29) (arguing that "contingent value" is riddled with conceptual problems and should be ignored by the law).

302 See Frank B. Cross, Restoring Restoration for Natural Resource Damages, 24 U Toledo L 
cost-benefit analysis cannot determine what value should be assigned to a species or a forest, but it can allow for incorporation of such values into regulatory assessments without entrenching any particular flawed methodology. Aesthetic, economic, and other values may seem incommensurate, but agencies cannot avoid at least implicitly balancing different values in making decisions. ${ }^{303}$ Predictive cost-benefit analysis provides a method for achieving such balancing without putting a thumb-or a weighty value judgment - on the scale. ${ }^{344}$

\section{CONCLUSION}

The tempest over FutureMAP may have prevented that project from producing useful experiments on the workings of information markets, but it did provide an important experiment about the willingness of the public to allow information markets a role in policymaking. That experiment revealed that the public is not yet ready for information markets, and this Article has suggested some reasons to support the public's caution. Insufficient experimentation has yet been done to establish the degree of information markets' susceptibility to attempts at manipulation, and some of the more adventurous information market designs, such as conditional markets, may be too noisy to be reliable. If such problems can be overcome, however, the objectivity of information markets might allow their predictions to be a useful input into the administrative process. The normative predictions of predictive cost-benefit analysis may be particularly useful, and less

Rev 319, 330-31 (1993) (identifying a problematic result of contingent valuation known as "embedding," where the expressed value for a subset of a resource was substantially the same as the entire resource).

303 See Matthew Adler, Incommensurability and Cost-Benefit Analysis, $146 \mathrm{U}$ Pa L Rev 1371, 1383-89 (1998) (defining "incommensurability" and describing its effects on cost-benefit analysis).

304 If predictive cost-benefit analysis were commonplace, it would be easier to produce summary statistics on judges' decisions in judicial review. It would be possible to assess not only how frequently individual judges overturned agency action, but also whether they tended to do so in cases in which predictive cost-benefit analysis expressed skepticism of the decision. It might also be possible to design predictive cost-benefit analysis in such a way to identify judges' ideological tendencies. Existing studies use proxies for whether decisions are "conservative" or "liberal," depending in part on the identity of the party challenging the agency decision. See, for example, Frank B. Cross and Emerson H. Tiller, Judicial Partisanship and Obedience to Legal Doctrine: Whistleblowing on the Federal Courts of Appeals, 107 Yale L J 2155, 2168 (1998). Predictive cost-benefit analysis could be modified so that in addition to the overall analysis, conditional securities predicted the result of the cost-benefit analysis conditional on the political party of the eventual retrospective decisionmaker. Such securities would provide an objective indication of expected differences in political parties' analyses of the decision. Across a large number of decisions, such information could improve analyses of the extent to which judges and courts are politically motivated. 
likely to excite public angst than direct predictions of variables such as terrorism deaths. Public acceptance will surely be slow, but further academic experimentation could either identify unsolvable problems or produce an academic consensus in favor of some uses of information markets that eventually might lead to gentle introduction of information markets into the policymaking process. 